\title{
Utilización de Agrotextiles. Análisis de viabilidad y modelización de la eficacia.
}

Antonio Giménez Morera 
ISBN 
TíTULO. Utilización de agrogeotextiles. Análisis de viabilidad y modelización de la eficacia.

Universidad Politécnica de Valencia

Tesis doctoral. Antonio Giménez Morera

3

Antonio Giménez Morera. Universidad Politécnica de Valencia 
Composición tribunal.

Presidente. Dr. José María García Álvarez-Coque

Secretaria. Dr. Maria Del Mar Marín Sánchez

Vocales. Dr. Artemio Cerdá Bolinches

Dr. José Damián Ruiz Sinoga

Dr. Antonio Jordán López

Director. Dr. José Miguel Ferrer Arranz 
Índice

Listas de figuras

Listas de tablas

006

008

Agradecimientos

011

Capítulo 1. Introducción

013

Capítulo 2. Pérdida de suelo y agua en las nuevas plantaciones de cítricos en laderas de la cuenca Mediterránea Occidental

Capítulo 3. Uso de geotextiles en agricultura

Capítulo 4. Geotextil versus herbicida en el control del agua y suelo en el secano valenciano en condiciones de lluvia real

049

Capítulo 5. El impacto de los geotextiles de algodón en el control de la pérdida de suelo y agua en cultivos agrícolas del secano valenciano en condiciones de lluvia real y lluvia simulada

061

Capítulo 6. Uso de geotextiles para el mantenimiento de un caudal ecológico y creación de una zona húmeda. El caso del Riu dels Sants en la comarca de la Costera. Valencia

Capítulo 7. Viabilidad económica del geotextil en citricultura. Estación Experimental de Montesa

093

Capítulo 8. Modelización de la eficiencia de geotextiles en plantaciones de cítricos

Capítulo 9. Conclusiones generales

Capítulo 10. Referencias bibliográficas 


\section{Lista de figuras}

Figura 1. Localización de las zonas de estudio en el Este de España. Montesa (1), Vallada (2), Genovés (3), Gandia (4), Canals (5), Monserrat (6), Pego (7), Llíria (8), L'Alcudia de Crespins (9) y Serra (10).

Figura 2a. Vista general de la zona de estudio de Vallada.

Figura 2b. Detalle de la zona de estudio de Vallada.

Figura 3. Relaciones entre el tiempo de encharcamiento (tp), tiempo de escorrentía (tr) y tiempo de retraso de la escorrentía respecto al encharcamiento (td-tr-tp).

Figura 4. Relación entre la escorrentía (\%), concentración de sedimentos $\left(\mathrm{g}^{-1}\right)$ y tasas de erosión del suelo $\left(\mathrm{g} \mathrm{m}^{-2} \mathrm{~h}^{-1}\right)$.

Figura 5 Vista de un geotextil de algodón colocado en un cultivo de cítricos maduros para comprobar su comportamiento.

Figura 6. Vista de un campo de cítricos con malla geotextil implantada, se observa la estética visual de la explotación.

Figura 7. Detalle de la malla de irrigación de fibras sintéticas.

Figura 8. Detalle de la malla de textiles reciclados.

Figura 9. El efecto de los herbicidas: vista del campo de olivar en invierno en el término municipal de Enguera. El uso indiscriminado de herbicidas conduce a la total eliminación de la vegetación incluso en los meses invernales.

Figura 10. Perfil esquemático de una de las parcelas.

Figura 11. Vista de la estación meteorológica con un detalle a la derecha de los datalogges donde se almacenan los datos (cada 5 minutos) medidos por los sensores de temperatura y humedad del suelo, radiación, precipitación, dirección y velocidad del viento. La temperatura y humedad del aire se registran en un datalogger incorporado al sensor situado dentro del protector de la radiación directa.

Figura 12. Precipitación diaria en la estación experimental El Teularet.

Figura 13a. Vista de la parcela con herbicida (a la derecha se puede ver también parte de la parcela de geotextiles).

Figura 13b. Vista de la parcela con geotextiles.

Figura 14. Manantial del Riu dels Sants. L'Alcudia de Crespins.

Figura 15. Desvío del cauce del Riu Sants a su paso por Canals.

Figura 16. Zona de actuación en el Riu dels Sants.

Figura 17. Vista de la zona del Gorg de I 'Omet.

Figura 18. Detalle geocelda y colocación de la misma en un talud.

Figura 19. Perfiles de colocación de los biorrollos.

Figura 20. Esquema con todos los componentes de la restauración.

Figura 21. El Riu dels Sants a su paso por Canals.

Figura 22. Vista de los dos tratamientos. Escarda tradicional manual (A), geotextil (B), estado del geotextil 17 meses después de la plantación $(C)$ donde se puede apreciar las marras. 
Figura 23. Evolución de la supervivencia de los árboles bajo geotextiles y escarda tradicional en la estación experimental de Montesa.

Figura 24. Evolución de la circunferencia del tronco de los plantones a $5 \mathrm{~cm}$ de la superficie desde su plantación hasta 16 meses después, bajo geotextiles.

Figura 25. Evolución de la circunferencia del tronco de los plantones a $5 \mathrm{~cm}$ de la superficie desde su plantación hasta 16 meses después bajo escarda tradicional.

Figura 26. Evolución del diámetro máximo de la copa de los plantones desde su plantación hasta 16 meses después bajo geotextil.

Figura 27. Evolución de diámetro máximo de la copa de los plantones desde su plantación hasta 16 meses después bajo escarda tradicional.

Figura 28. Evolución de la altura máxima media de los plantones desde su plantación hasta 16 meses después, bajo geotextiles.

Figura 29. Evolución de la altura media máxima de los plantones desde su plantación hasta 16 meses después, bajo escarda tradicional. 


\section{Lista de tablas}

Tabla 1. Media y desviación estándar (std) del tiempo de encharcamiento (tp), tiempo de escorrentía (tr) y tiempo de retraso de la escorrentía (td=tr-tp) en segundos en las 10 zonas de estudio ( $n=10$ parcelas) y para el conjunto de experimentos realizados ( $n=100$ parcelas).

Tabla 2. Media y desviación estándar del coeficiente de escorrentía.

(\% escorrentía/precipitación) y la escorrentía total (lluvia $=55 \mathrm{~mm}$ ) en las 10 zonas de estudio.

Tabla 3. Media y desviación estándar de la concentración de sedimentos $\left(\mathrm{g} \mathrm{l}^{-1}\right)$ y los sedimentos totales ( $\mathrm{g}$ ) en las 10 zonas de estudio.

Tabla 4. Media y desviación estándar de las tasas de erosión del suelo mostradas en $\mathrm{g} \mathrm{m}^{-2}$ $h^{-1} y^{M g} h^{-1} h^{-1}$.

Tabla 5a. Resultados obtenidos por otros autores en el Mediterráneo Occidental mediante el uso de lluvia simulada bajo distintos usos y manejos. La tabla muestra el autor, el año de publicación, la intensidad de la lluvia (RI), el coeficiente de escorrentía $(\mathrm{RC})$, la concentración de sedimentos (SC), la tasa de erosión (ER) y las características del uso y manejo del suelo.

Tabla 6. Pérdida de suelo $\left(\mathrm{Mg}^{-1} \mathrm{ha}^{-1}\right.$ año) bajo distintos usos y manejos del suelo en la estación experimental para el Estudio de la Erosión Hídrica del suelo de El Teularet-Sierra de Enguera en el año 2004 (Cerdà, 2006).

Tabla 7. Pérdida de suelo ( $\mathrm{Mg}^{-1} \mathrm{ha}^{-1}$ año) bajo distintos usos y manejos del suelo en la estación experimental para el Estudio de la Erosión Hídrica del suelo de El Teularet-Sierra de Enguera en el año 2005 (Cerdà, 2006).

Tabla 8. Tipos de mallas y precios de las mismas.

Tabla 9. Precipitación media anual $(\mathrm{mm})$ (1961-1990) para los tres observatorios cercanos y para la Estación Meteorológica de El Teularet-Sierra de Enguera en el año 2004.

Tabla 10. Precipitación (mm) (1961-1990) según intervalos de intensidades diarias en los observatorios de la Sierra de Enguera. El Teularet en el año 2004.

Tabla 11. Temperatura media, máxima, mínima y amplitud térmica media anual (19611990) en los observatorios de la Sierra de Enguera. Los datos de el Teularet corresponden al año 2004.

Tabla 12. Temperaturas medias mensuales (1961-1990) en los observatorios de la Sierra de Enguera. Los datos corresponden al año 2004.

Tabla 13. Pérdida de agua (coeficiente de escorrentía, \%) para las parcelas tratadas con herbicidas y geotextiles en la Estación Experimental de El Teularet-Sierra de Enguera para el año 2004.

Tabla 14. Pérdida de agua (litros por parcela) para las parcelas tratadas con herbicida y geotextiles en la Estación Experimental de El Teularet-Sierra de Enguera para el año 2004. 
Tabla 15. Pérdida de agua ( $\mathrm{mm}$ por parcela) para las parcelas tratadas con herbicida y geotextiles en la Estación Experimental de El Teularet-Sierra de Enguera para el año 2004.

Tabla 16. Concentración media de sedimentos en la escorrentía $\left(\mathrm{gr} \mathrm{l}^{-1}\right)$ para las parcelas tratadas con herbicida y geotextiles en la Estación Experimental de El TeularetSierra de Enguera para el año 2004.

Tabla 17. Tasa de erosión media ( $M g$ ha $^{-1}$ año-1) para las parcelas tratadas con herbicida y geotextiles en la Estación Experimental de El Teularet-Sierra de Enguera para el año 2004.

Tabla 18. Medias de las escorrentías totales y pérdida de suelos para las ocho parcelas con tratamiento de herbicida (4) y agrogeotextil (4) en la estación experimental de El Teularet bajo lluvia natural (2004). Los valores medios que aparecen en negrita son significativos $(P<0,05)$ con el test de la $U$ de Mann-Wintney.

Tabla 19. Cubierta de fragmentos de roca, pendiente, cubierta vegetal y material orgánico en las parcelas con lluvia simulada. Los valores medios en negrita indican que existen diferencias estadísticamente significativas $(P<0,05)$ siguiendo el test de la $\mathrm{U}$ de Mann-Whitney.

Tabla 20a. Pérdida de suelo bajo lluvia simulada $\left(55 \mathrm{~mm} \mathrm{~h}^{-1}\right)$. Los valores medios en negrita identifican diferencias estadísticas significativas (test de $U$ de MannWhitney $(P<0,05)$ entre los manejos de herbicidas y geotextiles.

Tabla 20b. Pérdida de suelo bajo lluvia simulada $\left(55 \mathrm{~mm} \mathrm{~h}^{-1}\right)$. Los valores medios en negrita identifican diferencias estadísticas significativas (test de $U$ de MannWhitney $(P<0,05)$ entre los manejos de herbicidas y geotextiles.

Tabla 21. El tiempo de encharcamiento (Tp), tiempo de escorrentía (Tr), y retraso del tiempo de escorrentía respecto al tiempo de encharcamiento (Tr-Tp) obtenidos a partir de experimentos con lluvias simuladas a $55 \mathrm{~mm} \mathrm{~h}^{-1}$. Y el Water Drop Penetration Time WDPT en segundos. Los valores medios en negrita identifican diferencias estadísticas significativas (test de $U$ de Mann-Witney, $P<0.05$ ) entre los manejos de herbicidas y geotextiles.

Tabla 22. Tabla de variable hidráulicas y comportamiento de la geocelda.

Tabla 23. Efectividad de la hidrosiembra siguiendo los protocolos y pruebas de PROJAR.

Tabla 24. Relación de los gastos de actuación.

Tabla 25. Costes del mantenimiento durante 17 meses distinguiendo entre geotextiles y escarda tradicional en la estación experimental de Montesa, Valencia.

Tabla 26. Evolución de la circunferencia media a $5 \mathrm{~cm}$ de la superficie y desviación estándar del tronco de los árboles desde el día de la plantación hasta el verano del 2007 para los árboles supervivientes.

Tabla 27. Evolución del diámetro máximo medio y desviación estándar de la copa de los árboles desde el día de la plantación hasta el verano del 2007 para los árboles supervivientes. 
Tabla 28. Evolución de la altura máxima media y desviación estándar de la copa de los árboles desde el día de la plantación hasta el verano del 2007 para los árboles supervivientes.

Tabla 29. Resultados según el método utilizado.

Tabla 30. Resultados de las dominancias.

Tabla 31. Ponderaciones. Métodos ND con los valores máximos sombreados.

Tabla 32. Ponderaciones. Tabla convertida.

Tabla 33..Resultados de la minimización.

Tabla 34 . Índices de eficiencia.

Tabla 35 .Ranking de eficiencias. 


\section{Agradecimientos}

A lo largo de estos años de investigación muchas son las personas que han hecho posible la escritura de esta tesis, pero principalmente tengo que agradecer a Fanny y a Tono que han sido los autores morales e imprescindibles de la misma. La paciencia que han demostrado en determinados momentos es infinita y quiero aprovechar estas líneas para disculparme por el tiempo que no les he podido dedicar. A ellos les debo mis mejores momentos y su apoyo incondicional en los momentos de flaqueza. A mis padres porque siempre me han dado todo su apoyo en todos los proyectos que he emprendido.

Al profesor Artemio Cerdà gracias al cual me inicié en el mundo de la investigación, ofreciéndome apoyo incondicional en todo momento, abriéndome nuevas líneas de investigación, haciendo posible la utilización de sus parcelas de estudio y aportando sus conocimientos que tanto me han servido en la preparación y redacción de esta tesis. $\mathrm{Mi}$ deuda intelectual con su persona es impagable.

A José Miguel Ferrer, director de esta tesis por su apoyo y dedicación a la misma, y cuyos consejos, aportaciones y guías han servido para llegar a este punto.

A mis compañeros José Enrique Rodríguez y Carmen Escribá de la Universidad Politécnica de Valencia que confiaron en su momento en mi persona para ejercer mi gran pasión; la actividad docente.

También quiero agradecer la colaboración de empresas privadas dentro de mi investigación que a través de proyectos e iniciativas se han involucrado de forma directa a través de la aportación de materiales o aportación de tecnología sin la cual no hubiera sido posible la consecución de ideas que finalmente se han plasmado en realidades. La ayuda inestimable de PROJAR a través de Jorge Fort cuyos consejos y discusiones enriquecedoras han servido para hacer posible lo que en un principio parecía imposible

La participación de la universidad de Akdeniz de Turquía en un proyecto de investigación ha sido también de relevancia para el conocimiento de otras metodologías de estudio al mismo tiempo que ha servido de intercambio de transferencia tecnológica entre nuestras universidades. Un reconocimiento a todos aquellos colegas que tan bien me acogieron en su país. 
Por último a todos aquellos que de forma consciente 0 inconsciente me han dado fuerzas para poder llegar hasta el final. 
Capítulo 1.

Introducción 
La presente Tesis Doctoral surge del interés que plantea la utilización o no de geotextiles en la agricultura, especialmente en cultivos tradicionales mediterráneos.

Tras una revisión de la literatura científica comprobamos que en España el uso de geotextiles en agricultura está muy poco extendido (López et al, 2002). La falta de información sobre su utilización va acompañada de tópicos que reiteran la inviabilidad en su utilización sin que se haya hecho ningún estudio riguroso y científico que haya podido comprobar la misma (Gíménez-Morera, 2008).

Demostrar los beneficios ambientales de su utilización, es necesario pero no fundamental para implantar su utilización. Es recomendable el estudio de viabilidad que confirme que su utilización va a ser rentable desde el punto de vista económico. Entendemos que la falta de estos estudios de viabilidad son los que han impedido que los geotextiles se estén utilizando en el campo español, aunque también existen algunas dudas de sus beneficios en la conservación de aguas y suelo agrícolas. En el caso de zonas afectadas por obras de infraestructura, como los taludes de carretera, su utilidad ambiental queda manifiesta por su observación debido al incremento de la utilización de los mismos como protectores frente a la erosión que se produce por escorrentías.

El contenido de esta tesis, tiene dos objetivos claramente diferenciados. Por una parte, dar a conocer las bondades de los geotextiles en cuanto a su aportación como mecanismos que favorecen la no pérdida de suelo y agua evitando la erosión, y en segundo lugar demostrar que su uso contribuye a una agricultura sostenible. Esta doble vertiente de estudio también viene condicionada por la posibilidad que puede suponer la utilización de geotextiles para la regeneración de nuestro tejido industrial textil. La Comunidad Valenciana ha sufrido en las últimas décadas una de las mayores crisis en uno de los sectores más tradicionales como es el textil. Las argumentaciones expuestas en esta tesis pueden ayudar a que las empresas textiles se planteen invertir en I+D+l para el desarrollo de nuevos productos que ayuden a su reconversión. Los trabajos de campo y laboratorio efectuados a lo largo de estos años han supuesto la obtención de potencialidades que pueden ayudar a tomar decisiones sobre dicha reconversión.

El uso de los geotextiles viene siendo cuestionado desde diferentes ópticas. Por un lado se cuestiona su viabilidad económica comparada con la aplicación de otros métodos no sostenibles. También han sido cuestionados por su baja durabilidad y por los impactos que se crean por su aplicación, especialmente si los mismos no han sido aplicados con estrategias paisajísticas adecuadas. En el desarrollo de esta tesis se demuestra que algunas de estas cuestiones pueden ser minimizadas e incluso eliminadas.

A lo largo de los capítulos que componen la tesis se demostrará que la utilización de geotextiles en agricultura permite la minimización de la utilización de productos químicos como los herbicidas. Esta minimización supone un adelanto importante en la aplicación de métodos para la consecución de una "agricultura ecológica" al mismo tiempo que se 
permite la mejora de condiciones térmicas de los suelos y se contribuye a minimizar la erosión en campos de cultivo mediterráneos.

La opción del autor de presentar la tesis mediante artículos surge de la creencia que las revistas y literatura científica tienen una rápida y extensa difusión que además cumple con otro requisito como es el de la posibilidad de poder ser consultadas. Este sistema de presentación de la tesis relativamente poco utilizado en las universidades españolas si lo comparamos con otras universidades europeas, permite dar divulgación de las investigaciones casi de forma inmediata pudiendo obtener una retroalimentación con otros autores e investigadores.

Debido al interés de las investigaciones realizadas durante los años de preparación de la tesis, se han ido recogiendo datos y conclusiones que se han publicado en libros de editoriales nacionales y revistas internacionales. Así podemos destacar la publicación en dos revistas científicas indexadas que se encuentran incluidas en la relación de revistas del Journal of Citation Reports Sciencie Edition (JCR-SCE) del capítulo I, en la revista Earth Surfaces Processes and Landforms y la publicación en Land Degradation \& Development del capítulo III ambos en el año 2009. Cabe destacar también la publicación de todos los demás capítulos de la tesis en la editorial Marfil dentro de los Cuadernos de Investigación en la Ingeniería durante los años 2007, 2008, 2009.

Durante el periodo de la investigación se han simultaneado colaboraciones con empresas privadas entre las que cabe destacar un proyecto financiado por el Impiva dirigido al reciclaje de tejidos textiles para la confección de geotextiles para la agricultura. Este proyecto aportó como conclusiones, no definitivas, el que es posible la utilización de materiales reciclados textiles para su uso en agricultura pero fruto de la investigación también se demostró que los mismos, pueden contener un gran número de estructuras poliméricas que hacen que dichos materiales presenten mucha repelencia al agua. Los resultados fueron compartidos con los laboratorios de AITEX como método de transferencia tecnológica.

En el ámbito académico, y haciendo referencia a la importancia de la publicación de los resultados de las investigaciones, se han logrado colaboraciones con universidades de otros países, en concreto con la universidad de Akdeniz en Antalya -Turquia- gracias a una invitación por parte de la misma durante un periodo de tres meses en el que se investigó conjuntamente la utilización de geotextiles, creados al efecto, para la rehabilitación medioambiental de canteras situadas en parques naturales, investigación que se encuentra en proceso con la posibilidad abierta de una posible patente. En este caso en concreto se practicaron una serie de trabajos de campo en los que se evalúa el comportamiento de un geotextil formado por dos capas de fibras de coco al 100\% entrelazadas que contienen en su interior un sustrato, coco turba, y semillas protegidas por un plástico que al contacto con el agua del primer riego se convierten en una sustancia gelatinosa que adhiere las semillas a la pared y las protege. Este tipo de manta, sirve para la estabilización del terreno debido a su estructura tridimensional ya que disminuyen los impactos de las lluvias torrenciales, 
cargadas de energía cinética. Además las mantas hacen efecto de acolchado y crean un microclima que favorece la germinación y adaptación de las especies sembradas 0 plantadas. También al estar constituidas por fibras higroscópicas, mejoran los terrenos secos ya que retienen la humedad del terreno. En este caso y a la espera de resultados concluyentes continúa la colaboración con esta Universidad, teniendo en marcha dos campos de experimentación uno en Turquía y otro en España que contribuyen a una aportación de datos experimentales.

Esta Tesis Doctoral se divide en dos grandes bloques. El primer bloque trata de corroborar la importancia de la utilización de los geotextiles como aportación a la sostenibilidad medioambiental. Para ello en el segundo capítulo se habla de la importancia que tiene la pérdida de suelo y agua en los campos de la vertiente mediterránea y como nuestros estudios pueden influir en la búsqueda de nuevos métodos para amortiguar estas pérdidas. En el tercer capítulo se habla de los geotextiles que están actualmente presentes en el mercado, y de sus características distintivas que han incidido en la decisión de utilizarlos como muestra en los trabajos de campo desarrollados, además de su posible aportación al desarrollo de nuevos productos en la industria textil y a la sostenibilidad. En el capítulo cuatro hablaremos del uso específico de los geotextiles en la agricultura acompañados de su estudio experimental en el campo haciendo referencia expresa a la comparativa del uso de los geotextiles con el uso de los herbicidas. En él fundamentaremos el impacto ejercido por los geotextiles como mecanismos de protección frente a la pérdida de los suelos que además argumentará y demostrará su beneficiosa aplicación en cuanto al mantenimiento de los recursos hídricos. En el capítulo cinco se confronta bajo lluvia simulada el impacto de los geotextiles de algodón en el control de la pérdida de suelo y agua en un ecosistema mediterráneo. El capítulo seis es dedicado a resaltar la posibilidad de utilización de los geotextiles para contribuir al mantenimiento de un caudal ecológico en un río mediterráneo y la aplicación práctica de geotextiles combinados para la creación de una zona húmeda contribuyendo con ella a la sostenibilidad de un río urbano y periurbano.

El segundo gran bloque de la tesis servirá para traducir la obtención de resultados económicos en un estudio de la viabilidad o no del agrotextil. Para ello en el capítulo siete se desarrolla un plan de viabilidad que contempla las variables que intervienen en la producción en campos de cultivo mediterráneos. En el capítulo ocho utilizaremos un estudio de modelización de la eficiencia nunca antes utilizado en este campo que ayude conjuntamente con los resultados del anterior capítulo a la toma de decisiones en cuanto a la utilización o no del uso de los geotextiles en agricultura.

Por último la tesis se cierra con un capítulo en el que se presentan las conclusiones que se derivan de todos los análisis anteriores y que tratará de responder a las preguntas de la investigación realizadas al principio del estudio introduciendo soluciones aportando la variable sostenibilidad. 
Publicado en Earth Surface Processes and Landforms (2009)

Cerdà, A., Giménez-Morera, A. y Bodí, M.B. 2009. Soil and water losses from new citrus orchards growing on sloped soils in the western Mediterranean basin. Earth Surface Processes and Landforms, 34, 1822-1830. DOI: 10.1002/esp. 1889

\section{Capítulo 2}

Pérdida de suelo y agua en las nuevas plantaciones de cítricos en laderas de la cuenca Mediterránea Occidental 


\subsection{Introducción}

\subsubsection{Erosión y usos del suelo}

Está ampliamente aceptado por la comunidad científica que la erosión del suelo es mayor en las tierras agrícolas que en los bosques, matorrales y praderas (Boardman et al., 1991). Esto es una consecuencia del manejo agrícola, y de la falta de aterrazamientos y nivelaciones en las tierras de secano, lo que ha desencadenado la erosión del suelo y otros procesos de degradación en zonas rurales (Cerdà et al., 2007). Las tasas de erosión se aceleran con el laboreo y con las bajas cubiertas vegetales que se pueden encontrar en los campos de cultivo (Gómez et al., 2004). Sin embargo, algunas explotaciones agrícolas tradicionales como los campos de arroz en laderas del sudeste asiático y los tradicionales sistemas agrarios con riego por inundación como la "huerta de valencia" alcanzaron altos niveles de sostenibilidad con tasas de erosión tolerable o nula (Pimentel, 1993). Esto es debido a que los sistemas de riego tradicional por inundación se localizan en llanura aluviales, terrazas fluviales o deltas, donde la remoción del suelo es insignificante pero si es importante la sedimentación fruto de la irrigación o las inundaciones naturales. De hecho, en las zonas de riego por inundación se produce una ganancia neta de materiales como demuestra la estratificación (Piqueras, 1999).

A escala mundial, la superficie agraria de secano es mayor, y se produce en laderas. Habitualmente, la única forma de de reducir o eliminar las malas hierbas ha sido el laboreo, lo que da lugar a suelos desnudos solo cubiertos con el cultivo durante la estación de crecimiento. Esto es lo que explica que las mayores tasas de erosión se hayan cuantificado en laderas cultivadas en secano, las cuales son comparables con las medidas en derrubios de minas, (Nicolau, 2002), taludes de carretera (Cerdà, 2007) y badlands (Regüés y Gallart, 2004; Cerdà, 1999).

En la cuenca mediterránea occidental, el mismo patrón regional de erosión del suelo está presente: altas tasas de erosión en las laderas con cultivos de secano y sedimentación en las llanuras aluviales, terrazas fluviales y deltas donde el regadío por inundación se ha desarrollado. Los sistemas de riego por inundación tradicionales dan lugar a la redistribución de los sedimentos en las partes bajas de las cuencas de drenaje ya que los canales de irrigación (acéquias) y los colectores de las escorrentías (azudes) redistribuyen el caudal dentro de la llanura aluvial durante la estación de riego y las inundaciones. La erosión del suelo en los campos agrícolas en la Cuenca mediterránea occidental es alta debido al uso de laboreo y herbicidas, lo que da lugar a la eliminación de la vegetación y a suelos desnudos. La agricultura de conservación y la agricultura ecológica no están muy extendidas, aunque son cada vez más conocidas.

Las mediciones realizadas por distintos autores y bajo distintas condiciones ecológicas demuestran que el Oeste del mediterráneo presenta una agricultura que sufre altas pérdidas de suelo y agua (Giráldez et al., 1989; Martínez Raya et al., 1993; de Alba, 1998; 
Bienes et al., 2000; Lasanta et al., 2000b; Cerdà, 2001/2002; Cerdà 2001; Gómez et al., 2004). Los manejos agrícolas propician el desarrollo de regueros y cárcavas (Belmonte et al., 1998; Casalí et al., 1999), las cuales son eliminadas por el laboreo. Por el contrario, las tasas de erosión en los montes son normalmente menores a $1 \mathrm{Mg} \mathrm{ha}^{-1} \mathrm{año}^{-1}$, e incluso inferiores a $0.1 \mathrm{Mg} \mathrm{ha}^{-1}$ año-1 (González Hidalgo, 1994; Romero Díaz et al., 1999; Ceballos, 1997, Puigdefabregas et al., 1996; Imeson et al., 1998; Albaladejo et al., 2000; Cantón et al., 2001). Esta es la razón por la que es necesario más investigación en las zonas agrícolas con el fin de conocer mejor los procesos de erosión del suelo y controlar las tasa de erosión no-sostenible.

\subsubsection{El cultivo de cítricos en el Mediterráneo Occidental}

La producción de cítricos se localiza en el cinturón climático tropical donde las temperaturas y la precipitación son altas, y donde no existen las heladas. Sin embargo, en la actualidad las plantaciones de cítricos se pueden encontrar lejos de su zona ecológica. La producción de cítricos más alejados del cinturón tropical está localizada en latitud $40^{\circ} \mathrm{N}$, en la zona costera donde las heladas son raras. Los cítricos no pueden sobrevivir a periodos de frío intensos típicos del invierno del cinturón climático templado. California y Valencia son ejemplos de la producción en la zona límite del hemisferio norte.

Otro factor limitante de la localización de las plantaciones de cítricos es la disponibilidad de agua. Los cítricos son originarios de las zonas tropicales, las cuales tienen las mayores precipitaciones durante la estación cálida, y por lo tanto no necesitan disponer de riego. Sin embargo, en la zona climática mediterránea la estación cálida entre junio y septiembre es seca, y la irrigación es necesaria para alcanzar una producción óptima y para conseguir la supervivencia de los naranjos.

Los sistemas de riego fueron heredados de los romanos y sobretodo de los musulmanes en el Este peninsular español y permitieron el desarrollo de las huertas dedicadas a cultivos de verduras con escaso arbolado. A lo largo de los siglos XVIII y XIX la producción de cítricos se expandió por estas zonas dedicadas tradicionalmente a la producción de verduras para el mercado local, y progresivamente para el mercado europeo. A lo largo del siglo XX, el desarrollo de la máquina de vapor y de bombas eléctricas permitió la expansión de los cítricos, un cultivo comercial, a zonas de mayor altitud. Los nuevos sistemas de regadío localizados en los abanicos aluviales y terrazas fluviales se realizaron por medio de la irrigación por inundación, con el desarrollo de terrazas de cultivo y nivelación del terreno como se había realizado durante milenios en la agricultura de secano.

Durante la década de los 1980 s un nuevo y muy eficiente método de regadío se introdujo en el cultivo en España: el riego por goteo. Este sistema se basa en elevar el agua del acuífero por la noche cuando el precio de la electricidad es bajo y almacenarla en grandes balsas, para después distribuirla mediante una red cerrada y goteros. Este sistema de regadío de alta tecnología es controlado por ordenadores, bombas, balsas, tubos y goteros 
con el fin de redistribuir el agua de una forma eficiente e incorporando mejora agronómicas como la fertilización automática, herbicidas para la eliminación de las malas hierbas e insecticidas para el control de las plagas en lo que es ahora una agricultura hiperespecializadas de cítricos y que cubre 284.674 ha, la más extensa de Europa.

Una ventaja adicional del regadío localizado es que no necesita de aterrazamientos 0 nivelaciones del terreno, ya que pueden distribuir eficientemente el agua a pesar de las diferencia de altura. Los nuevos campos de cítricos se han instalado en pendientes entre 5 y $40 \%$. Sin embargo, el manejo de laboreo y herbicida es aplicado a los nuevos campos de cítricos. En los campos plantados recientemente, en los que la cubierta del cultivo es insignificante, el suelo queda desnudo debido al masivo uso de herbicidas. Después de 15 años, el cultivo debe cubrir el $50 \%$ del suelo pero después de varios años sin cubierta vegetal el suelo se verá seriamente afectado y los procesos de degradación edáfica estarán ya presentes debido a la pérdida del horizonte superficial. Además, estos nuevos campos agrícolas deben estar afectados por el tránsito de maquinaria pesada que aplica los pesticidas, herbicidas y fertilizantes, lo que provoca el aumento de la compactación del suelo (Cerdà y Jurgensen, 2008). Esto también estará relacionado con la reducción de la infiltración.

La nueva expansión de los campos de cítricos en laderas es un paso más en la concentración de la actividad citrícola en la agricultura Valenciana, con la producción de naranjas y clementinas para el mercado del norte de Europa. La Comunidad Valenciana produce dos tercios de las naranjas españolas, y es el mayor exportador y el tercer productor del mundo (Piqueras, 1999). Este proceso de la expansión de los cítricos con la especialización agrícola y el monocultivo ha disparado cambios ambientales como son la contaminación del agua, el aire y el suelo, la pérdida de biodiversidad, cambios en el balance hídrico y en los procesos superficiales, lo que ha dado lugar también a cambios en las geoformas. Cerdà y Doerr (2007) mostraron que las plantaciones de cítricos el este de España desencadenaron un incremento de las pérdidas de suelo y agua en comparación con otros usos del suelo tales como el matorral o el cultivo tradicional del olivo en terrazas. Los trabajos de Cerdà y Doerr (2007) y Cerdà y Jurgensen (2010) han mostrado tasas de erosión elevadas en el valle del río Canyoles en el NW de la provincia de Valencia. Sin embargo, los procesos erosivos en los campos de cítricos son prácticamente desconocidos.

\subsubsection{Objetivos}

Con el fin de aportar más información sobre los procesos erosivos en los campos de cítricos, en agosto de 2007 se realizó una campaña de trabajo de campo en distintos términos municipales para determinar las pérdidas de suelo en los nuevos naranjales españoles. El objetivo de este artículo es aportar información sobre las pérdidas de suelo en campos de cítricos en el este de España. Y para cubrir este objetivo, los experimentos fueron desarrollados en 10 campos de cítricos de nueva plantación en laderas. Como el objetivo del estudio es evaluar las tasas de erosión en medios semiáridos en los que la 
Iluvia es muy variable, se llevaron a cabo experimentos con lluvia simulada como un primer paso para iniciar la investigación sobre los procesos de erosión en campos de cítricos.

\subsection{Material y métodos}

\subsubsection{Zona de estudio}

Diez zonas de experimentación fueron seleccionadas en el Este de España. Todas fueron seleccionadas en calizas, el roquedo más característico del mediterráneo Occidental. La precipitación de las zonas de estudio oscila entre 498 y $715 \mathrm{~mm}$ año-1, con pendientes entre 8 y $14 \%$ con el fin de evitar diferencias debido a factores que no fueron los usos y manejos agrícolas entre los campos de cultivos de cítricos. Las zonas de estudio se encuentran en los términos municipales de Montesa, Vallada, Genovés, Gandia, Canals, Montserrat, Pego, Llíria, L'Alcúdia y Serra (Fig. 1), y son representativas de las nuevas plantaciones de cítricos en la región de Valencia y el Mediterráneo Occidental. Plantaciones similares se pueden encontrar en Andalucía, la Región de Murcia, Italia, Sur de Francia, Marruecos y Argelia. En cada zona se seleccionó una plantación joven (menos de tres años) de cítricos, y en ella se realizaron los experimentos entre las líneas de árboles. El sistema de riego por goteo (entre 1 y 3 goteros por árbol) se localiza bajo los árboles y cubre menos del $2 \%$ de la superficie de la plantación. Todas las zonas estudiadas siguieron el manejo más utilizado: herbicida para controlar las malas hierbas, pesticidas y una alta mecanización de las labores agrícolas. En estas plantaciones el riego por goteo afecta solo a $0.15 \mathrm{~m}^{2}$ por planta de cítrico, las cuales están espaciadas a razón de una planta por cada 28-35 m² (4-5 $\mathrm{m} \times 7 \mathrm{~m}$ ) (Fig. 2a, 2b).

Con el objetivo de determinar la respuesta hidrológica y erosiva bajo eventos de alta magnitud y baja frecuencia, aquellos que controlan la respuesta erosiva e hidrológica en medios mediterráneos, se realizaron experimentos con lluvia simulada a $55 \mathrm{~mm} \mathrm{~h}^{-1}$ en 0.25 $\mathrm{m}^{2}$ parcela. La elevada intensidad de la lluvia (5 años de periodo de retorno en las zonas de estudio) fue seleccionado debido a que ha sido muy utilizado en los experimentos en el mediterráneo occidental y a que representa el tipo de evento que produce arroyada superficial en condiciones climáticas mediterráneas (Thornes, 1975). El simulador de lluvia diseñado por Cerdà et al., (1997) fue elegido para estos experimentos porque es portátil, fácil de manejar y se pueden realizar un gran número de experimentos debido a su reducido tamaño. Las mediciones tomadas son representativas de los procesos de erosión que se producen a escala de entre reguero o pendón. Las mediciones de erosión a escala de reguero y cárcava no se han tenido en cuenta en este trabajo. 


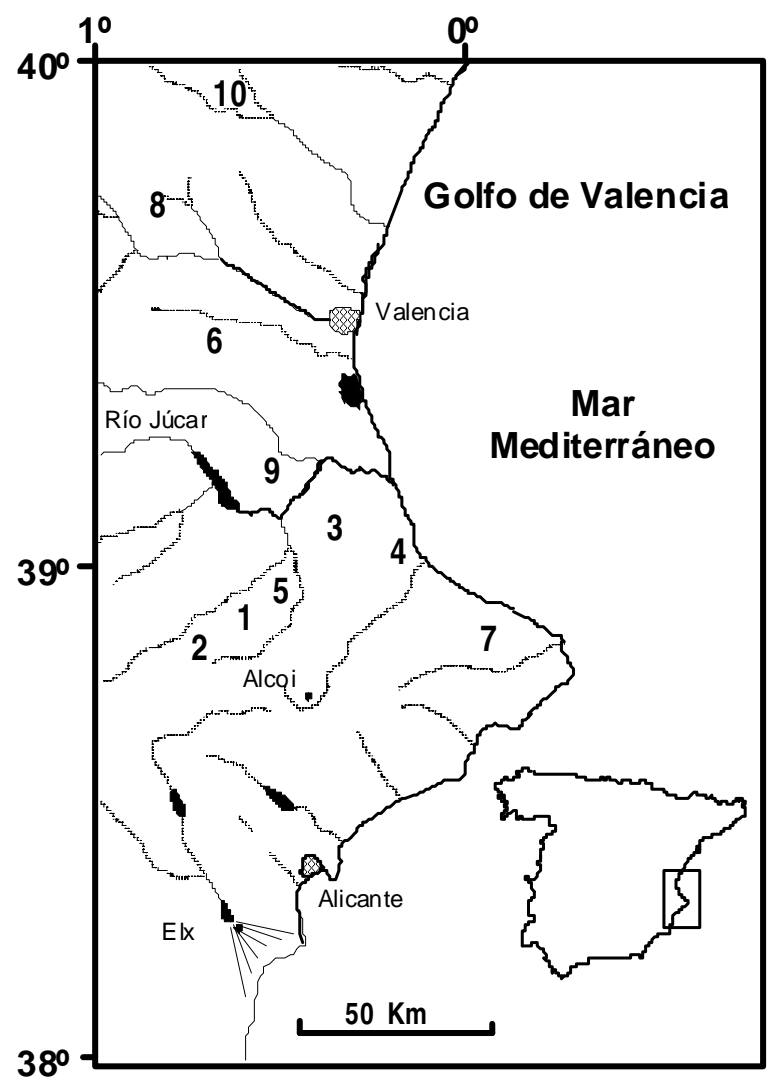

Figura 1. Localización de las zonas de estudio en el Este de España. Montesa (1), Vallada (2), Genovés (3), Gandía (4), Canals (5), Monserrat (6), Pego (7), Llíria (8), L’Alcúdia (9) y Serra (10). 


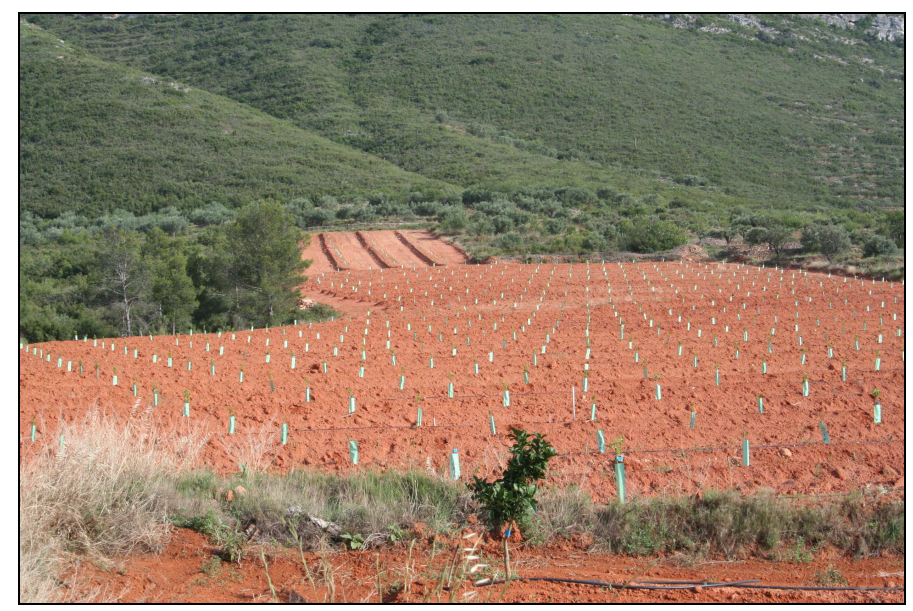

Figure 2a. Vista general de la zona de estudio de Vallada

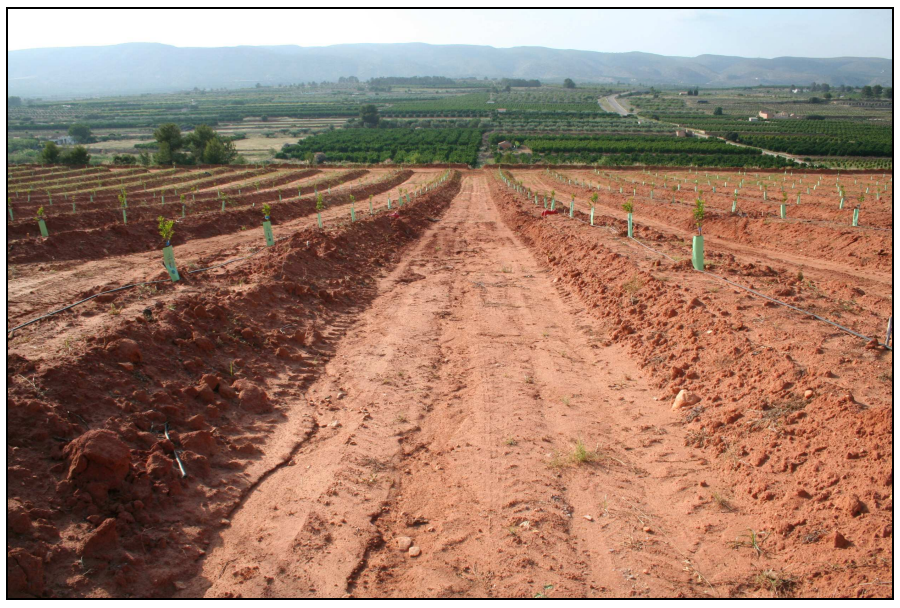

Figure $2 \mathbf{b}$. Detalle de la zona de estudio de Vallada 
Las nuevas plantaciones de cítricos han reemplazado los sistemas tradicionales de agricultura de secano en terrazas. Aquellos campos de olivos de entre 2 y $20 \mathrm{~m}$ de anchura han sido transformados en amplios campos que han eliminado tanto los muros de piedra seca como los sistemas de drenaje. El aterrazamiento durante siglos de estas laderas ha sido eliminado para permitir una mecanización total de las labores agrícolas. Ahora, nuevos campos de cítricos de entre 100 y 500 metros de anchura permiten tareas mecanizadas pero no han desembocado en una nueva agricultura con sistemas de conservación del suelo (abonos verdes o laboreo en el sentido de las curvas de nivel) o control de la erosión. En las zonas de estudio siempre se seleccionaron explotaciones en el tramo inferiores de las laderas con el fin de que fuesen comparables las mediciones. Aunque existen, las explotaciones de cítricos se suelen localizar en las zonas coluviales de los pies de ladera con el fin de reducir los costes del bombeo de las aguas del acuífero, y disponer de un mejor suelo que en los tramos medios y altos de las laderas. No obstante, también existen explotaciones de cítricos en posiciones elevadas.

\subsubsection{Muestreo y diseño experimental}

Cien experimentos con lluvia simulada se llevaron a cabo en 10 zonas experimentales representativas de las plantaciones de cítricos en el Mediterráneo Occidental. Cien parcelas fueron construidas a lo largo del verano de 2007 en las diez zonas de estudio (ver figura 1). Los experimentos se realizaron en agosto de 2007 durante el periodo de sequia típico de las zonas mediterráneas. La lluvia simulada con agua destilada fue aplicada desde una altura de 2 metros de altura sobre una superficie de $1 \mathrm{~m}^{2}$. La parcela de $0.25 \mathrm{~m}^{2}$ se colocó en la zona central de la superficie humectada por la lluvia. Un colector permitía recoger la escorrentía y los sedimentos en la parte baja de la parcela. La lluvia simulada tuvo una duración de 1 hora con una intensidad de $55 \mathrm{~mm} \mathrm{~h}^{-1}$, lo que equivale a una tormenta típica de zona mediterránea con un periodo de retorno de 5 años. Información más detallada del protocolo y de los instrumentos utilizados se puede encontrar en Cerdà (1996) y Cerdà et al., (1997). El amplio uso del simulador de lluvia utilizado entre la comunidad científica del mediterráneo occidental posibilita la comparación con los resultados de otros investigadores. Los experimentos llevados a cabo durante agosto de 2007 mostraron suelos extremadamente secos debido al periodo de sequía estival y a la compactación de los suelos agrícolas por el paso de maquinaría pesada. En todas las muestras de superficie $(0-2 \mathrm{~cm})$ nunca se superó el $5 \%$ de humedad del suelo. La mediciones se realizaron mediante el método gravimétrico.

La arroyada superficial se midió cada minuto en el campo y cada diez minutos se produjo la toma de una muestra para determinar la concentración de sedimentos y calcular la pérdida de suelo. La precipitación, las tasas de escorrentía y la concentración de sedimentos permitieron calcular los sedimentos totales, la escorrentía total, el coeficiente de 
escorrentía, la tasa de infiltración y las tasas de erosión (Cerdà, 1999). La vegetación y la cubierta de fragmentos de rocas fueron estimadas en el campo como \% de la superficie cubierta por plantas o piedras antes y después de la aplicación de la lluvia simulada.

Tabla 1. Media y desviación estándar (std) del tiempo de encharcamiento (tp), tiempo de escorrentía (tr) y tiempo de retraso de la escorrentía ( $t d=t r-t p)$ en segundos en las 10 zonas de estudio ( $n=10$ parcelas) y para el conjunto de experimentos realizados $(n=100$ parcelas $)$

\begin{tabular}{|c|c|c|c|c|c|c|}
\hline & $\begin{array}{c}\text { tp } \\
\text { Media }\end{array}$ & $\begin{array}{l}t p \\
\text { std }\end{array}$ & $\begin{array}{c}\text { tr } \\
\text { Media }\end{array}$ & $\begin{array}{c}\text { tr } \\
\text { Std }\end{array}$ & $\begin{array}{c}t d \\
\text { Media }\end{array}$ & $\begin{array}{c}t d \\
\text { Std }\end{array}$ \\
\hline Montesa & 93,1 & 40,1 & 154,1 & 47,0 & 61,0 & 20,2 \\
\hline Vallada & 113,7 & 45,5 & 189,5 & 60,1 & 75,8 & 24,4 \\
\hline Genovés & 144,5 & 76,6 & 217,6 & 95,5 & 73,1 & 35,3 \\
\hline Gandía & 54,6 & 33,3 & 103,9 & 48,1 & 49,3 & 22,4 \\
\hline Canals & 139,3 & 68,2 & 220,6 & 93,0 & 81,3 & 45,0 \\
\hline Montserrat & 141,2 & 58,0 & 229,4 & 69,9 & 88,2 & 26,3 \\
\hline Pego & 116,4 & 85,7 & 178,3 & 107,4 & 61,9 & 28,0 \\
\hline Llíria & 158,2 & 44,4 & 239,6 & 46,8 & 81,4 & 17,2 \\
\hline L'Alcúdia & 125,4 & 68,0 & 204,6 & 95,1 & 79,2 & 37,1 \\
\hline Serra & 124,6 & 57,9 & 214,2 & 81,1 & 55,3 & 83,1 \\
\hline Media & 121,1 & 57,8 & 193,7 & 74,2 & 70,7 & 33,9 \\
\hline Std & 29,8 & 17,0 & 40,4 & 23,0 & 12,9 & 19,2 \\
\hline
\end{tabular}

\section{Resultados}

\subsubsection{Encarcamiento e inicio de la escorrentía}

El tiempo medio de encharcamiento (tp) después del comienzo de la lluvia simulada fue de 121 segundos (desviación estándar de 58) con valores que oscilan entre 10 y 269 segundos. Todas las parcelas mostraron encharcamiento y escorrentía durante los experimentos. El tiempo medio del inicio de la escorrentía fue de 194 segundos (desviación estándar 74), oscilando entre 23 y 415 segundos. De las 10 zonas de estudio (10 parcelas por zona) Gandia fue la que mostró un tiempo de encharcamiento menor (55 segundos) y Llíria el mayor (158 segundos). El tiempo de inicio de la escorrentía osciló entre 104 segundos en Gandia y 220 segundos en Llíria. El tiempo de retraso de la escorrentía respecto al encharcamiento mostro un valor medio de 71 segundos (desviación estándar 34), y osciló entre 13 y 165 segundos para parcelas individuales y entre 49 segundos en Gandía y 88 segundos en Montserrat (Tabla 1). 
Tabla 2. Media y desviación estándar del coeficiente de escorrentía (\% escorrentía/precipitación) y la escorrentía total (lluvia $=55 \mathrm{~mm}$ ) en las 10 zonas de estudio

\begin{tabular}{lcccc}
\hline & \multicolumn{2}{c}{ Escorrentía (\%) } & \multicolumn{2}{c}{ Escorrentía (I) } \\
& Media & std & Media & std \\
\hline Montesa & 42,9 & 7,7 & 5,9 & 1,1 \\
Vallada & 33,8 & 16,1 & 4,6 & 2,2 \\
Genovés & 34,8 & 18,7 & 4,8 & 2,6 \\
Gandía & 51,9 & 21,5 & 7,1 & 3,0 \\
Canals & 30,1 & 20,1 & 4,1 & 2,8 \\
Montserrat & 23,9 & 12,3 & 3,3 & 1,7 \\
Pego & 37,9 & 17,8 & 5,2 & 2,5 \\
Llíria & 25,0 & 9,7 & 3,4 & 1,3 \\
L'Alcúdia & 32,1 & 24,6 & 4,4 & 3,4 \\
Serra & 20,5 & $\mathbf{9 , 9}$ & $\mathbf{2 , 8}$ & 1,4 \\
\hline Average & $\mathbf{3 3 , 3}$ & $\mathbf{1 5 , 9}$ & $\mathbf{4 , 6}$ & $\mathbf{2 , 2}$ \\
Std & $\mathbf{9 , 4}$ & $\mathbf{5 , 7}$ & $\mathbf{1 , 3}$ & $\mathbf{0 , 8}$ \\
\hline
\end{tabular}

\subsubsection{Producción de escorrentía}

La media de la producción de la escorrentía fue de $33,3 \%$ de la lluvia (desviación estándar 9.4\%), con valores medios para las diez zonas de estudio que osciló entre $20,5 \%$ en Serra y $51,9 \%$ en Gandía. La desviación estándar media fue de 15.9 y osciló entre 9,7 en Llíria y 24,6 en L'Alcúdia. Los coeficientes de escorrentía por parcelas oscilaron entre $86,4 \%$ y $2,4 \%$.

De los 13,75 litros precipitados con la lluvia simulada en cada parcela una media de 4,6 litros (desviación estándar de 1,3) fueron transformados en escorrentía. Entre las zonas de estudio este valor osciló entre 7,1 litros en Gandia y 2,8 litros en Serra. La escorrentía total presento valores de desviación estándar elevados, los cuales oscilaron entre 1,1 en Montesa y 3,4 en L'Alcúdia. La escorrentía total osciló entre 0,32 y 11,87 litros entre las 100 parcelas estudiadas.

\subsubsection{Producción de sedimentos}

La media de la concentración de sedimentos fue de 10,4 $\mathrm{g} \mathrm{l}^{-1}$ oscilando entre 1,25 y 26,35 $\mathrm{gl}^{-1}$ entre las 100 parcelas estudiadas. La zona de Serra mostró la menor media $\left(5,5 \mathrm{~g} \mathrm{l}^{-1}\right)$ y Gandia la más alta $\left(17,7 \mathrm{gl}^{-1}\right)$. La media de la desviación estándar fue de 4,5 y osciló entre 2,2 en Llíria y Serra, y 7 en L'Alcúdia. 
La media de la producción de sedimentos en la parcela de $0.25 \mathrm{~m}^{2}$ fue de 59,6 gramos por experimento. Serra tuvo la menor media de producción de sedimentos $(16,6 \mathrm{~g})$ y Gandia la mayor (141,5 g). La desviación estándar fue de 50 gramos, oscilando entre los 11,5 gramos de Llíria y los 93,7 gramos de Gandia. De las 100 medidas tomadas la menor producción de sedimentos fue de $0,54 \mathrm{~g}$ y la mayor de $304,6 \mathrm{~g}$.

Tabla 3. Media y desviación estándar de la concentración de sedimentos $\left(\mathrm{g} \mathrm{l}^{-1}\right)$ y los sedimentos totales $(\mathrm{g})$ en las 10 zonas de estudio

\begin{tabular}{lcccc}
\hline & \multicolumn{2}{c}{ Concentración de sedimentos $\left(\mathbf{g ~}^{-1}\right)$} & \multicolumn{2}{c}{ Sedimento totales $\left(\mathrm{g} \mathrm{m}^{\mathbf{2}} \mathbf{~ h}^{-1}\right)$} \\
& Media & Std & Media & Std \\
\hline Montesa & 14,6 & 3,1 & 87,2 & 29,1 \\
Vallada & 10,5 & 5,7 & 57,6 & 62,5 \\
Genovés & 14,4 & 4,2 & 78,4 & 64,8 \\
Gandía & 17,7 & 6,5 & 141,5 & 93,7 \\
Canals & 8,5 & 5,6 & 45,3 & 48,8 \\
Montserrat & 7,4 & 3,6 & 29,0 & 31,6 \\
Pego & 10,1 & 5,1 & 59,1 & 53,7 \\
Llíria & 6,4 & 2,2 & 23,5 & 11,5 \\
L'Alcúdia & 8,8 & 7,0 & 58,1 & 92,6 \\
Serra & 5,5 & 2,2 & 16,6 & 12,0 \\
\hline Average & 10,4 & 4,5 & 59,6 & $\mathbf{5 0 , 0}$ \\
Std & 4,0 & $\mathbf{1 , 7}$ & 36,7 & $\mathbf{2 9 , 5}$ \\
\hline
\end{tabular}

\subsubsection{Producción de sedimentos}

La media de pérdida de suelo por parcela y zonas se muestra en $\mathrm{g} \mathrm{m}^{-2} \mathrm{~h}^{-1}$ ya que las parcelas utilizadas para la medición son de reducido tamaño (menos de $1 \mathrm{~m}^{2}$ ), y también se presenta con la medida más tradicional de $\mathrm{Mg} \mathrm{ha}^{-1}$ para la comparación con los resultados de otros investigadores (Tabla 4). La media de pérdida de suelo para las 100 parcelas fue de $238.5 \mathrm{~g} \mathrm{~m}^{-2} \mathrm{~h}^{-1}$ (desviación estándar 200.1) y por zonas de estudio osciló entre $66.4 \mathrm{~g} \mathrm{~m}$ $2 \mathrm{~h}^{-1}$ en Serra (desviación estándar 48) y $566.2 \mathrm{~g} \mathrm{~m}^{-2} \mathrm{~h}^{-1}$ en Gandia (desviación estándar 375). Las tasas de erosión medidas por parcelas $(n=100)$ oscilaron entre 2,1 y $1.218,2 \mathrm{~g} \mathrm{~m}$ $2 h^{-1}$. 
Tabla 4. Media y desviación estándar de las tasas de erosión del suelo mostradas en $\mathrm{g} \mathrm{m}^{-2} \mathrm{~h}^{-1}$ y $\mathrm{Mg}$ $\mathrm{ha}^{-1} \mathrm{~h}^{-1}$.

\begin{tabular}{lcccc}
\hline & \multicolumn{2}{c}{ Erosión $\left(\mathrm{g} \mathrm{m}^{-2} \mathrm{~h}^{-1}\right)$} & \multicolumn{2}{c}{ Erosión $\left(\mathrm{Mg} \mathrm{ha}^{-1} \mathbf{h}^{-1}\right)$} \\
& Media & Std & Media & Std \\
\hline Montesa & 348,8 & 116,2 & 3,5 & 1,2 \\
Vallada & 230,5 & 249,9 & 2,3 & 2,5 \\
Genovés & 313,5 & 259,4 & 3,1 & 2,6 \\
Gandía & 566,2 & 374,7 & 5,7 & 3,7 \\
Canals & 181,2 & 195,2 & 1,8 & 2,0 \\
Montserrat & 115,9 & 126,5 & 1,2 & 1,3 \\
Pego & 236,4 & 214,8 & 2,4 & 2,1 \\
Llíria & 94,0 & 45,8 & 0,9 & 0,5 \\
L'Alcúdia & 232,3 & 370,4 & 2,3 & 3,7 \\
Serra & 66,4 & 47,9 & 0,7 & 0,5 \\
\hline Average & $\mathbf{2 3 8 , 5}$ & $\mathbf{2 0 0 , 1}$ & $\mathbf{2 , 4}$ & $\mathbf{2 , 0}$ \\
Std & $\mathbf{1 4 6 , 9}$ & $\mathbf{1 1 7 , 9}$ & $\mathbf{1 , 5}$ & $\mathbf{1 , 2}$ \\
\hline
\end{tabular}

\subsection{Discusión}

Las nuevas plantaciones de cítricos en laderas mostraron una rápida respuesta a la lluvia. El encharcamiento se alcanzó después de 2 minutos y la escorrentía superficial se inició tras 3 minutos. Esto significa que cualquier lluvia veraniega procedente de tormentas convectivas dará lugar a la movilización de sedimentos y agua vertiente abajo en estos campos de cultivo. Además, los eventos ciclónicos de otoño darán lugar a abundantes escorrentías y pérdidas de suelo debido a su elevada magnitud. Lluvias de más de $100 \mathrm{~mm}$ día $^{-1}\left(>800 \mathrm{~mm} \mathrm{~d}^{-1}\right.$ también han sido medidas) darán lugar a pérdidas de suelo y agua extraordinarias (López Bermúdez y Romero Díaz, 1992-1993; White et al., 1997).

El encharcamiento del suelo se produjo en todas las parcelas, y en ninguna de ellas se produjo la infiltración de toda la lluvia, aunque la variabilidad especial fue muy elevada entre las zonas de estudio y sobretodo entre las parcelas. La escorrentía fue generalizada en todas las parcelas bajo lluvias de 5 años de periodo de recurrencia, a pesar de los suelos secos. En todos los experimentos la escorrentía se inicio antes de 8 minutos desde el inicio de la lluvia, el $90 \%$ de las parcelas produjeron escorrentía antes de 6 minutos y el $50 \%$ antes de 3 minutos. Esto demuestra que la escorrentía será muy frecuente en las nuevas explotaciones de cítricos durante las estaciones secas, cuando fueron realizados los experimentos. Debemos apuntar aquí que el encharcamiento y la escorrentía aún será más abundante durante las estaciones húmedas (Cerdà, 1999). La falta de cubierta vegetal contribuye a una alta erodibilidad como demuestran concentraciones medias de sedimentos 
superiores a $10 \mathrm{~g} \mathrm{l}^{-1}$. Esta combinación de alta descarga hídrica y alta concentración de sedimentos da como resultado tasas de erosión extremadamente altas (2.4 $\mathrm{Mg} \mathrm{ha}^{-1}$ hora $\left.^{-1}\right)$.

La interacción entre la pérdida de suelo y agua en suelos desnudos en laderas en pendiente es el tema de la primera parte de la discusión que presentamos a continuación. El segundo tema muestra la comparación entre los resultados publicados por otros autores que han estudiado distintos manejos en el Mediterráneo Occidental con la misma metodología.

\subsubsection{Relaciones entre la pérdida de suelo y agua}

El tiempo de encharcamiento determina el tiempo de inicio de la escorrentía $\left(R^{2}=0.90\right)$. El tiempo de retraso entre el $T p$ y $\operatorname{Tr}$ muestra una relación con el tiempo de relación entre tiempo de escorrentía $\left(R^{2}=0.56\right)$ que el tiempo de encharcamiento $\left(R^{2}=0.24\right)$ (Fig. 3). La media del tiempo de encharcamiento y escorrentía ( $T d$ ) es de 70 segundos, lo que demuestra que la conectividad de la escorrentía dentro de la ladera es muy eficiente por la falta de vegetación $(<1 \%)$ y de fragmentos de roca $(<4 \%)$. Se debe resaltar que todas las parcelas muestran encharcamiento y escorrentía, lo que es poco usual en otros manejos del suelo, donde la vegetación y la hojarasca son abundantes (Ceballos, 1997). De hecho, en otros tipos de suelos y manejos el encharcamiento es raro (Cerdà, 1997; Imeson et al., 1998) y la escorrentía insignificante (Sala y Calvo, 1991; Árnaez et al., 1996; Pérez Cabello, 2001). El tiempo de encharcamiento es corto (2 minutos) y la escorrentía (3 minutos) bajo condiciones de suelos secos en verano cuando las tasas de infiltración son las más altas debido a las condiciones de verano. Solo en superficies de badlands se producen condiciones similares a las de los naranjales debido a la ausencia de vegetación y a la alta densidad aparente de los suelos (Regüés y Gallart, 2004). La rápida respuesta de los suelos ante la lluvia es debido a la falta de de vegetación. Esta falta de malas hierbas es fruto del uso masivo de herbicidas. La rápida respuesta a la lluvia es fruto también de la baja porosidad de los suelos como consecuencia del paso de maquinaria pesada, además de la falta de vegetación (Cerdà y Jurgensen, 2008). La repelencia al agua es rara en este tipo de suelos debido al escaso contenido de materia orgánica (Cerdà y Doerr, 2005).

La escorrentía (\%) muestra una clara relación con la erosionabilidad del suelo (concentración de sedimentos, $\left.\mathrm{g}^{-1}\right)\left(\mathrm{r}^{2}=0.67\right)$. También se muestra una clara relación entre la escorrentía y la erosión del suelo $\left(r^{2}=0.90\right)$ y la concentración de sedimentos y la pérdida de suelo $\left(r^{2}=0.83\right)$ (Fig. 4). Estas relaciones muestran que hay una relación que potencia la pérdida de suelo al aumentar la erosionabilidad de los suelos con el aumento de la escorrentía. Esta relación demuestra que los procesos de erosión en los campos de cítricos están controlados por la capacidad de transporte, ya que la cantidad de sedimentos disponible es ilimitada. Como demuestran los datos obtenidos con las 100 simulaciones de lluvia, a mayor caudal mayor concentración de sedimentos y por lo tanto mayor erosión, y por lo tanto es la capacidad de trasporte la que determinará cuanto sedimento es exportado. 

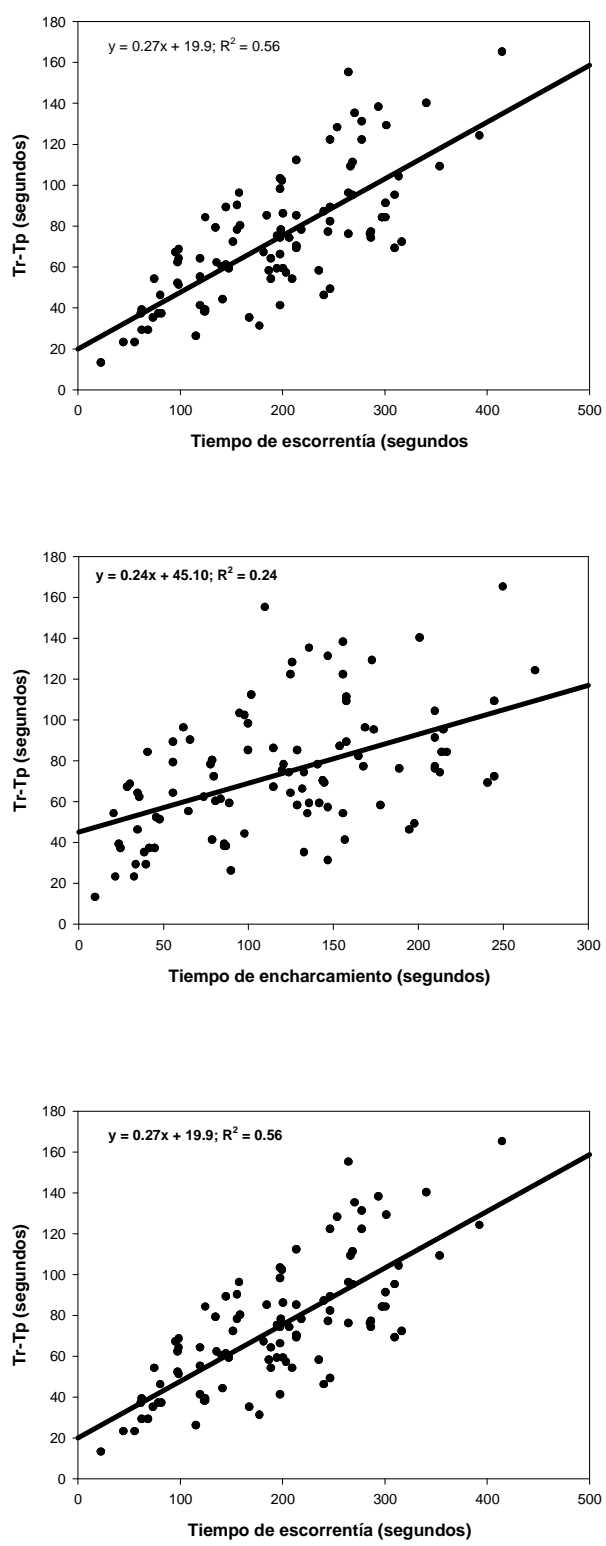

Figura 3. Relaciones entre el tiempo de encharcamiento (tp), tiempo de escorrentía (tr) y tiempo de retraso de la escorrentía respecto al encharcamiento (td = tr-tp). 
Los resultados también demuestran que la cantidad de sedimentos disponibles para ser removidos no se agotó después de una lluvia con un periodo de retorno de 5 años. Y esta es una características de las 10 zonas de estudio. En cambio, en los suelos vegetados, el proceso de erosión está controlado por la remoción de material debido al efecto que ejercen las plantas. Así, en los suelos con plantas la concentración de sedimentos decrece cuando la escorrentía aumenta debido a que los sedimentos disponibles se agotan y son diluidos por la mayor descarga de escorrentía. Los datos aportados por esta investigación demuestran que en las nuevas plantaciones de cítricos la concentración de sedimentos aumenta con el caudal, y por lo tanto ante lluvias intensas la erosión del suelo se disparará y dará lugar a la formación de regueros y cárcavas.

Las altas tasas de escorrentía medidas durante los experimentos deben ser destacadas aquí ya que habitualmente las escorrentía son bajas 0 insignificantes en suelos mediterráneos durante el verano debido a los bajos contenidos de humedad del suelo (Cerdà, 1996). La alta densidad del suelo $\left(1.4 \mathrm{~g} \mathrm{~cm}^{-3}\right)$ es la explicación clave del rápido encharcamiento y el inicio de la escorrentía, los elevados volúmenes de escorrentía producidos y la exportación de sedimentos. En esto influye la falta de vegetación que permite el impacto de las gotas en suelos desnudos (Cerdà and Jurgensen, 2008).

\subsection{2. ¿Son las pérdidas de suelo altas en campos de cítricos?. Comparación con otros usos del suelo.}

Desde el punto de vista de la sostenibilidad de la producción agrícola, las tasas de erosión alcanzadas durante una hora de experimentos (5 años de periodo de retorno) muestra valores no sostenibles ni tolerables. En una hora, más de 2 toneladas por hectárea de un suelo agrícola se han perdido. La comparación con otras mediciones realizadas en el mediterráneo occidental demuestra que las tasas de erosión en los campos de cítricos muestra valores similares a los badlands, derrubios de minas o campos de cultivo recientemente abandonados y degradados. Mediante la comparación con los 352 experimentos con lluvia simulada revisados a partir de la literatura científica (ver tablas 5 a y 5 b) se puede concluir que los campos de cultivo de cítricos en laderas muestran pérdidas de suelo superiores a las zonas afectadas por incendios forestales, matorrales, bosques, los pediments de los badlands o incluso que los derrubios de minas recientes. De hecho, en la actualidad, los campos de cultivo de cítricos son una fuente de sedimentos relevante en la cuenca mediterránea y dan lugar a una contribución significativa a la degradación del suelo. La razón última de estas elevadas tasas de pérdida de suelo y agua en explotaciones altamente tecnificadas la podemos encontrar en el uso masivo de herbicidas. Los agricultores han entendido que el campo de cultivo debe estar libre de malas hierbas y por ello no dejan crecer ninguna planta ha excepción del cultivo. Esta es la razón por la que los naranjales del mediterráneo occidental muestran incluso mayores tasas de erosión que en otros usos y manejos agrícolas, incluido el laboreo (Gómez et al., 2004; García Orenes et al., 2009). 

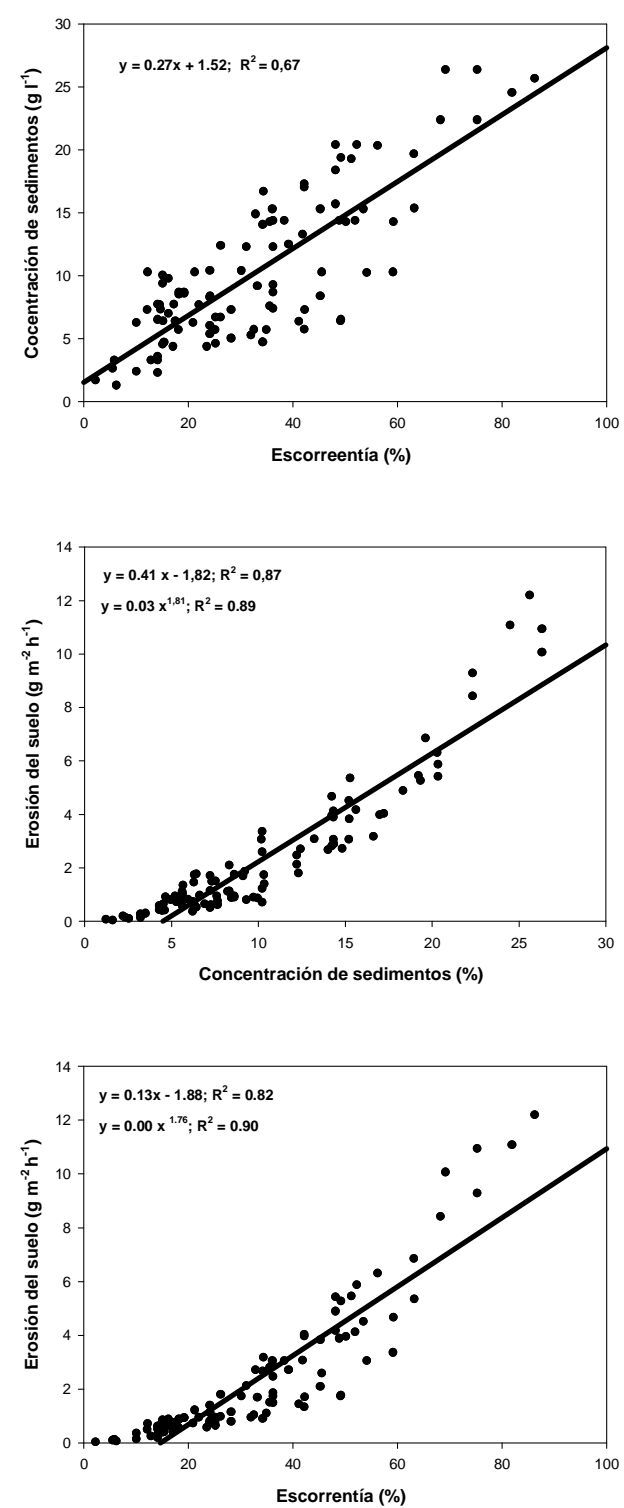

Figura 4. Relación entre la escorrentía (\%), concentración de sedimentos $(\mathrm{g} \mathrm{l}-1)$ y tasas de erosión del suelo $\left(\mathrm{g} \mathrm{m}^{-2} \mathrm{~h}^{-1}\right)$. 
Tabla 5a. Resultados obtenidos por otros autores en el Mediterráneo Occidental mediante el uso de Iluvia simulada bajo distintos usos y manejos. La tabla muestra el autor, el año de publicación, la intensidad de la lluvia (RI), el coeficiente de escorrentía (RC), la concentración de sedimentos (SC), la tasa de erosión (ER) y las características del uso y manejo del suelo.

\begin{tabular}{|c|c|c|c|c|c|c|c|}
\hline Author & Year & $\begin{array}{c}\mathbf{R} \mathbf{I} \\
\mathrm{mm} \mathrm{h}^{-1}\end{array}$ & $\begin{array}{c}\text { RC } \\
\% \\
\end{array}$ & $\begin{array}{l}\text { CS } \\
\mathrm{G} \mathrm{I}^{-1}\end{array}$ & $\begin{array}{c}\text { ER } \\
\mathrm{Mg} \mathrm{ha}^{-1} \mathrm{~h}^{-1}\end{array}$ & $\begin{array}{c}\text { Plots } \\
n^{0}\end{array}$ & Characteristics \\
\hline Sala y Calvo & 1990 & 60,0 & 1,8 & 0,5 & 0,00 & 6 & Bosque \\
\hline Cerdà y García-Fayos & 1997 & 55,0 & 70,0 & 2,29 & 0,95 & 3 & Pediment badland \\
\hline Cerdà y García-Fayos & 1997 & 55,0 & 74,0 & 60,61 & 23,73 & 13 & Ladera badland \\
\hline Cerdà et al,, & 1996 & 55,0 & $0-41$ & $0-1,52$ & $0-0,27$ & 10 & Stipa tenacissima \\
\hline Ceballos & 1997 & 53,6 & 55,8 & 0,4 & 0,11 & 40 & Praderas \\
\hline Arnáez et al,, & 1996 & 58,2 & 33,8 & 0,6 & 0,18 & 1 & Matorral \\
\hline Arnáez et al,, & 1996 & 58,2 & 31,5 & 0,7 & 0,12 & 1 & Praderas \\
\hline Arnáez et al,, & 1996 & 58,2 & 58,8 & 3,8 & 2,08 & 1 & Desnudos \\
\hline Arnáez et al,, & 1996 & 58,2 & 48,0 & 0,8 & 0,74 & 1 & Fragmentos de rocas \\
\hline Nicolau & 1996 & 21,4 & 30,4 & 1,9 & 0,49 & 1 & Derrubio de minas 2 años \\
\hline Nicolau & 1996 & 58,4 & 8,2 & 0,8 & 0,14 & 1 & Derrubio de minas 6 años \\
\hline Nicolau & 1996 & 25,8 & 29,1 & 19,0 & 5,72 & 1 & Derrubio de minas 3 años \\
\hline Nicolau & 1996 & 30,1 & 52,9 & 14,1 & 8,96 & 1 & Derrubio de minas 3 años \\
\hline Nicolau & 1996 & 29,7 & 62,1 & 13,8 & 10,14 & 1 & Derrubio de minas 3 años \\
\hline Nicolau & 1996 & 58,4 & 82,2 & 50,1 & 96,17 & 1 & Derrubio de minas 7 años \\
\hline Cerdà y Navarro & 1997 & 55,0 & 46,0 & 42,0 & 10,20 & 10 & Ballands \\
\hline Cerdà y Navarro & 1997 & 55,0 & 62,0 & 59,0 & 19,30 & 10 & Badlands \\
\hline Cerdà & $1997 c$ & 55,0 & 19,0 & 2,0 & 0,13 & 5 & Badlands margas \\
\hline Cerdà & $1997 c$ & 55,0 & 72,0 & 57,6 & 19,97 & 5 & Badlands. Margas \\
\hline Solé et al,, & 1997 & 55,0 & 44,6 & 4,3 & 2,50 & 16 & Badlands \\
\hline Cerdà & $1997 b$ & 47,0 & 0,0 & 0,0 & 0,0 & 6 & Tillage (bare) \\
\hline Cerdà & $1997 b$ & 47,0 & 35,4 & 16,9 & 3,3 & 6 & 2-años abandonado \\
\hline Cerdà & $1997 b$ & 47,0 & 9,2 & 0,1 & 0,0 & 6 & 10-años abandonado \\
\hline Cerdà & $1997 b$ & 47,0 & 4,6 & 0,1 & 0,0 & 6 & Stipa tenacísima \\
\hline Cerdà & $1997 \mathrm{~b}$ & 47,0 & 13,6 & 0,3 & 0,0 & 6 & Pinus halepensis \\
\hline Cerdà & $1998 \mathrm{~b}$ & 55,00 & 12,33 & 1,32 & 0,09 & 33 & Matorral \\
\hline
\end{tabular}


Tabla 5a. Resultados obtenidos por otros autores en el Mediterráneo Occidental mediante el uso de Iluvia simulada bajo distintos usos y manejos. La tabla muestra el autor, el año de publicación, la intensidad de la lluvia (RI), el coeficiente de escorrentía (RC), la concentración de sedimentos (SC), la tasa de erosión (ER) y las características del uso y manejo del suelo.

\begin{tabular}{|c|c|c|c|c|c|c|c|}
\hline Author & Year & $\mathbf{R I}$ & $\mathrm{RC}$ & CS & ER & Plots & Characteristics \\
\hline & & $\mathrm{mm} \mathrm{h}^{-1}$ & $\%$ & $\mathrm{~g} \mathrm{l}^{-1}$ & $M g h^{-1} h^{-1}$ & $\mathrm{n}^{0}$ & \\
\hline Cerdà & $1998 a$ & 60,0 & 0,90 & 0,2 & 0,01 & 5 & Quemado (1día después) \\
\hline Cerdà & $1998 a$ & 60,0 & 57,3 & 4,8 & 1,48 & 5 & Quemado (4 días después) \\
\hline Cerdà & $1998 a$ & 60,0 & 34,4 & 0,3 & 0,02 & 5 & Quemado (12 días después) \\
\hline Cerdà & $1998 a$ & 60,0 & 31,4 & 0,8 & 0,19 & 5 & Quemado (18 días después) \\
\hline Cerdà & $1998 a$ & 60,0 & 3,7 & 0,6 & 0,05 & 5 & Quemado (24 días después) \\
\hline Cerdà & $1998 \mathrm{a}$ & 60,0 & 14,4 & 0,1 & 0,01 & 5 & Quemado (30 días después) \\
\hline Cerdà & $1998 \mathrm{a}$ & 60,0 & 3,0 & 0,2 & 0,00 & 5 & Quemado (48 días después) \\
\hline Cerdà & $1998 \mathrm{a}$ & 60,0 & 4,1 & 0,1 & 0,00 & 5 & Quemado (52 días después) \\
\hline Cerdà & $1998 \mathrm{a}$ & 60,0 & 1,9 & 0,0 & 0,00 & 5 & Quemado (64 días después) \\
\hline Cerdà & 1998d & 55,0 & 32,3 & 0,7 & 0,1 & 9 & Scrubland \\
\hline Imeson et al,, & 1998 & 55,0 & $4-34$ & $0,9-2,9$ & $0,04-0,44$ & 4 & Scrubland \\
\hline Imeson et al,, & 1998 & 55,0 & $15-24$ & $1-2,6$ & $0,05-0,20$ & 2 & Scrubland \\
\hline Imeson et al,, & 1998 & 55,0 & 0,08 & $0,4-0,9$ & $0,02-0,035$ & 2 & Scrubland \\
\hline Imeson et al,, & 1998 & 55,0 & $18-40$ & $0,4-1,4$ & $0,13-0,19$ & 2 & Scrubland \\
\hline Imeson et al,, & 1998 & 55,0 & 4-7 & $0-0,37$ & $0-0,012$ & 2 & Scrubland \\
\hline Imeson et al,, & 1998 & 55,0 & $27-35$ & $0,9-2,9$ & $0,04-0,44$ & 2 & Scrubland \\
\hline Imeson et al,, & 1998 & 55,0 & $1-11$ & $0-3,37$ & $0-0,062$ & 4 & Scrubland \\
\hline Imeson et al,, & 1998 & 55,0 & 0 & 0,0 & 0,00 & 2 & Scrubland \\
\hline Imeson et al,, & 1998 & 55,0 & $0-24$ & $0-0,65$ & $0-0,07$ & 3 & Scrubland \\
\hline Imeson et al,, & 1998 & 55,0 & $0-24$ & $0-1,02$ & $0-0,01$ & 6 & Scrubland \\
\hline Regüés and Gallart & 1998 & 48,9 & 43,3 & 13,4 & 3,08 & 25 & Badlands \\
\hline Gómez Amelia et al,, & 1998 & 53,6 & 36,5 & 0,5 & 0,08 & 5 & Grassland \\
\hline Ries et al, & 2000 & 40,0 & 58,4 & 1,3 & 0,5 & 13 & 6 años abandonados \\
\hline Ries et al,, & 2000 & 40,0 & 41,4 & 1,7 & 0,39 & 16 & 60 años abandonados \\
\hline Ries et al,, & 2000 & 40,0 & 18,4 & 8,4 & 0,60 & 4 & Cultivado \\
\hline Pérez-Cabello & 2001 & 40,0 & 14,7 & 1,0 & 0,10 & 15 & Incedios forestales \\
\hline
\end{tabular}

La escorrentía alcanzó $1 / 3$ de la lluvia en las laderas con cultivos de cítricos. Tasas de escorrentía similares solo se pueden encontrar en suelos saturados o extremadamente húmedos (Arnáez et al., 1996; Ceballos et al., 1998; Cerdà, 1998b), en badlands (Cerdà y García Fayos, 1997) y derrubios de minas (Nicolau, 1996) bajo condiciones de lluvia simulada similares a las empleadas en esta investigación. Estas escorrentías súbitas y abundantes deben ser vistas como un potencial incremento de la pérdida de recursos hídricos para el cultivo pero también un riesgo para las inundaciones (Poesen and Hooke, 1997). Otros investigadores usan otros métodos para medir la erosión del suelo, pero, en 
ningún caso se han aportado valores de pérdida de suelo similares 0 superiores a las apuntadas aquí para campos de cultivos en cítricos, aunque sean cultivos que degradan los suelos y favorecen elevadas pérdidas de agua y suelos (Kosmas et al., 1997; Puigdefábregas et al., 1999; Ries et al., 2000; Lasanta et al., 2000). En los suelos forestales las pérdidas de suelos fueron insignificantes con las presentadas aquí (Romero Díaz et al., 1988). Sólo hemos encontrado valores similares de pérdida de suelo en cultivos de olivos en laderas con fuertes pendientes y laboreo en Andalucía (Gómez et al., 2004).

Debido a estas elevadas tasas de erosión nuevos sistemas de control de la erosión deben ser aplicados para su control. Esto permitirá reducir la pérdida de suelo, agua y nutrientes y por lo tanto conseguir una agricultura sostenible, o en todo caso con tasas de erosión tolerables. Cerdà et al. (2007) desarrollaron una primera aproximación en este tema, si bien es necesario más trabajo no solo investigador, sino también de coordinación con los técnicos, científicos y agricultores con el fin de alcanzar un método sostenible para la producción en laderas de cítricos.

\subsection{Conclusiones}

La erosión del suelo en campos de cultivo de cítricos en pendiente muestra valores extremadamente elevados bajo lluvias de 5 años de periodo de retorno y a escala de pedón. Los coeficientes de escorrentía son más altos y la erosionabilidad del suelo mayor en estas explotaciones agrícolas extremadamente mecanizadas que en ningún otro uso del suelo en el mediterráneo occidental. Todas las parcelas $(n=100)$ estudiadas mostraron elevadas tasas de escorrentía y elevadas tasas de erosión a pesar de haberse realizado los experimentos en condiciones de suelos secos, cuando las tasas de infiltración son más altas. En esa estación la baja humedad edáfica, las grietas y los macroporos suelen reducir las escorrentías en otros suelos pero no en los de las explotaciones de cítricos debido a su elevada densidad y falta de vegetación. En comparación con otros usos del suelo y manejos agrícolas los campos de cítricos necesitan de la aplicación urgente de medidas de conservación para reducir la pérdida de suelo y agua que permita alcanzar las condiciones de una agricultura sostenible. Las altas tasas de escorrentía y la elevada erosionabilidad de los suelos, y la relación positiva entre ellas, debe ponernos en guardia sobre la aceleración de los procesos erosivos en el futuro y con ello la degradación del territorio y su desertificación. Además, el que escorrentía y erosionabilidad del suelo muestren relaciones positivas producirá una intensificación del proceso erosivo a escala de ladera y cuenca de drenaje, como lo confirman los regueros y cárcavas tras episodios de lluvia intensos. Una opción para el control de estas elevadas tasas de erosión es implementar medidas novedosas como pueden ser los geotextiles. 


\section{Capítulo 2. Pérdida de suelo y agua en las nuevas plantaciones de cítricos en laderas de la cuenca Mediterránea Occidental}

Resumen. Diez zonas representativas fueron seleccionadas en el este de la España para evaluar las tasas y los procesos de erosión en los nuevos campos de cítrico en laderas. Las parcelas experimentales se seleccionaron en zonas representativas sobre roquedo calizo, con 498-715 mm año-1 de precipitación media anual, en laderas norte, con manejo de herbicida y en plantaciones de menos de tres años. Diez experimentos con lluvia simulada ( 1 hora a $55 \mathrm{~mm} \mathrm{~h}^{-1}$ en parcelas de $0,25 \mathrm{~m}^{2}$ ) se realizaron en 10 zonas (10 parcelas $\times 10$ zonas $=100$ experimentos) para determinar las tasas de erosión y escorrentía a escala entre regueros $\left(<1 \mathrm{~m}^{2}\right)$. El encharcamiento y el inicio de la escorrentía se produjo de forma rápida en todas las parcelas: 121 y 195 segundos después de la lluvia para los valores medios. La escorrentía alcanzo 1/3 de la lluvia, y la concentración de sedimentos alcanzó los $10.4 \mathrm{~g} \mathrm{l}^{-1}$. Las tasas de erosión fueron $2,4 \mathrm{Mg} \mathrm{ha}^{-1} \mathrm{~h}^{-1}$ para lluvias con un periodo de recurrencia de 5 años. Estas tasas de erosión están entre las más altas cuantificadas en la cuenca mediterránea occidental, y son similares a las de badland, derrubios de minas y taludes de carretera. La relación positiva entre el caudal y la concentración de sedimentos $\left(r^{2}=0,83\right)$ demuestra que el suministro de sedimentos es muy elevado. Las tasas de erosión en las nuevas plantaciones de cítricos en laderas no son ni tolerables ni sostenibles.

Palabras clave: Erosión del suelo, Plantaciones de cítricos, Arroyada superficial, Simulador de Lluvia, Este de España.

Abstract. Ten representative research sites were selected in Eastern Spain to assess soil erosion rates and processes in new citrus orchards on sloping-soils. The experimental plots were located representatives sites on limestone, in areas with 498 to $715 \mathrm{~mm} \mathrm{y}^{-1}$ mean annual rainfall, north-facing slopes, herbicide treated, and new (less than 3 years old) plantations. Ten rainfall simulation experiments ( 1 hour at $55 \mathrm{~mm} \mathrm{~h}^{-1}$ on $0.25 \mathrm{~m}^{2}$ plots) were carried out at each of the 10 selected study sites to determine the interill soil erosion and runoff rates. The 100 rainfall simulation tests $(10 \times 10 \mathrm{~m})$ showed that ponding and runoff occurred in all the plots, and quickly: 121 and 195 segundos respectively, following rainfall initiation. Runoff discharge was one third of the rainfall, and sediment concentration reached $10.4 \mathrm{~g} \mathrm{l}^{-1}$. The soil erosion rates were $2.4 \mathrm{Mg} \mathrm{ha}^{-1} \mathrm{~h}^{-1}$ under 5-year return period rainfall thunderstorms. These are among the highest soil erosion rates measured in the Western Mediterranean basin, similar to badland, mine spoil and road embankment land surfaces. The positive relationship between runoff discharge and sediment concentration $\left(r^{2}=0.83\right)$ shows that the sediment availability is very high. Soil erosion rates on new citrus orchards growing on sloped-soils are neither tolerable nor sustainable.

Key words: Soil erosion, Citrus orchards, Overland flow, Rainfall simulator, Eastern Spain. 
Publicado en Cuadernos de Investigación en la Ingeniería (2008)

Giménez-Morera, A. 2008. Uso de agrogeotextiles en agricultura. Cuadernos de Investigación en la Ingeniería II, 93-105.

\section{Capítulo 3}

Uso de geotextiles en agricultura 


\subsection{Introducción}

La industria textil valenciana y española, está sufriendo una de las mayores crisis de su historia, debido principalmente a los altos costes que la misma presenta comparativamente con otros países. La consecuencia de la liberalización de los mercados ha supuesto para el sector textil la presencia de artículos procedentes del mercado asiático a precios no competitivos para nuestros costes industriales. La innovación y el desarrollo de nuevos productos pueden y debe de ser la clave para el mantenimiento de nuestra industria. Es por lo tanto una necesidad el encontrar nuevas aplicaciones que puedan formar parte de los nichos de mercado de productos textiles y aplicar a los mismos las potencialidades que se obtienen fruto de la investigación e innovación en el laboratorio y en los trabajos de campo. Entre los productos que presentan unas mayores perspectivas se encuentran los textiles diseñados para el uso agrícola, denominados agrogeotextiles así como los textiles diseñados para la estabilización de los taludes denominados geotextiles (Pérez Cueva, 1994).

El uso de los geotextiles ha sido siempre cuestionado principalmente por los costes de aplicación de los mismos y por su baja resistencia por su exposición a la luz, el calor y a la radiación ultravioleta que conlleva a la degradación de las cadenas poliméricas y una pérdida de resistencia mecánica. El efecto que dicha radiación puede ocasionar dependerá de las cantidades de fibras utilizadas, tipo de tejidos de color, procesos de acabados aplicados y presencia de aditivos (Montava, 1997).

En los campos de cultivo valencianos debido a las condiciones ambientales y culturales la pérdida de suelo es muy alta (Cerdà, 2001; 2002; 2006). El uso de herbicidas en las últimas tres décadas ha incrementado las pérdidas de suelo y la alteración de los ecosistemas agrícolas tradicionales (Giráldez et al., 1989). Con el manejo de los geotextiles, se mejoran las condiciones térmicas e hídricas de los suelos, reduciendo la pérdida de nutrientes, semillas y agua. Con ello se mejora la producción agrícola y se reduce su impacto ambiental, uno de los grandes problemas de este siglo para el sector primario.

La aparición de una nueva óptica con respecto al tratamiento de la tierra y laboreo de la misma mediante "agricultura ecológica" ha irrumpido con fuerza y hace necesaria la aparición de nuevos materiales que ayuden a la proliferación de la misma. Esta nueva óptica que algunos autores (Maroto, 1987) la encuadran sobre los años 60 preconiza el empleo de métodos y sistemas lo más naturales posibles evitando al máximo la utilización de productos químicos de cualquier tipo a lo largo del proceso productivo, en aras a conseguir productos no expuestos a agentes externos principalmente químicos.

En su momento, las tesis expuestas por los precursores de esta nueva óptica fueron ampliamente criticadas ya que la misma no tenía una consistencia real y además los resultados que se obtenían de su aplicación eran de difícil asunción si se comparaban con los resultados que se obtenían con la aplicación de productos químicos. 
La utilización desmesurada y casi siempre incontrolada de medios químicos utilizados en la agricultura (fertilizantes en plantas, pesticidas, herbicidas etc.) en busca de la obtención de mejores rentabilidades de la tierra, ha conducido a unos efectos realmente negativos ya que se ha desestabilizado el ecosistema y ha afectado a la salubridad tanto del consumidor como la del manipulador del producto (Carson, 1960).

El amplio desarrollo que ha tenido la utilización de estos agentes químicos ha supuesto la proliferación de plagas debido fundamentalmente a la poca selectividad de los insecticidas utilizados en relación con los predadores y parásitos de los propios enemigos de las plantas cultivadas, en la pirámide trófica. Un hecho constatable es el de que aunque se haya mejorado los rendimientos a corto plazo de las explotaciones agrícolas con el uso de pesticidas también no es menos cierto que la quimio-dependencia de las explotaciones ha supuesto la aparición de nuevas plagas desconocidas que crean problemas de difícil solución en zonas de agricultura muy intensiva.

Los textiles cubren el suelo de forma que permiten la infiltración de las aguas de lluvia con lo que reducen o anulan las escorrentías y con ello la erosión. Además, conservan el agua del suelo ante la potente evaporación de la atmósfera bajo un clima mediterráneo y son especialmente indicados en la fertirrigación. Ello propicia que el agua disponible para las plantas sea mayor que mediante el uso de otros materiales como los plásticos que impiden la infiltración, favorecen la escorrentía y anulan la recarga hídrica del suelo. Además estos últimos materiales son muy contaminantes en su fabricación y difíciles de reciclar, mientras que entre los textiles se pueden utilizar materias primas vegetales, que en algunos casos además proceden del reciclado, con lo que se alivian problemas ambientales relacionados con los residuos propios de nuestra sociedad de consumo.

El diseño de nuevos materiales basados en las fibras naturales es una línea prioritaria para la FAO que propuso el año 2009 como el de las fibras naturales. Esta propuesta fue aprobada por la ONU a finales del año 2006. Esta decisión contribuirá a que se alcancen los Objetivos de Desarrollo del Milenio, incrementando la eficacia y la sostenibilidad de industrias agrícolas que dan empleo a millones de personas en algunos de los países más pobres del mundo. Los medios de subsistencia de millones de personas en todo el mundo, entre ellas las más pobres en algunos de los países con menos recursos, dependen de la producción y elaboración de fibras naturales. Estas fibras contribuyen a la seguridad alimentaría y el desarrollo económico de esos agricultores. El año elegido por la FAO, sensibilizará a los consumidores sobre las fibras naturales y fortalecerá la demanda de productos de estas fibras a la vez que con esta promoción se estará beneficiando al medio ambiente. Como se verá en la investigación uno de los principales objetivos de la misma es el estudio del comportamiento de los agrogeotextiles producidos por fibras naturales.

Las tasas de erosión hídrica en el área mediterránea debida a la acción de las aguas pluviales y fluviales sobre el suelo, son extremadamente elevadas ya que a la erosión geológica 0 natural se han sumado las actividades humanas debidas a manejos poco adecuados y a la ancestral ocupación del territorio. Son especialmente vulnerables a la 
pérdida de suelo los espacios agrarios de interior debido a las fuertes pendientes, la aridez del clima y a manejos poco sostenibles.

Tabla 6. Pérdida de suelo $\left(\mathrm{Mg}^{-1}\right.$ ha $^{-1}$ año) bajo distintos usos y manejos del suelo en la estación experimental para el Estudio de la Erosión Hídrica del suelo de El Teularet-Sierra de Enguera en el año 2004 (Cerdà, 2006)

\begin{tabular}{lcccc}
\hline Parcela & A & B & C & D \\
Superficie $\left(\mathbf{m}^{2}\right)$ & $\mathbf{1}$ & $\mathbf{2}$ & $\mathbf{4}$ & $\mathbf{1 6}$ \\
\hline Herbicida de contacto & 6,55 & 3,63 & 3,55 & 3,23 \\
Herbicida sistémico & 3,28 & 2,82 & 2,31 & 2,27 \\
Herbicida residual & 1,94 & 2,1 & 1,72 & 1,98 \\
Laboreo & 0,9 & 0,93 & 0,53 & 0,4 \\
No laboreo (Avena-Veza) & 0,36 & 0,33 & 0,18 & 0,22 \\
No laboreo (Medicago sp) & 0,35 & 0,29 & 0,18 & 0,21 \\
Laboreo (Avena-Veza) & 0,48 & 0,3 & 0,24 & 0,24 \\
Control & 0,43 & 0,3 & 0,16 & 0,2 \\
Acolchado de paja & 0,47 & 0,2 & 0,15 & 0,2 \\
Acolchado con resto de poda & 0,32 & 0,16 & 0,15 & 0,2 \\
Geotextil & 0,11 & 0,08 & 0,06 & 0,17 \\
Matorral (Ulex parviflorus) & 0,05 & 0,04 & 0,05 & 0,16 \\
Matorral (Quercus coccifera) & 0,05 & 0,04 & 0,05 & 0,16 \\
\hline
\end{tabular}

Más de la mitad de la superficie agraria de la Comunidad Valenciana presenta cultivos de secano, de los que destacan los frutales (141.243 ha) con especial referencia a los almendros, olivar (98.618 ha) y viñedo (85.849 ha), a los que les siguen los cereales y forrajes con 42.063 y 21.776 ha respectivamente (MAPA, 2007). Estas explotaciones utilizan básicamente el laboreo (arado al estilo cultivador) como control de las malas hierbas, lo que da lugar a la degradación de la estructura del suelo y la pérdida de partículas de suelo además de semillas, materia orgánica y agregados. Las características ambientales de las zonas donde se desarrolla esta agricultura de secano, en contraposición a la de regadío de las llanuras aluviales y terrazas fluviales, es la de espacios de laderas y conos aluviales donde las fuertes pendientes favorecen la aceleración de las tasas de erosión por medio de la escorrentía. A todo esto tenemos que unir la creciente demanda de 
infraestructuras viarias y de ferrocarril con la creación implícita de taludes que no conllevan aparejadas medidas correctoras con respecto a la erosión que las mismas provocan de forma incontrolada.

Tabla 7. Pérdida de suelo ( $\mathrm{Mg}^{-1}$ ha-1 $^{-1}$ año) bajo distintos usos y manejos del suelo en la estación experimental para el Estudio de la Erosión Hídrica del suelo de El Teularet-Sierra de Enguera en el año 2005 (Cerdà, 2006)

\begin{tabular}{lllll}
\hline Parcela & A & B & C & D \\
Superficie $\left(\mathbf{m}^{2}\right)$ & $\mathbf{1}$ & $\mathbf{2}$ & $\mathbf{4}$ & $\mathbf{1 6}$ \\
\hline Herbicida de contacto & 0,93 & 0,63 & 0,33 & 0,43 \\
Herbicida sistémico & 1,27 & 1,01 & 0,82 & 0,22 \\
Herbicida residual & 0,78 & 0,74 & 0,35 & 0,18 \\
Laboreo & 1,1 & 0,63 & 0,59 & 0,34 \\
No laboreo (Avena-Veza) & 0,11 & 0,04 & 0,05 & 0,02 \\
No laboreo (Medicago sp) & 0,12 & 0,07 & 0,14 & 0,13 \\
Laboreo (Avena-Veza) & 0,68 & 0,3 & 0,21 & 0,07 \\
Control & 0,1 & 0,08 & 0,07 & 0,03 \\
Acolchado de paja & 0,1 & 0,1 & 0,06 & 0,02 \\
Acolchado con resto de poda & 0,11 & 0,13 & 0,1 & 0,03 \\
Geotextil & 0,03 & 0,02 & 0,02 & 0,01 \\
Matorral (Ulex parviflorus) & 0,03 & 0,02 & 0,01 & 0,01 \\
Matorral (Quercus coccifera) & 0,03 & 0,02 & 0,01 & 0 \\
\hline
\end{tabular}

Los geotextiles, además de la protección del suelo al reducir la erosión y aumentar la humedad del suelo, pueden tener una aplicación innovadora en la agricultura valenciana, evitando o reduciendo el estrés hídrico y el consumo de agua. En las tierras valencianas ha sido la implantación y la extensión del riego localizado en poco más de una década la que ha producido la expansión del regadío, el aumento del consumo de agua, y la sobreexplotación de los acuíferos. Las nuevas plantaciones de cítricos y el crecimiento de del regadío son sinónimos en la Comunidad Valenciana. Procesos similares se encuentran en Murcia y en Andalucía.

Todos estos cambios en los usos del suelo han supuesto una alteración relevante de los recursos hídricos subsuperficiales al basarse el nuevo regadío en la explotación de los 
acuíferos. Esta alteración de los flujos hídricos naturales ha dado lugar en muchos casos a la desaparición de los flujos superficiales.

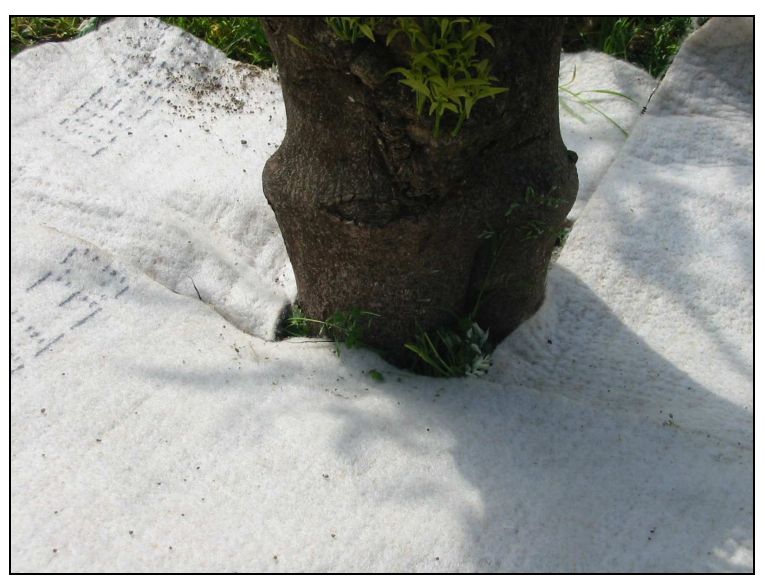

Figura 5. Vista de un geotextil de algodón colocado en un cultivo de cítricos maduros para comprobar su comportamiento.

Del uso de geotextiles también podemos obtener ventajas indirectas como pueden ser la estética visual de la explotación y su potencial de apoyo a las ventajas de su producción. Estos geotextiles deben de ser los sustitutivos de los plásticos ya que ejercen la misma función que estos a la hora de impedir la aparición de malas hierbas.

Además los geotextiles permiten la infiltración de las aguas y la recarga hídrica natural del suelo, impiden la evaporación del agua del suelo y el recalentamiento de este, situación que si se viene produciendo con los plásticos y que acarrea graves problemas sanitarios y de calidad de los productos agrarios. Los geotextiles son generalmente utilizados de forma extendida en los invernaderos.

Es cada vez más habitual su uso en aquellos dedicados a la producción de plantas ornamentales y en instalaciones hortícolas. Sin embargo en el sector frutícola, su introducción está siendo todavía baja a pesar de las importantes ventajas que pueden aportar tanto a niveles de rentabilidades directas o indirectas.

Una gran parte del progreso tecnológico en agricultura se ha conseguido mediante la realización rigurosa de un trabajo de investigación y observación. En nuestro caso, dicha investigación y observación aunque muy a pequeña escala ya ha podido dar sus primeros frutos con la obtención de resultados que desmienten la utópica frase de que "lo que es correcto medioambientalmente hablando, no es viable económicamente". 


\subsection{Experimental}

Se ha realizado una exhaustiva revisión de los productos agrogeotextiles presentes en el mercado. Visitas a tiendas especializadas, en Internet y el contacto con los productores y consumidores de geotextiles ha permitido elaborar una amplia base de datos que aquí presentamos parcialmente.

La visita a campos, fincas y estaciones experimentales, y las entrevistas con los usuarios ha permitido catalogar los geotextiles por su utilidad. Además, las empresas suministradoras han aportado información de las características del agrogeotextil que son relevantes para entender sus características y funcionalidad.

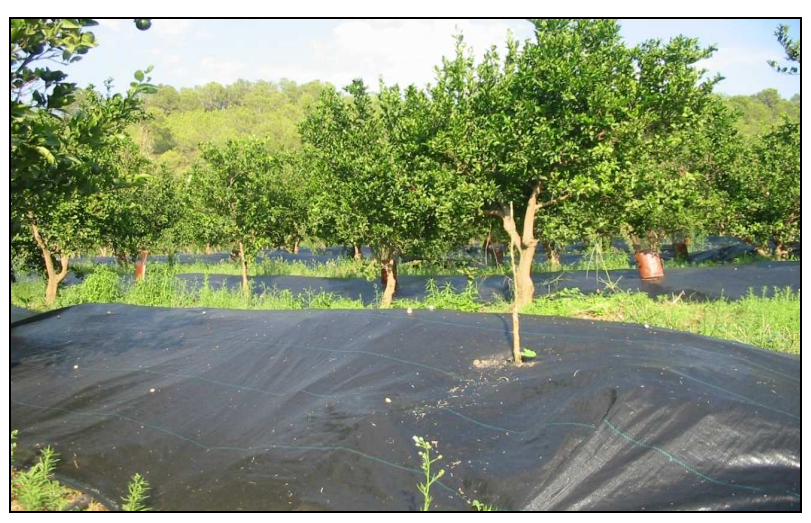

Figura 6. Vista de un campo de cítricos con malla geotextil implantada, se observa la estética visual de la explotación.

\subsection{Resultados}

Los geotextiles presentan distintas y variadas posibilidades de aplicación. Los geotextiles disponibles para el agricultor valenciano son variados. Aquí destacamos los más importantes:

-Malla de irrigación capilar para mesas de cultivo. Está fabricada con fibras sintéticas. Excelente dispersión del agua con una capacidad de retención de 11 $\mathrm{m}^{-2}$. Es de fácil manejo y larga duración. Las mallas pueden adquirirse de 2 ó 3 capas, siendo la de 3 capas la que retiene durante más tiempo el agua porque cuenta con capa de plástico micro perforado en la base. 
-Malla de irrigación capilar para mesas de cultivo fabricada con fibras sintéticas reforzadas. La misma asegura una retención de agua de 3 litros $/ \mathrm{m} 2$ así como una dispersión del agua excelente. El uso de esta malla evita la aparición de puntos secos. Tiene larga duración y es muy fácil de aplicar. Las mallas pueden adquirirse de 2 ó 3 capas, la de 3 capas es la que retiene durante más tiempo el agua porque cuenta con capa de plástico micro perforado en la base.

-Malla de irrigación fabricada en materiales textiles reciclados. Es una alternativa económica a las mallas de irrigación de fibras sintéticas. La misma es capaz de absorber 3 litros $/ \mathrm{m} 2$.

-Manta natural $100 \%$ paja. Se utiliza para situaciones de escasa erosividad para su prevención, sobre la misma es fácil la instauración de la vegetación. Mantiene las partículas del suelo entre su estructura, y facilita es establecimiento de semillados o hidrosiembras.

-Manta natural $50 \%$ paja y $50 \%$ esparto. Similar a la anterior pero utilizada en situaciones de mediana erosividad.

-Manta natural $100 \%$ esparto o $100 \%$ coco. Se aplica para situaciones de acusada erosividad y difícil instauración de la vegetación.

Tabla 8. Tipos de mallas y precios de las mismas.

\begin{tabular}{lc}
\hline Tipos de Mallas & Precios \\
Tipos de Mallas & $€ \mathrm{~m}^{-2}$ \\
\hline Malla de irrigación capilar de fibras sintéticas 3 capas & 0,21 \\
Malla de irrigación capilar de fibras sintéticas reforzadas 3 capas & 0,23 \\
Malla de irrigación de textiles reciclados & 0,18 \\
Manta natural 100\% paja & 0,75 \\
Manta natural $50 \%$ paja + 50\% esparto & 1,25 \\
Manta natural $100 \%$ esparto o 100\% coco & 2,00 \\
\hline
\end{tabular}

Después de la experimentación se ha confirmado la buena resistencia de los geotextiles a la climatología, la durabilidad y estabilidad de los mismos, que los costes de adquisición asimilables por el productor, la elevada capacidad de absorción de los geotextiles, su eficiencia el control de las malas hierbas, la disminución de costes de roturación, la reducción en los costes de herbicidas y su positivo resultados en la reducción de la erosión y degradación de los suelos. 


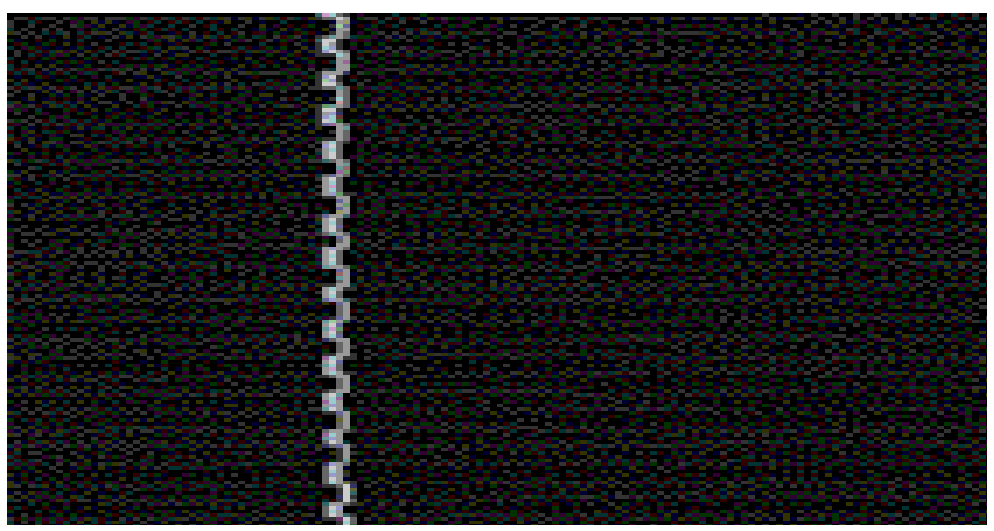

Figura 7. Detalle de la malla de irrigación de fibras sintéticas.

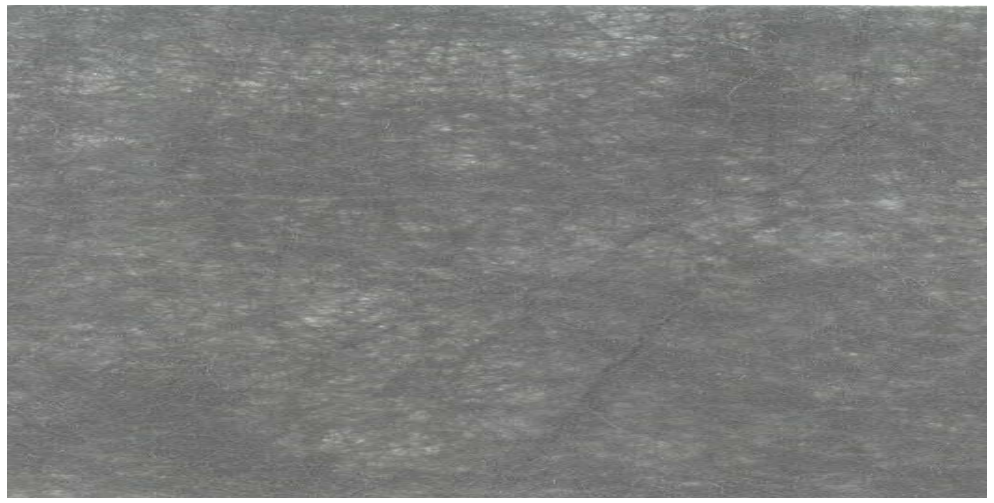

Figura 8. Detalle de la malla de textiles reciclados.

\subsection{Discusión}

Los resultados del trabajo demuestran que en la malla de fibras sintéticas se observa que se produce una mayor dispersión del agua y evita en mayor cuantía la aparición de puntos secos ya que la capa de plástico micro perforado de la base hace que exista una mayor retención del agua. La capacidad de absorción de los dos materiales utilizados es similar, siendo inapreciable y despreciable el pequeño porcentaje que existe entre la absorción de una y otra malla. 
Con respecto a la función de herbicida, las dos mallas cumplen a la perfección su cometido, no observándose durante la experimentación ningún crecimiento de hierbas en el lugar de colocación y solamente se observa un crecimiento de rastrera lateral a la aplicación de geotextil que en ocasiones invade con mayor frecuencia el geotextil de malla de textiles reciclados.

Con respecto a la biodegradabilidad, no se ha observado debido al corto periodo de experimentación aunque es evidente que la malla compuesta por fibras sintética no será biodegradable creando un problema de residuos difíciles y costosos de reciclar mientras que la malla de reciclado textil posiblemente debido a su composición puede llegar a ser incorporada el suelo y ser transformada en nutrientes.

La malla de fibra sintética tiene un inconveniente que no tiene la malla de textil reciclado que es la menor permisibilidad de entrada de aire lo que puede originar aunque no se han observado durante el periodo de experimentación, problemas en la actividad biológica del suelo.

El uso de los geotextiles evita el uso de herbicidas y laboreo para el control de las malas hierbas. Esto hace que en el campo de aplicación se haya eliminado totalmente el uso de los herbicidas, evitando el efecto nocivo en el medio ambiente. En las parcelas en las que se han utilizado los geotextiles, hemos evitado la roturación en su totalidad durante todo un año, favoreciendo la estabilización biológica del suelo. En las mismas hemos evitado por lo tanto la elevada tasa de costes de roturación especialmente en maquinaria, en combustible y además, acompañados de una menor emisión de gases como el dióxido de carbono. Con respecto a la desinfección de los suelos, en las parcelas con uso del geotextil se ha evitado la utilización de compuestos, altamente pernicioso para la atmósfera y se han evitado tratamientos anti plagas como el de los caracoles.

Los precios de los geotextiles no suponen un coste excesivo para su aplicación, ya que la misma reduce otros manejos y costes indirectos.

\subsection{Conclusiones}

El uso de los geotextiles es una alternativa real al uso de herbicidas y laboreo, favorece la recuperación de suelos degradados como los agrícolas y posibilita una agricultura más respetuosa con el medio ambiente. La viabilidad en términos ecológicos ha sido confirmada por los usuarios y la diversidad en la oferta de productos geotextiles es suficientemente amplia y variada como para cubrir todas las necesidades del sector agrícola. 


\section{Capítulo 3.Uso de geotextiles en agricultura}

Resumen. A pesar de sus beneficios ambientales y económicos el uso de geotextiles está poco extendido en España por falta de información entre los usuarios. Los geotextiles, son adecuados en zonas de baja pluviometría al mejorar la retención hídrica de los suelos y evitar la evaporación directa y la evapotranspiración de las plantas. A pesar de estar evaluada positivamente su utilidad en horticultura y fruticultura no se ha extendido su uso. La crisis en la que está envuelta la industria textil, hace que se busquen nuevos productos que permitan la diversificación de la producción. Los agrogeotextiles son uno de ellos. Además los agrogeotextiles mejoran la gestión de las explotaciones agrícolas y reducen el impacto ambiental de la agricultura. Se evita el uso de herbicidas y fitosanitarios que alteran los ecosistemas agrícolas. En este trabajo se realiza una revisión de los agrogeotextiles disponibles en el mercado y se exponen ejemplos de su uso en el campo.

Palabras clave: Agrogeotextil, Biodegradabilidad, Textil reciclado, Fibra de coco, Fibra sintética.

Abstract. In spite of its environmental and economic benefits the use of geotextiles little is extended in Spain by lack of information between the users. The geotextiles, are adapted in zones of low pluviometría when improving the hydric retention of grounds and to avoid the direct evaporation and the evapotranspiración of the plants. In spite of being evaluated positively its utility in horticulture and fruitgrowing its use has not extended. The crisis in which the textile industry is surrounded, causes that new products look for that allow the diversification of the production. The geotextiles are one of them. In addition the geotextiles improve the management of the agricultural operations and reduce the environmental impact of agriculture. It is avoided the use of herbicidas and fitosanitarios that alter the agricultural ecosystems. In this work a revision of the geotextiles available in the market is made and examples of their use in the field are exposed.

Key words: Geotextil, Biodegradabilidad, Recycled textile, Fiber of the coco, Synthetic fiber 
Publicado en Cuadernos de Investigación en la Ingeniería (2008)

Cerdà, A.,Giménez-Morera, A.,Bodí, M.B. 2008. Geotextil versus herbicida en el control de la pérdida de agua y suelo en el secano valenciano. Cuadernos de Investigación en la Ingeniería. II, 119-132.

Capítulo 4

Geotextil versus herbicida en el control de la pérdida de agua y suelo en el secano valenciano en condiciones de lluvia real 


\subsection{Introducción}

Los suelos agrícolas son los que contribuyen con mayores pérdidas de suelo y aguas (Kirkby et al. 1980). En los ecosistemas mediterráneos, donde la agresividad del clima y el relieve favorecen la aceleración de las tasas de erosión naturales cuando los suelos pierden la cubierta vegetal, las zonas cultivadas son las más afectadas por la degradación edáfica. Proteger el suelo permite retener más recursos hídricos, reducir la erosión del suelo y evitar la desertificación (López Bermudez et al. 2002).En la Comunidad Valenciana, donde la explotación del territorio por el hombre y las condiciones naturales propician elevadas tasas de erosión (Cerdà, 2001), el manejo agrícola es relevante para la conservación de los recursos edáficos (Cerdà, 2001/2002).

Una estrategia para conservar el agua en los suelos es el uso de herbicidas que al secar la vegetación en los periodos de mayor demanda hídrica evitan la pérdida de agua por transpiración. Ello permite que más recursos hídricos estén disponibles para el cultivo. Además, los restos vegetales en superficie deben proteger el suelo del impacto de las gotas y la arroyada superficial durante el periodo estival en el que las lluvias son escasas pero de alta intensidad debido a las tormentas de carácter convectivo. Otro método de reciente implantación es el geotextil, el cual se coloca en la superficie del suelo y con ello se consigue evitar el arrastre de materiales, se propicia la infiltración de las aguas y su conservación al evitar la presencia de malas hierbas que incrementen la transpiración.

Más de 300.000 ha de la superficie agraria de la Comunidad Valenciana presentan cultivos de secano, entre los que destacan los frutales, el olivar y el viñedo, con forrajes y cereales en último término (MAPA.2007). La expansión del uso de los herbicidas ha hecho que el laboreo esté quedando en segundo plano, especialmente en el olivar. Los herbicidas han sido muy bien aceptados por los agricultores por su eficacia y rentabilidad. Sin embargo, su uso indiscriminado está haciendo que las malas hierbas desaparezcan totalmente, incluso en invierno (Fig. 9). Ello puede propiciar un aumento de la pérdida de suelo. Una alternativa al uso de herbicidas, especialmente cerca del árbol, es la instalación de mantas de geotextiles que permitirán aumentar la infiltración de las aguas, conservar el agua infiltrada al evitar la evaporación y transpiración, y finalmente reducirán las pérdidas de suelo. Esta es una buena estrategia para los cultivos que siguen el reglamento de la Agricultura Ecológica, al no poder aplicar herbicidas y al reducir la superficie laboreada.

Para evaluar la eficacia del uso de los herbicidas y de los agrogeotextiles se seleccionaron 2 parcelas pareadas en la Estación Experimental para el Estudio de la Erosión del suelo de El Teularet-Sierra de Enguera, las cuales se componen de cuatro subparcelas de distintos tamaños. Durante el año 2004 se hizo un seguimiento de la precipitación, escorrentía, concentración de sedimentos y pérdida de suelo después de cada evento de lluvia. Aquí se presentan los valores medios del primer año con el fin de ilustrar el efecto de ambas estrategias de conservación de aguas y suelo. El objetivo de este artículo es determinar 
cual de los manejos -herbicida o geotextil- es el más adecuado para reducir las pérdidas de agua y suelo.

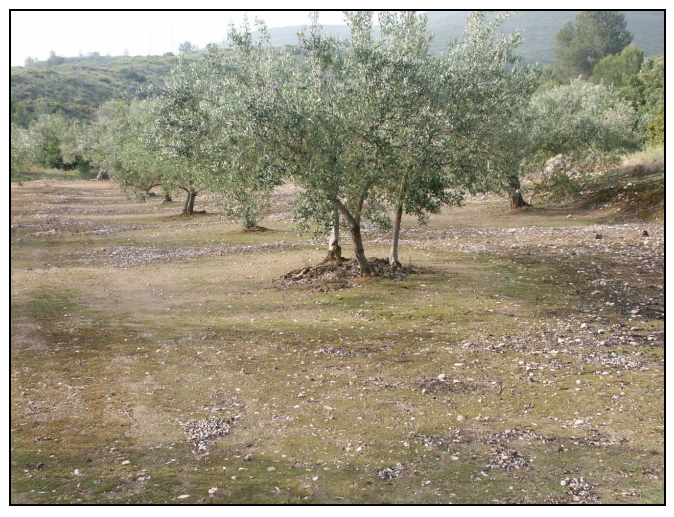

Figura 9. El efecto de los herbicidas: vista del campo de olivar en invierno en el término municipal de Enguera. El uso indiscriminado de herbicidas conduce a la total eliminación de la vegetación incluso en los meses invernales.

\subsection{Materiales y métodos}

En la Estación Experimental para el Estudio de la Erosión Hídrica del Suelo de El TeularetSierra de Enguera, se construyeron dos parcelas (4 subparcelas en cada una de ellas) a las que durante el año 2004 se aplicó un manejo de herbicida sistémico en cuatro aplicaciones anuales para la parcela denominada Herbicida (Glifosato) y un acolchado con geotextiles de algodón para la parcela denominada Agrogeotextil. Las parcelas se componen de un canalón para recoger las arroyadas, conectado a un depósito totalizador (125-500 litros) mediante empalme (codo) y manguera de $20 \mathrm{~mm}$ de diámetro. Las parcelas están delimitadas por planchas de hierro galvanizado de $200 \mathrm{~mm}$ de altura y $1 \mathrm{~mm}$ de grosor. Con el fin de evaluar las tasas de erosión a distintas escalas las parcelas son de distintas dimensiones: 1 ( 1 x 1), 2 ( 1 x 2), 4 ( 1 x 4) y 16 ( 2 x 8) m² (Figura 10). La medición de la precipitación durante el año 2004 se realizó con dos pluviómetros totalizadores y un fluviógrafo (DAVIS) de registro continuo con una precisión de $0,2 \mathrm{~mm}$. La temperatura y la humedad del aire se midieron con un sensor HOBO Pro RH/Temp., el cual está conectado al registrador $\mathrm{HOBO} \mathrm{H} 8 \mathrm{Pro}$, en el que graban los datos medidos cada 5 minutos. El rango de medición de la temperatura del aire oscila entre $-30 \stackrel{\circ}{\circ}$ y $+50 \stackrel{\circ}{\circ}$ y el de la humedad relativa entre $0-100 \%$. Estos sensores están colocados dentro de un protector de lluvia y de la insolación. Otros parámetros meteorológicos y climáticos son registrados (radiación, dirección y velocidad del viento y humedad absoluta) además de la temperatura y humedad del suelo, quedando registrado en los data-loggers situados en la misma estación 
meteorológica (Figura 11). Después de cada lluvia se revisaron los colectores y depósitos. En aquellos eventos con escorrentía se cuantificó el volumen de agua y se tomaron muestras para determinar la concentración de sedimentos (por desecación) y calcular la tasa de erosión.

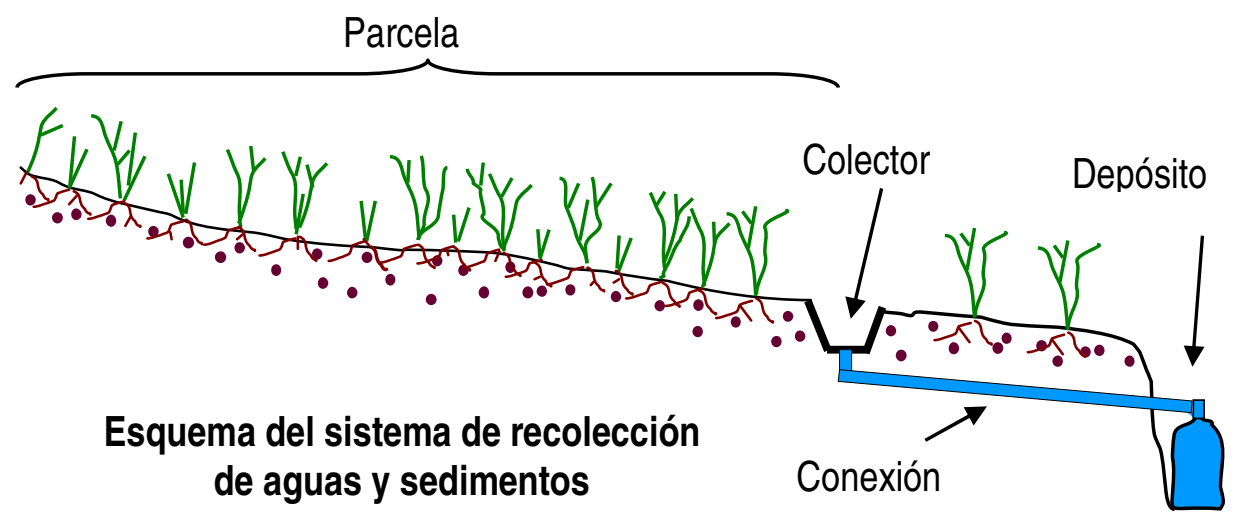

Figura 10. Perfil esquemático de una de las parcelas.

En el Macizo del Caroig, y en concreto en la Sierra de Enguera, donde está situada la Estación Experimental, la roca madre más abundante son las calizas del Mesozoico. Sin embargo, los agricultores tuvieron una especial predilección por las margas para localizar sus cultivos. Sin duda, fertilidad y capacidad de retención hídrica fueron las razones para situar el campo en estas condiciones ambientales, además de la facilidad de laboreo frente a los suelos pedregosos de las calizas y depósitos de ladera. A diferencia de las calizas en el Macizo del Caroig, y de otras comarcas cercanas como la Vall d'Albaida o los valles del Vinalopó, las margas aquí ocupan retazos donde se han desarrollado campos de cereal y olivar. En uno de estos campos está situada la estación experimental de El Teularet- Sierra de Enguera- . La roca madre son margas, las cuales han dado lugar a suelos limo-arcilloso, con textura grumosa en las zonas forestales, mientras que en los campos de cultivos la estructura es muy pobre y se encuentran abundantes cubiertas de costras cuando los suelos sufren el impacto de las gotas de lluvia. El contenido de materia orgánica es inferior al $2 \%$, siendo la cubierta vegetal inexistente en ambos casos. En la parcela tratada con herbicida la emergencia de nuevas plántulas era eliminada por el tratamiento con glifosato y en el geotextil las semillas germinadas no eran viables por la falta luz. 

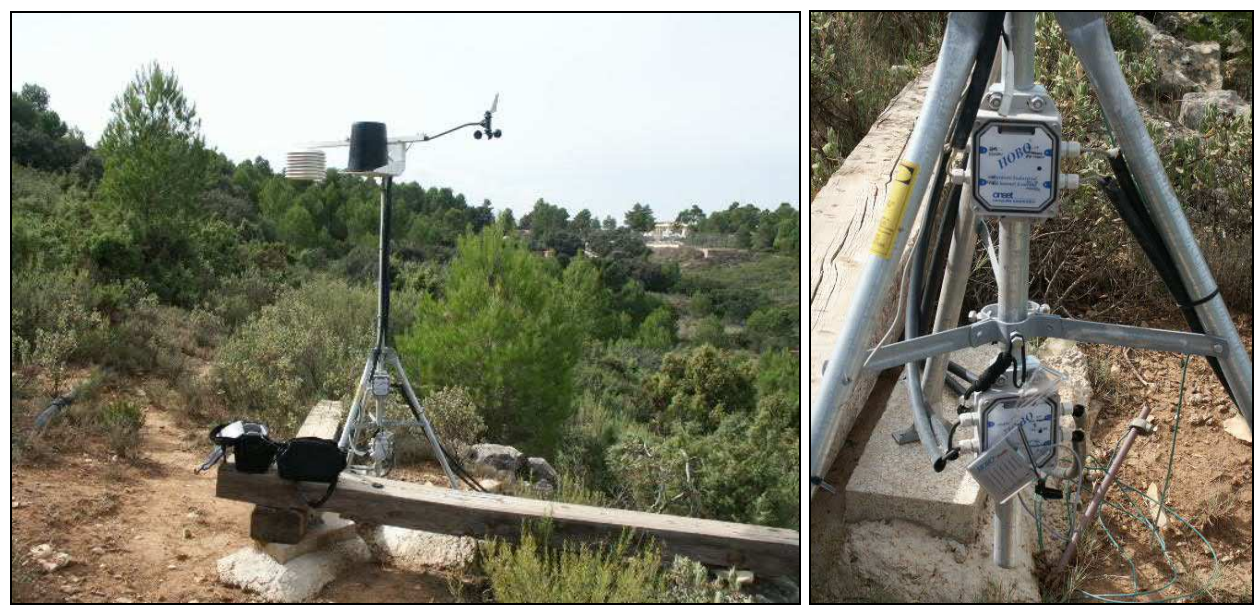

Figura 11. Vista de la estación meteorológica con un detalle a la derecha de los data-logger donde se almacenan los datos (cada 5 minutos) medidos por los sensores de temperatura y humedad del suelo, radiación, precipitación y dirección y velocidad del viento. La temperatura y humedad del aire se registran en un data-logger incorporado al sensor situado dentro del protector de la radiación directa.

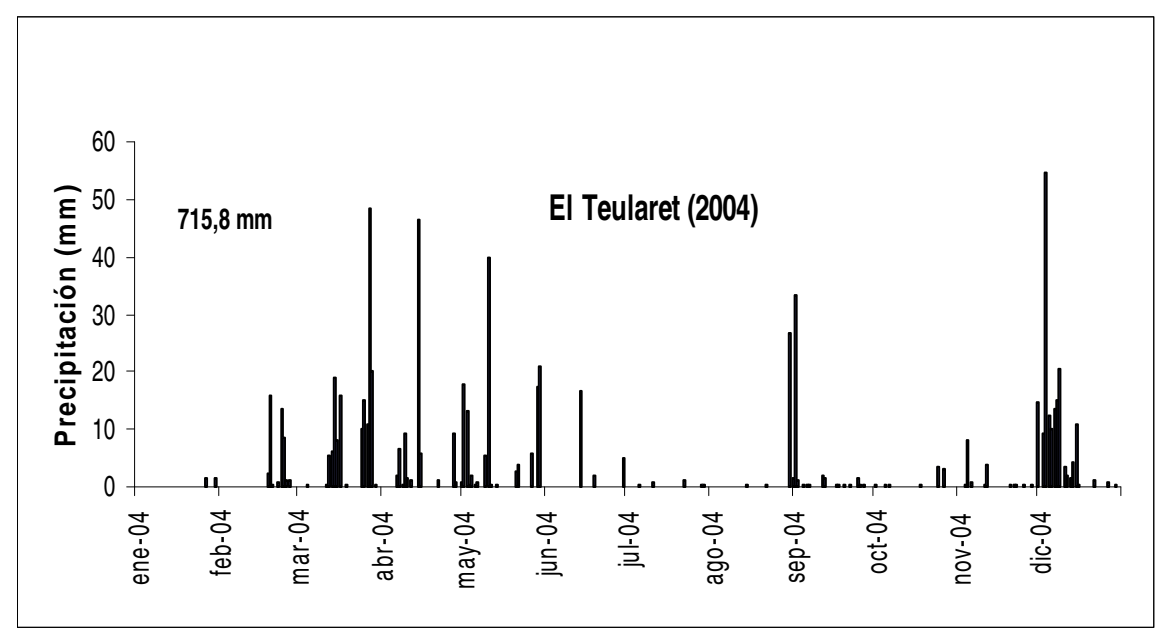

Figura 12. Precipitación diaria en la estación experimental El Teularet. 


\subsection{Resultados}

\subsubsection{Precipitación}

El año 2004 fue especialmente húmedo al registrarse una precipitación de 715,8 mm. Los registros históricos del Macizo del Caroig son inferiores a $500 \mathrm{~mm}_{\text {año-1 }}$ en valor medio. Las mediciones registradas durante el año 2004 demuestran que las lluvias fueron abundantes pero poco intensas (ver figura 12 y tablas 9 y 10), y dieron lugar a tasas de erosión que entendemos inferiores a las habituales por dos razones: (i) lluvias poco intensas causan tasas de erosión bajas, y (ii) los tratamientos sólo se han aplicado durante un año, por lo que los efectos acumulados aún no se han producido, especialmente en el caso del herbicida en el que el encostramiento y la pérdida de hojarasca por descomposición se espera sean más evidentes en los próximos años.

En el año 2004 se produjeron periodos de lluvias abundantes, entre las que destacaron la primera quincena de diciembre con quince días ininterrumpidos de lluvia, y toda la primavera con periodos prolongados de lluvia.

Tabla 9. Precipitación media anual (mm) (1961-1990) para los tres observatorios cercanos y para la Estación Meteorológica de El Teularet-Sierra de Enguera en el año 2004.

\begin{tabular}{lc} 
Observatorio & Precipitación media anual (mm) \\
\hline Enguera, CHJ & 590 \\
Enguera, La Matea & 537,3 \\
Enguera, Las Arenas & 479,2 \\
El Teularet (2004) & 715,8 \\
\hline
\end{tabular}

Tabla 10. Precipitación (mm) (1961-1990) según intervalos de intensidades diarias en los observatorios de la Sierra de Enguera. El Teularet en el año 2004.

\begin{tabular}{lccccccc}
\hline Precipitación (mm dia-1) & $\mathbf{0 - 5}$ & $\mathbf{5 - 1 5}$ & $\mathbf{1 5 - 3 0}$ & $\mathbf{3 0 - 6 0}$ & $\mathbf{6 0 - 1 0 0}$ & $\mathbf{1 0 0 - 2 0 0}$ & $>\mathbf{2 0 0}$ \\
\hline Enguera, La Matea & 24,68 & 143,88 & 214,70 & 133,61 & 52,28 & 3,76 & 0,00 \\
Enguera, Las Arenas & 42,30 & 140,25 & 178,42 & 102,73 & 40,59 & 29,92 & 0,00 \\
El Teularet (2004) & 222,6 & 220,8 & 202,8 & 69,6 & 0 & 0 & 0 \\
\hline
\end{tabular}




\subsubsection{Temperatura}

La temperatura media anual para el año 2004 en el Teularet fue de $14,66^{\circ} \mathrm{C}$, con una media máxima de $19,69{ }^{\circ} \mathrm{C}$, una media mínima de $9,68{ }^{\circ} \mathrm{C}$ y una amplitud térmica de 10,02 ${ }^{\circ} \mathrm{C}$. El observatorio de El Teularet presenta valores semejantes a los del observatorio de Enguera-La Matea, aunque las mínimas son similares a las del observatorio de EngueraLas Arenas. Así, la estación experimental de El Teularet-Sierra de Enguera es representativa del clima de la montaña media valenciana en general y de Macizo de Caroig en particular (Tabla 11).

Tabla 11. Temperatura (ํ) $\left.{ }^{\circ}\right)$ media, máxima, mínima y amplitud térmica media anual (1961-1990) en los observatorios de la Sierra de Enguera. Los datos de El Teularet corresponden al año 2004.

\begin{tabular}{|c|c|c|c|c|}
\hline Observatorio & $\mathrm{T}^{\mathrm{T}} \mathrm{Media}$ & T⿳a Máxima & T⿳a Mínima & Amplitud térmica \\
\hline Enguera, La Matea & 14,2 & 19,8 & 8,7 & 11,2 \\
\hline Enguera, Las Arenas & 12,7 & 15,7 & 9,8 & 6,0 \\
\hline El Teularet (2004) & 14,66 & 19,69 & 9,68 & 10,02 \\
\hline
\end{tabular}

Las temperaturas medias mensuales del año 2004 en el observatorio del Teularet frente a las de los observatorios de la Matea y las Arenas en la Sierra de Enguera demuestran que los meses de diciembre, mayo, abril y marzo, aquellos meses en los que la precipitación fue abundante, fueron más fríos de lo habitual. En cambio, el resto de meses la temperatura estuvo por encima de la temperatura registrada en los observatorios de la Sierra de Enguera entre 1961 y 1990 (Pérez.1994). Los meses de agosto y junio son dos buenos ejemplos de temperaturas superiores a la media (Tabla 12).

Tabla 12. Temperaturas medias mensuales (1961-1990) en los observatorios de la Sierra de Enguera. Los datos de El Teularet corresponden al año 2004.

\begin{tabular}{lccccccccccccc}
\hline Observatorio & \multicolumn{1}{c}{ Enero } & Febrero Marzo & \multicolumn{1}{c}{ Abril Mayo Junio Julio } & Agosto & Sept. Octubre & Nov. Dic. \\
\hline Enguera, La Matea & 7,6 & 8,6 & 9,5 & 11,2 & 15,7 & 19,2 & 22,9 & 23,0 & 20,1 & 15,0 & 10,2 & 7,6 \\
Enguera, Las Arenas & 7,6 & 7,3 & 9,0 & 10,6 & 13,8 & 17,2 & 20,0 & 20,1 & 17,2 & 12,6 & 9,3 & 8,1 \\
El Teularet (2004) & 9,05 & 8,02 & 8,79 & 12,88 & 13,51 & 21,08 & 22,77 & 25,71 & 20,62 & 16,90 & 10,02 & 6,55 \\
\hline
\end{tabular}




\subsubsection{Precipitación}

El manejo con herbicida ha dado lugar a una pérdida de $11,6 \%$ en forma de escorrentía. En el caso del geotextil la pérdida ha sido del $16,4 \%$ de la lluvia. Se ha comprobado también que cuanto mayor es la parcela menor es la pérdida por escorrentía, lo que apunta a una redistribución de la escorrentía y su re infiltración. Las parcelas de $1 \mathrm{~m}^{2}$ son las que han alcanzado la mayor pérdida de agua: $26,05 \%$ para el geotextil y $20,46 \%$ para el herbicida. En el caso de parcelas de $16 \mathrm{~m}^{2}(2 \times 8 \mathrm{~m})$ la pérdida fue del 5,03 y el $11,32 \%$ respectivamente (Tabla 13).

Tabla 13. Pérdida de agua (coeficiente de escorrentía, \%) para las parcelas tratadas con herbicida y geotextiles en la Estación Experimental de El Teularet-Sierra de Enguera para el año 2004.

\begin{tabular}{lccccc}
\hline Subparcela & A & B & C & D & Media \\
Superficie $\left(\mathbf{m}^{2}\right)$ & $\mathbf{1}$ & $\mathbf{2}$ & $\mathbf{4}$ & $\mathbf{1 6}$ & \\
\hline Herbicida & 20,46 & 13,26 & 7,65 & 5,03 & 11,60 \\
Geotextil & 26,05 & 15,65 & 12,57 & 11,32 & 16,40 \\
\hline
\end{tabular}

Las escorrentías totales por parcelas oscilaron entre 146,4 y 186,5 litros en las parcelas de $1 \mathrm{~m}^{2}$ para el herbicida y geotextil respectivamente. En las de $16 \mathrm{~m}^{2}$ la pérdida fue mayor: 575,6 litros para la de herbicida y 1296,7 litros para la de geotextil (Tabla 14). Sin embargo, la producción relativa de escorrentía (por $\mathrm{m}^{2}$ ) demuestra que con el aumento de la superficie estudiada hay una reducción de la pérdida de agua. Las escorrentías medias totalizaron durante el año $200483,04 \mathrm{~mm}$ sobre los 715,8 mm de lluvia en la parcela con tratamiento de herbicida y de $117,37 \mathrm{~mm}$ en la de geotextil. Pero esos valores son claramente inferiores al aumentar el área de las parcelas (Tabla 15).

Tabla 14. Pérdida de agua (litros por parcela) para las parcelas tratadas con herbicida y geotextiles en la Estación Experimental de El Teularet-Sierra de Enguera para el año 2004.

\begin{tabular}{lccccc}
\hline Subparcela & A & B & C & D & Media \\
Superficie $\left(\mathbf{m}^{2}\right)$ & $\mathbf{1}$ & $\mathbf{2}$ & $\mathbf{4}$ & $\mathbf{1 6}$ & \\
\hline Herbicida & 146,4 & 189,9 & 219,1 & 575,6 & 282,8 \\
Geotextil & 186,5 & 224,0 & 360,0 & 1296,7 & 516,8 \\
\hline
\end{tabular}


Tabla 15. Pérdida de agua ( $\mathrm{mm}$ por parcela) para las parcelas tratadas con herbicida y geotextiles en la Estación Experimental de El Teularet-Sierra de Enguera para el año 2004.

\begin{tabular}{lccccc}
\hline Subparcela & A & B & C & D & Media \\
Superficie $\left(\mathbf{m}^{2}\right)$ & $\mathbf{1}$ & $\mathbf{2}$ & $\mathbf{4}$ & $\mathbf{1 6}$ & \\
\hline Herbicida & 146,44 & 94,95 & 54,77 & 35,98 & 83,04 \\
Geotextil & 186,45 & 112,00 & 89,99 & 81,04 & 117,37 \\
\hline
\end{tabular}

\subsubsection{Pérdida de suelo}

El suelo transportado por la arroyada fue prácticamente nulo en el caso de la cubierta de geotextil al ser este muy denso y cubrir el $100 \%$ de la superficie evaludada. La concentración de sedimentos de la escorrentía no supero los 0,04 $\mathrm{gr} \mathrm{l}^{-1}$ en el geotextil y osciló entre 3,53 y 6,86 para las cuatro parcelas del suelo tratado con herbicida. No hay una clara relación entre el aumento del área de estudio con la concentración de la escorrentía, aunque se aprecia un ligero aumento posiblemente fruto de la mayor escorrentía concentrada frente a la difusa en las parcelas de mayor tamaño. La concentración de sedimentos media para las cuatro parcelas fue de 5,2 $\mathrm{gr} \mathrm{l}^{-1}$ en la parcela con herbicida frente a 0,03 $\mathrm{gr} \mathrm{l}^{-1}$ del geotextil (Tabla 16).

Tabla 16. Concentración media de sedimentos en la escorrentía $\left(\mathrm{gr} \mathrm{l}^{-1}\right)$ para las parcelas tratadas con herbicida y geotextiles en la Estación Experimental de El Teularet-Sierra de Enguera para el año 2004.

\begin{tabular}{lccccc}
\hline Subparcela & A & B & C & D & Media \\
Superficie $\left(\mathbf{m}^{2}\right)$ & $\mathbf{1}$ & $\mathbf{2}$ & $\mathbf{4}$ & $\mathbf{1 6}$ & \\
\hline Herbicida & 3,53 & 6,04 & 6,86 & 4,39 & 5,20 \\
Geotextil & 0,04 & 0,03 & 0,01 & 0,04 & 0,03 \\
\hline
\end{tabular}

La tasa de erosión media del suelo para las tres parcelas es extraordinariamente baja para el geotextil $\left(0,1 \mathrm{Mg} \mathrm{ha}^{-1}\right.$ año-1) mientras que el caso del herbicida se alcanzan los 2,56 Mg ha ${ }^{-1}$ año-1. En el caso de la erosión del suelo no se aprecia una clara relación entre tamaño de la parcela y pérdida de suelo (Tabla 17). 
Tabla 17. Tasa de erosión $m$

edia (Mg ha-1 año-1) para las parcelas tratadas con herbicida y geotextiles en la Estación Experimental de El Teularet-Sierra de Enguera para el año 2004.

\begin{tabular}{lccccc}
\hline Subparcela & A & B & C & D & Media \\
Superficie $\left(\mathrm{m}^{2}\right)$ & $\mathbf{1}$ & $\mathbf{2}$ & $\mathbf{4}$ & $\mathbf{1 6}$ & \\
\hline Herbicida & 3,12 & 2,70 & 2,23 & 2,21 & 2,56 \\
Geotextil & 0,10 & 0,07 & 0,06 & 0,17 & 0,10 \\
\hline
\end{tabular}

\subsection{Discusión}

El uso de herbicidas que esquilman la cubierta vegetal durante todo el año da lugar a pérdidas de suelo elevadas. En el caso del experimento de El Teularet la pérdida de suelo para el año 2004 ha sido reducida al ser las precipitaciones de baja intensidad y quedar restos vegetales en el suelo que redujeron su pérdida. Un dato relevante respecto a la importancia de la intensidad de la lluvia es que el $98 \%$ de todos los sedimentos transportados en la parcela de herbicida durante el año 2004 fueron debidos a tres eventos, dos tormentas estivales y una primaveral, siendo insignificante la pérdida durante eventos de mayor volumen y duración pero de escasa intensidad como las precipitaciones de diciembre de 2004 con 15 días consecutivos de lluvias. Los herbicidas han sustituido al laboreo con el fin de reducir las pérdidas de suelo, pero con el uso masivo y recurrente con el que se suele aplicar en el secano valenciano está produciendo un aumento de la pérdida de suelo. En la parcela estudiada en El Teularet la pérdida de suelo ha alcanzado los 2,56 $\mathrm{Mg} \mathrm{ha}^{-1}$ año-1, pero ese valor podría ser hasta un orden de magnitud mayor en años con lluvias intensa. Es evidente que el geotextil reduce la pérdida de suelo al no permitir que el impacto de la gota o la arroyada arranquen materiales del suelo. Sin embargo, es relevante que la pérdida de agua haya sido mayor en el agrogeotextil que en herbicida. Esto es fruto de la repelencia al agua de algunos materiales textiles, lo que debe ser estudiado en profundidad para poder evitarlo en los geotextiles de nuevo diseño.

Otros autores han encontrado manejos poco adecuados para la conservación del suelo (Cerdà, 2006; Giráldez at al, 1989), por lo que se debe potenciar manejos más sostenible (Naredo, 2004). La investigación en este sentido debe buscar manejos viables económicamente pero también ambientalmente.

\subsection{Conclusiones}

La pérdida de agua es elevada en el agrogeotextil debido a la hidrofobia del material de algodón utilizado, aspecto que debe ser estudiado y subsanado en futuras aplicaciones. El 
manejo con herbicida, además de proporcionar elevadas tasas de escorrentía destaca por las elevadas tasas de erosión. Los herbicidas deberían ser aplicados sólo en los momentos de escasez de recursos hídricos para el cultivo y no indiscriminadamente a lo largo del año como se está haciendo en el secano y el regadío valenciano. 


\section{Capitulo 4. Geotextil versus herbicida en el control de la pérdida de agua y suelo en} el secano valenciano

Resumen. Los suelos agrícolas son los que contribuyen con mayores pérdidas de suelo y aguas. El uso de herbicidas es el manejo más extendido en la agricultura de secano valenciana. La búsqueda de alternativas más sostenibles ha hecho que el uso de geotextiles aplicados a la agricultura (agrogeotextiles) sea cada vez más extendida. Este trabajo presenta los resultados de las mediciones tomadas en ocho parcelas de 1, 2, 4 y 16 $\mathrm{m}^{2}$ pareadas con tratamiento de herbicida y agrogeotextiles en la "Estación Experimental para el Estudio de la Erosión del Suelo de El Teularet-Sierra de Enguera" en los que se ha comprobado que el uso de herbicidas favorece la pérdida de suelo. Los agrogeotextiles producen mayores escorrentías durante el año de estudio, pero es el tratamiento con herbicida el que contribuye con pérdidas de suelo elevadas al quedar los campos desnudos por la ausencia de vegetación. En concreto, la concentración de sedimentos de la arroyada procedente de las parcelas tratadas con herbicida alcanzó valores 173 veces más altos que los del tratado con geotextil, y la tasa de erosión final fue de 26 veces mayor en el herbicida. El agrogeotextil tan sólo presenta el problema de una mayor escorrentía lo que se debió a la hidrofobicidad del tejido de algodón, un problema que debe ser estudiado para ser subsanado en los geotextiles para su en agricultura.

Palabras clave: Agricultura ecológica, Tasas de erosión, Secano, Herbicida, Precipitación.

Abstract. Los agricultural grounds is those that contribute with greater losses of ground and waters. The use of herbicidas is the extended handling more in the Valencian agriculture of dry land. The search of more sustainable alternatives has done than the use of geotextiles applied to agriculture (agrogeotextiles) more and more is extended. This work presents/displays the results of the measurements taken in eight parcels of 1,2, twin 4 and $16 \mathrm{~m}^{2}$ with herbicida treatment and agrogeotextiles in the "Experimental Station for the Study of the Erosion of Soil of the Teularet-Mountain range of Enguera" in which it has been verified that the use of herbicidas favors the loss of ground. The agrogeotextiles produce greater run-offs during the year of study, but the one is the treatment with herbicida that contributes with losses of ground elevated when being the naked fields by the vegetation absence. In particular, the sediment concentration of the poured one coming from the parcels dealt with herbicida reached values 173 times higher than those of the deal with geotextil, and the rate of final erosion was of 26 times greater in the herbicida. The agrogeotextil only presents/displays the problem of a greater run-off which had to the hidrofobicidad of the cotton weave, a problem that must be studied to be corrected in the geotextiles for his in agriculture.

Key words: Organic farming, Erosion rates, Rainfed, Herbicide, Precipitation. 
Publicado en Land Degradation and Developement (2010)

Gimenez-Morera, A., Ruiz Sinoga, J.D. y Cerdà, A.. 2010. The impact of cotton Geotextiles on soil and water losses in Mediterranean rainfed agricultural land. Land Degradation and Development, 21, 1-10. DOI: 10.1002/ldr.971.

\section{Capítulo 5.}

El impacto de los geotextiles de algodón en el control de la pérdida de suelo y agua en cultivos agrícolas del secano mediterráneo en lluvia real y lluvia simulada. 


\subsection{Introducción}

Los ecosistemas mediterráneos se caracterizan por las altas tasas de erosión debido a las condiciones climáticas y geomorfológicas, pero también como consecuencias de la Desertificación (Thornes, 1985). Los suelos cultivados son propensos a altas tasas de erosión debido a una historia de intenso laboreo durante milenios y al extendido uso de herbicidas que dan lugar a suelos desnudos y encostrados (Boardman et al., 1990; Lal, 1999; Cerdà et al., 2009). Las altas tasas de erosión pueden dar como resultado una agricultura no sostenible (Montgomery, 2007) y con ello la subsiguiente degradación y abandono del territorio (Barrow, 1991).

De los distintos biomas del planeta, el mediterráneo presenta tasas de erosión elevadas (Kosmas et al., 1997; Boardman y Poesen, 2006), pero son especialmente elevadas en los suelos agrícolas (López Bermúdez and Albaladejo, 1990; Cerdà, 2002). La combinación de las condiciones climáticas mediterráneas y las prácticas agrícolas ha dado como resultado la no sostenibilidad de la agricultura mediterránea como consecuencia de las elevadas pérdidas de suelo (Gómez et al., 1999; Cerdà y Doerr, 2007; Cerdà et al., 2009). En España, una comparación entre zonas vegetadas bajo condiciones mediterráneas como el bosque, los matorrales y las praderas con las zonas cultivadas ha mostrado un aumento de entre 2 y 5 órdenes de magnitud en la pérdida de suelo (García-Ruiz et al., 1995; López Bermúdez et al., 1998; Cerdà, 2001; Ruiz Sinoga y Martínez Murillo, 2009). Esta es la razón por la que el control de la erosión debe centrarse en las tierras de cultivo, aunque poca atención se ha prestado en este aspecto en las zonas mediterráneas donde se ha visto el problema de la degradación del suelo o desertificación más como un proceso de degradación del bosque en lugar de un fracaso en el manejo sostenible de las zonas agrícolas (Cerdà et al., 2007).

Una reducción en la pérdida de suelo y agua es esencial para conseguir una agricultura sostenible (Montgomery, 2007). Si las pérdidas de suelos se reducen menos sedimento y contaminantes se liberarán en las tierras agrícolas, y con ello menos fertilizantes se aplicarán a los suelos. Tasas de erosión extremas han sido cuantificadas en los ecosistemas agrarios mediterráneos donde el cultivo es difícil sin fertilización química (Giménez Morera et al., 2008). En estas condiciones, el uso de los geotextiles -también denominados agrogeotextiles cuando se utilizan en agricultura- puede contribuir a la reducción de la erosión del suelo.

El algodón y otras fibras recicladas son ampliamente utilizadas en muchas industrias, como la automovilísticas. Los geotextiles reciclados son muy económicos y son producidos en zonas rurales de España. Estas características son clave para los agricultores ya que permiten que los geotextiles de algodón sean baratos, fáciles de conseguir, aplicar, y cuentan con la ventaja de que pueden ser producidos localmente. Debido a que una cubierta de geotextil de algodón evita las malas hierbas y tiene un costo de $0,5 € \mathrm{~m}^{-2}$ puede 
ser una magnífica opción para evitar el coste de otros manejos. Investigaciones previas por Giménez Morera et al., (2008) ha mostrado que los geotextiles pueden ser una alternativa ecológica para los agricultores, especialmente en los tres primeros años de una plantación de frutales o cítricos cuando el suelo alrededor de las plantas pueden protegerlo de las malas hierbas con la cubierta de geotextil.

Este capítulo evalúa el potencial del uso de geotextiles en agricultura para reducir la pérdida de suelo agrícola y aumentar la infiltración de las aguas. Geotextiles similares han sido utilizados en el control de taludes de carretera donde las tasas de erosión son elevadas (Cerdà, 2007), con resultados de gran éxito desde los años 1980s en taludes de carreteras y ferrocarril (Martínez, 1986; Baker, 1988; Theisen, 1992), y en la actualidad están siendo utilizados con resultados muy positivos en distintos campos (Bhattacharyya, 2009). Sin embargo, el uso de geotextiles de algodón para el control de la pérdida de suelo en agricultura todavía necesita más investigación e innovación para alcanzar resultados de éxito. El objetivo de este capítulo es evaluar la eficiencia de los geotextiles de algodón en el control de las pérdidas de suelo en una zona de agricultura mediterránea de secano en el este de la península ibérica. El estudio del manejo de geotextiles sería viable en campos de olivos, almendros, frutales y viñedos, que son aquellos en los que se han medido tasas de erosión más altas en la Comunidad Valenciana (Cerdà, 2001).

\subsection{Material y Métodos}

Un campo de secano fue seleccionado en la Sierra de Enguera (38 $50^{\prime} \mathrm{N} ; 0^{\circ} 42^{\prime}$ W) como representativo del cultivo de secano en la montañas del Este de la península Ibérica. Viñas, olivos, almendros y frutales son los cultivos más habituales en esta zona donde durante milenios han compartido con el cereal los aprovechamientos más representativos. El roquedo de la zona son margas del Cretáceo, y el suelo un Typic Xerorthent con pendientes entre 5 y $8 \%$. En el campo de experimentación se cultivo almendros y cereal en el siglo XX por lo que el laboreo fue continuo. Tras el abandono de finales del siglo XX el campo fue labrado en 2003 , tras lo que se realizó la instalación de las parcelas, colectores y depósitos, siendo aplicado en 2004 los manejos correspondientes (Cerdà y Bodí, 2008).

La escorrentía y la concentración de sedimentos en cada parcela fue medida durante el año 2004, y las pérdidas de suelo fueron calculadas después de cada evento de lluvia. La intensidad (24 horas) más elevada fue de $57 \mathrm{~mm} \mathrm{día}^{-1}$, y de $25 \mathrm{~mm} \mathrm{~h}^{-1}$ para una intensidad máxima de 30 minutos $\left(l_{30}\right)$. Debido a la baja intensidad de las lluvias durante el periodo de estudio y con el fin de completar el experimento, se realizaron 40 experimentos con lluvia simulada, 20 en verano (julio de 2004), en invierno (diciembre de 2004) con el fin de cuantificar las pérdidas de suelo y agua que se producirían bajo lluvias intensas.

El clima de la Sierra de Enguera es típicamente mediterráneo con 3 ó 5 meses de sequía estival, normalmente entre junio y septiembre. La precipitación media anual es de $479 \mathrm{~mm}$ Los pluviómetros localizados en la propia estación experimental de El Teularet-Sierra de 
Enguera cuantificaron en 2004 una lluvia total de 715,8 mm (precisión de 0,2 mm). El numero medio de días de lluvia anuales es de 38 y la temperatura media anual es $14,2{ }^{\circ} \mathrm{C}$, mientras que la temperatura media mensual oscila entre los $23^{\circ} \mathrm{C}$ de agosto y los $7.3^{\circ} \mathrm{C}$ de Enero.

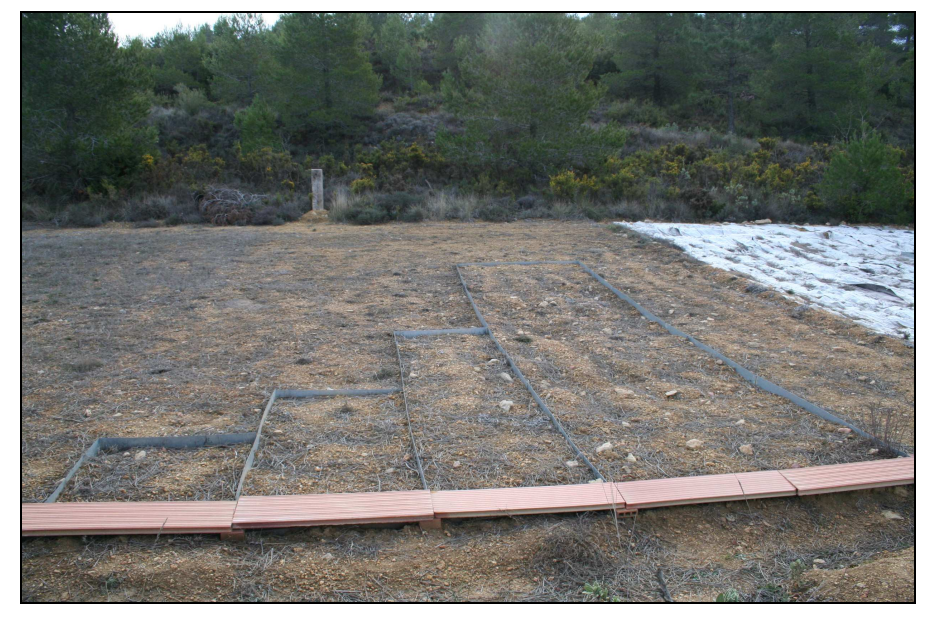

Figure 13a. Vista de la parcela con herbicida (a la derecha se puede ver también parte de la parcela de geotextiles).

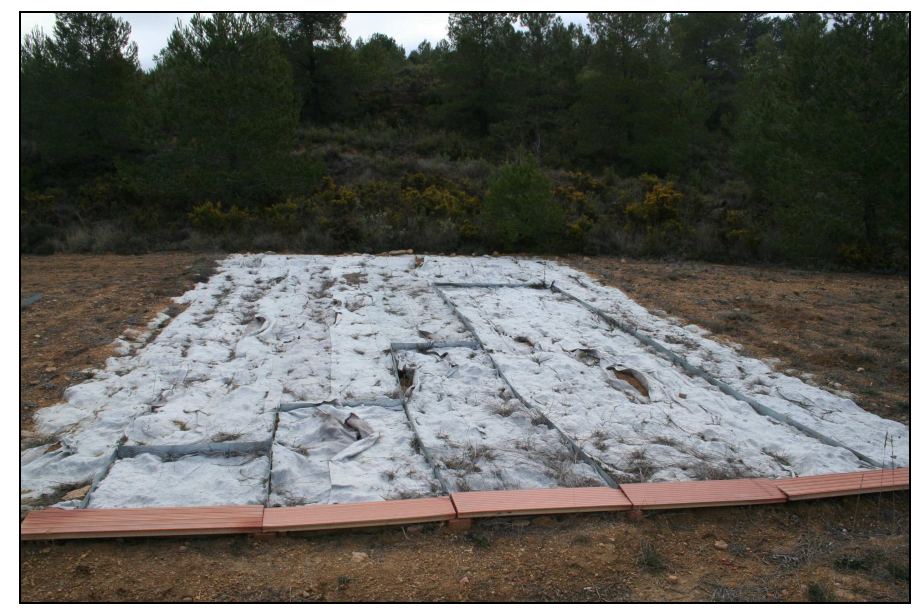

Figure 13b. Vista de la parcela con Geotextiles. 
Dos parcelas de $200 \mathrm{~m}^{2}$ tratadas con 'Herbicida' (Glyphosato 68 \%) y 'Geotextil' (una aplicación) fueron instalados en 2003. A lo largo de 2004, el herbicida fue aplicado 4 veces por año (enero, abril, junio y septiembre) en la parcelas de herbicida. En la parcela de 'Geotextil', un geotextil de algodón de $1 \mathrm{~cm}$ de profundidad, $80 \mathrm{~cm}$ de anchura y $20 \mathrm{~m}$ de longitud fue instalado. En cada parcela un grupo de 4 parcelas de erosión de diferentes tamaños (1, 2, 4 y $16 \mathrm{~m}^{2}$ ) fueron instalados (ver Cerdà y Bodí, 2008; Bodí y Cerdà, 2008) (Fig. 13a, 13b). El herbicida es el método más utilizado en el manejo de los suelos en la región del Macizo del Caroig en el Este de España, donde se encuentra la Sierra de Enguera. En general, el herbicida ha superado en extensión y uso en todo el Este de España, y en general en todas las montañas mediterráneas el manejo del suelo en las plantaciones de olivo, cítricos y frutales. Sólo los almendros y las viñas presentan aún un extensivo uso del laboreo.

Los geotextiles no se utilizan en agricultura en la región del Macizo del Caroig, donde el laboreo es cada vez menos utilizado y los herbicidas están siendo aplicados en al menos el $80 \%$ de las explotaciones. El uso de los geotextiles debe ser favorecida con el fin de reducir los gastos de maquinaria, de consumo de agroquímicos y mano de obra, y también para favorecer el establecimiento de la agricultura ecológica. Los agricultores suelen utilizar los geotextiles durante los primeros 3 ó 5 años después de la plantación, cuando las malas hierbas pueden reducir el crecimiento de los árboles, y cuando la mano de obra para eliminar las malas hierbas puede representar más del $20 \%$ del total de los gastos de una explotación. En ese periodo de crecimiento de los árboles, y debido a su poca biomasa, las tasas de erosión pueden ser extraordinarias (Cerdà et al., 2009). Por lo tanto, los agricultores planifican el uso de geotextiles para mejorar el enraizamiento de las plantas en los primeros años. Este capítulo aporta información sobre la contribución de los geotextiles de algodón para controlar la pérdida de suelo, y comprobar si es una opción viable para los agricultores.

Los experimentos con lluvia simulada se llevaron a cabo en julio y diciembre de 2004, con los suelos secos y húmeros respectivamente. La lluvia simulada permite cuantificar la respuesta hidrológica y erosiva de las parcelas bajo condiciones de suelos secos y suelos húmedos bajo las mismas características de intensidad de lluvia. Un total de cuarenta experimentos se llevaron a cabo: 10 experimentos $\times 2$ tratamientos $x 2$ estaciones. La lluvia simulada se produjo con agua destilada desde una altura de dos metros sobre una superficie de $1 \mathrm{~m}^{2}$, donde una parcela de $0.25 \mathrm{~m}^{2}$ colocada en el centro de la zona humectada permite medir la escorrentía y la pérdida de suelo. La lluvia simulada se mantuvo durante una hora a una intensidad de $55 \mathrm{~mm} \mathrm{~h}^{-1}$. La escorrentía superficial de las parcelas circulares de $0,25 \mathrm{~m}^{2}$ se midió a intervalos de 1 minuto. Una muestra para la determinación de la concentración de sedimentos se tomó cada diez minutos y fue trasladada al laboratorio donde se determinó la concentración de sedimentos. Las tasas de escorrentía, y la concentración de sedimentos permiten calcular los sedimentos totales, la escorrentía total, la infiltración y las tasas de erosión como muestra Cerdà (1999). La vegetación y la cubierta de fragmentos de roca fueron medidas en el campo como 
porcentaje de la superficie del suelo cubierta por plantas utilizando un marco con una red de $25 \mathrm{~mm}$ de luz. La escorrentía fue calculada como porcentaje de la lluvia. La concentración de sedimentos $\left(\mathrm{g} \mathrm{L}^{-1}\right)$ se midió por desecación y el total de la pérdida de suelo $\left(\mathrm{g} \mathrm{m}^{2} \mathrm{~h}^{-1}\right)$ se calculó a partir de la concentración de sedimentos y la escorrentía. Información más detallada sobre las características de la lluvia y del simulador de lluvia, del tratamiento de los datos y del diseño experimental de cada experimento se puede encontrar en Cerdà (1996) y Cerdà et al., (1997).

La repelencia al agua fue medida in situ utilizando el Water Drop Penetration Time (WDPT) test (Wessel, 1988). El test comprende el uso de 25 gotas $(0,05 \mathrm{ml})$ sobre la superficie del suelo (o sobre el geotextil) y se mide el tiempo hasta que se produce la infiltración de todas las gotas. La media de esas 25 mediciones han sido utilizadas con el índice WDPT. Siguiendo la clasificación de Bisdom et al., (1993), WDPTs $\leq 5$ segundos es indicativo de un suelo hidrofílico, 5-60 segundos como ligera, 60-600 segundos como fuerte, 600-3600 segundos como severa y $>3600$ segundos como repelencia extrema. El tiempo de encharcamiento $(T p)$ y el tiempo de escorrentía $(T r)$ también indican el grado de repelencia o hidrofilia del suelo al agua. Tp es el tiempo entre el inicio de la lluvia y la formación de pequeños charcos (40\% de la superficie encharcable), y $\operatorname{Tr}$ es el tiempo en el que se produce escorrentía dentro de la parcela (Cerdà y Doerr, 2008).

En cada parcela se tomaron cinco muestras de suelo $(0-2 \mathrm{~cm}$ de profundidad), se secaron a $105^{\circ} \mathrm{C}$, mezclaron y se tamizaron (2 mm). El método de medición de Walkley-Black (1934) se utilizó para determinar el contenido de materia orgánica. El test no paramétrico de la $U$ de Mann-Whitney se utilizó para determinar las diferencias entre los suelos tratados con herbicidas y con Geotextiles.

\subsection{Resultados}

\subsubsection{Pérdida de agua y suelo bajo lluvia natural}

La escorrentía y la concentración de sedimentos fueron medidas después de cada evento de lluvia natural. La escorrentías total (mm, \% de lluvia y litros, L), la concentración media de sedimentos $\left(\mathrm{g} \mathrm{L}^{-1}\right)$ y la pérdida de suelo $\left(\mathrm{Mg} \mathrm{ha}^{-1} \mathrm{año}^{-1}\right)$ para el año 2004 se muestra en la tabla 18. Las parcelas con tratamiento de Herbicida muestran altas tasas de escorrentía, con valores que oscilan entre 4,0 y $14,8 \%$ de la lluvia para todas las parcelas. La escorrentía media fue de $8,2 \%$ de la lluvia. La lluvia total por parcela osciló entre los 457,7 litros de la parcelas de $16 \mathrm{~m}^{2}$ y los 105,5 litros de la parcelas de $1 \mathrm{~m}^{2}$. En el tratamiento con Geotextiles la pérdida de agua fue mucho mayor. Para valores medios durante el año 2004 osciló entre $26,1 \%$ de la parcela de $1 \mathrm{~m}^{2}$ y $11,3 \%$ de la parcelas de $16 \mathrm{~m}^{2}$. El caudal total fue de 186,5 y $1.296,7$ litros respectivamente para las parcelas de 1 y $16 \mathrm{~m}^{2}$. 
Tabla 18. Medias de las escorrentías totales y pérdida de suelos para las ocho parcelas con tratamiento de herbicida (4) y agrogeotextil (4) en la estación experimental de El Teularet bajo lluvia natural (2004). Los valores medios que aparecen en negrita son significativos $(P<0.05)$ con el test de la U de Mann-Whitney.

\begin{tabular}{|c|c|c|c|c|c|}
\hline Parcelas & A & B & C & D & Media \\
\hline Superficie $\left(m^{2}\right)$ & 1 & 2 & 4 & 16 & \\
\hline \multicolumn{6}{|l|}{ Escorrentía (mm) } \\
\hline Herbicida & 105,52 & 63,20 & 38,73 & 28,60 & 59,01 \\
\hline Agrogeotextil & 186,45 & 112,00 & 89,99 & 81,04 & 117,37 \\
\hline \multicolumn{6}{|l|}{ Escorrentía (\%) } \\
\hline Herbicida & 14,74 & 8,83 & 5,41 & 4,00 & 8,24 \\
\hline Agrogeotextil & 26,05 & 15,65 & 12,57 & 11,32 & 16,40 \\
\hline \multicolumn{6}{|l|}{ Escorrentía (I) } \\
\hline Herbicida & 105,52 & 126,39 & 154,93 & 457,66 & 211,12 \\
\hline Agrogeotextil & 186,45 & 223,99 & 359,96 & 1296,66 & 516,76 \\
\hline \multicolumn{6}{|c|}{ Concentración de sedimentos $\left(\mathrm{g}^{-1}\right)$} \\
\hline Herbicida & 2,48 & 2,63 & 2,60 & 3,45 & 2,79 \\
\hline Agrogeotextil & 0,04 & 0,03 & 0,01 & 0,04 & 0,03 \\
\hline \multicolumn{6}{|c|}{ Tasa de erosión (Mg ha-1 $\left.\mathrm{y}^{-1}\right)$} \\
\hline Herbicida & 6,44 & 3,56 & 3,51 & 3,17 & 4,17 \\
\hline Agrogeotextil & 0,1 & 0,07 & 0,06 & 0,17 & 0,1 \\
\hline
\end{tabular}

La concentración de sedimentos en la escorrentía alcanzó valores mucho más altos en los manejos con herbicidas. La media de la concentración de sedimentos fue de $2,8 \mathrm{~g} \mathrm{l}^{-1}, \mathrm{y}$ osciló entre 2,5 y $3,5 \mathrm{~g} \mathrm{l}^{-1}$ respectivamente para parcelas entre 1 y $16 \mathrm{~m}^{2}$. En los suelos cubiertos por geotextil, la concentración de sedimentos fue extremadamente baja, y osciló entre 0,01 y $0,04 \mathrm{~g} \mathrm{l}^{-1}$, un centenar de veces más bajo que en los tratamientos con herbicida. La pérdida de suelo fue insignificante en los geotextiles $\left(0,1 \mathrm{Mg} \mathrm{ha}^{-1}\right.$ año-1) y elevada en los herbicidas (4,2 Mg ha-1 año-1) con valores que oscilaron entre los 3,2 y 6,4 $\mathrm{Mg} \mathrm{ha}^{-1}$ año-1 respectivamente para las parcelas de 16 y $1 \mathrm{~m}^{2}$. 
Tabla 19. Cubierta de fragmentos de roca, pendiente, cubierta vegetal y materia orgánica en las parcelas con lluvia simulada. Los valores medios en negrita indican que existen diferencias estadísticamente significativas $(P<0.05)$ siguiendo el test de la $U$ de Mann-Whitney.

\begin{tabular}{|c|c|c|c|c|c|c|c|c|}
\hline Parcelas & $\begin{array}{c}\text { Fragmentos de } \\
\text { Herbicida }\end{array}$ & $\begin{array}{l}\text { roca }(\%) \\
\text { Geotextil }\end{array}$ & $\begin{array}{l}\text { Pendiente } \\
\text { Herbicida }\end{array}$ & $\begin{array}{c}(\%) \\
\text { Geotextil }\end{array}$ & $\begin{array}{c}\text { Vegetación } \\
\text { Herbicida }\end{array}$ & $\begin{array}{c}(\%) \\
\text { Geotextil }\end{array}$ & $\begin{array}{c}\text { Materia } \\
\text { Herbicida }\end{array}$ & $\begin{array}{c}\text { orgánica (\%) } \\
\text { Geotextil }\end{array}$ \\
\hline 1 & 25 & 0 & 5 & 5 & 0 & 0 & 2,15 & 1,78 \\
\hline 2 & 35 & 0 & 8 & 4 & 0 & 0 & 2,01 & 1,98 \\
\hline 3 & 21 & 0 & 6 & 6 & 1 & 0 & 2,16 & 1,85 \\
\hline 4 & 32 & 0 & 7 & 7 & 2 & 0 & 2,14 & 1,95 \\
\hline 5 & 26 & 0 & 9 & 9 & 0 & 0 & 1,89 & 1,67 \\
\hline 6 & 35 & 0 & 8 & 5 & 0 & 0 & 1,98 & 2,01 \\
\hline 7 & 36 & 0 & 9 & 6 & 1 & 0 & 1,68 & 2,15 \\
\hline 8 & 38 & 0 & 6 & 9 & 2 & 0 & 2,01 & 2,26 \\
\hline 9 & 34 & 0 & 4 & 8 & 2 & 0 & 2,06 & 2,14 \\
\hline 10 & 32 & 0 & 5 & 4 & 1 & 0 & 2,16 & 2,14 \\
\hline Media & 31,40 & 0,00 & 6,70 & 6,30 & 0,90 & 0,00 & 2,02 & 1,99 \\
\hline 1 & 42 & 0 & 7 & 4 & 20 & 0 & 2,15 & 1,65 \\
\hline 2 & 31 & 0 & 5 & 7 & 25 & 0 & 2,30 & 1,98 \\
\hline 3 & 36 & 0 & 7 & 9 & 21 & 0 & 1,98 & 1,47 \\
\hline 4 & 51 & 0 & 6 & 8 & 20 & 0 & 1,68 & 1,58 \\
\hline 5 & 37 & 0 & 4 & 5 & 16 & 0 & 1,67 & 1,89 \\
\hline 6 & 26 & 0 & 7 & 9 & 15 & 0 & 1,89 & 1,84 \\
\hline 7 & 27 & 0 & 8 & 8 & 18 & 0 & 1,58 & 1,97 \\
\hline 8 & 29 & 0 & 5 & 5 & 16 & 0 & 2,14 & 1,64 \\
\hline 9 & 33 & 0 & 4 & 5 & 17 & 0 & 1,89 & 1,75 \\
\hline 10 & 34 & 0 & 9 & 5 & 20 & 0 & 1,78 & 1,74 \\
\hline Media & 34,60 & 0,00 & 6,20 & 6,50 & 18,80 & 0,00 & 1,91 & 1,75 \\
\hline
\end{tabular}

5.3.2 Pérdida de suelo y agua en los experimentos con lluvia simulada

Debido a que las lluvias intensas son raras, pero son las que determinan los procesos erosivos en medios semiáridos, se realizaron experimentos con un periodo de retorno de 
10-años de retorno en el Macizo del Caroig. Estos experimentos se aplicaron tanto en parcelas con tratamiento de herbicidas como con geotextiles.

Entre las características de las parcelas destaca la nula cubierta vegetal en el geotextil ya que éste cubre toda la superficie de la parcela. En el tratamiento con herbicida la cubierta vegetal alcanza el $0,9 \%$ de media en verano, cuando debido a la sequia estival y a los tres tratamientos previos con herbicida el suelo quedó prácticamente desnudo al no superar nunca el $2 \%$ de cubierta de plantas, y quedar en un $0 \%$ en la mayoría de los casos. En invierno, la cubierta vegetal en la zona tratada con herbicida alcanzó el 18,8 \% debido a las lluvia de otoño y porque el último tratamiento con herbicida se produjo 98 días antes de la realización de los experimentos con lluvia simulada. La cubierta vegetal osciló entre 15 y 25 $\%$ para parcelas individuales (Tabla 19).

Los fragmentos de roca mostraron una cubierta insignificantes en el manejo con geotextil ya que el tejido cubrió toda la superficie del suelo (ver Figura 13b) y alcanzó los 31,4 y 34,6 $\%$ respectivamente para las muestras del verano y el invierno en la parcelas de herbicida. Las diferencias entre las parcelas de herbicida y geotextil fueron estadísticamente significativas en cuanto a la cubierta vegetal y de fragmentos de roca (Tabla 19).

La pendiente fue ligeramente superior al $6 \%$ de media y fue regular. El contenido de materia orgánica fue ligeramente superior en verano (2,02 y 1,99 \%) que en invierno (1,91 y $1,75 \%$ respectivamente para el herbicida y el geotextil). Las diferencias entre ambos manejos por lo que respecta a la materia orgánica y la pendiente no fueron estadísticamente significativas.

Los coeficientes de escorrentía oscilaron entre $26,5 \%$ en el verano y $50,1 \%$ en invierno para la parcela de herbicida. Por el contrario, los geotextiles produjeron menos escorrentías en invierno (57,6 \%) que en verano (87,4\%). La escorrentía media del año 2004 fue mucho mayor (x 2) en el suelo con tratamiento con geotextil que con herbicida. La escorrentía total mostró un patrón similar, elevada escorrentía y un incrementos en la estación veraniega en el geotextil, lo contrario que el tratamiento con herbicida .

La concentración de sedimentos fue elevada en el tratamiento con herbicida. Las diferencias fueron mucho mayores durante la estación veraniega (4.6 $\mathrm{g} \mathrm{l}^{-1}$ de media) que en el invierno $\left(1,8 \mathrm{~g} \mathrm{l}^{-1}\right)$. La concentración de sedimentos fue prácticamente insignificante en el "Geotextil", y las diferencias entre el verano y el invierno fueron prácticamente nulas.

La producción de sedimentos total fue mucho más baja en el geotextil y osciló entre 0,34 (invierno) y $0,45 \mathrm{~g}$ (verano), mientras que la producción de sedimentos en el tratamiento con herbicida osciló entre $12,1 \mathrm{~g}$ (invierno) y $16,8 \mathrm{~g}$ (verano). Así, la erodibilidad del suelo se redujo a valores extremadamente bajos debido al efecto de la cubierta del geotextil. La pérdida de suelo se muestra en la tabla 11. Los geotextiles producen escasas pérdidas $\left(0,03 \mathrm{Mg} \mathrm{ha}^{-1} \mathrm{año}^{-1}\right)$ en comparación con los herbicidas $\left(0,6 \mathrm{Mg} \mathrm{ha}^{-1}\right.$ año-1) en los que las pérdidas de suelo fueron 20 veces más altas (Tabla 20a y 20b). 
Tabla 20a. Pérdida de suelo bajo lluvia simulada $\left(55 \mathrm{~mm} \mathrm{~h}^{-1}\right)$. Los valores medios en negrita identifican diferencias estadísticas significativas (test de $U$ de Mann-Whitney, $P<0.05$ ) entre los manejos de herbicidas y geotextiles

\begin{tabular}{|c|c|c|c|c|c|c|}
\hline \multirow[b]{2}{*}{ Plots } & \multirow{2}{*}{$\begin{array}{c}\text { Escorrentía } \\
\text { Herbicida }\end{array}$} & \multirow{2}{*}{$\begin{array}{c}(\%) \\
\text { Geotextil }\end{array}$} & \multicolumn{2}{|c|}{ Contr. de sedimentos $\left(\mathrm{g} \mathrm{l}^{-1}\right)$} & \multicolumn{2}{|c|}{ Escorrentía (I) } \\
\hline & & & Herbicida & Geotextil & Herbicida & Geotextil \\
\hline \multicolumn{7}{|c|}{ Julio 2004} \\
\hline 1 & 25,36 & 89,23 & 6,66 & 0,05 & 3,49 & 12,27 \\
\hline 2 & 28,18 & 87,25 & 4,62 & 0,04 & 3,87 & 12,00 \\
\hline 3 & 24,35 & 96,32 & 5,14 & 0,03 & 3,35 & 13,24 \\
\hline 4 & 33,32 & 94,77 & 5,35 & 0,02 & 4,58 & 13,03 \\
\hline 5 & 34,26 & 97,74 & 4,67 & 0,04 & 4,71 & 13,44 \\
\hline 6 & 23,32 & 85,14 & 3,45 & 0,05 & 3,21 & 11,71 \\
\hline 7 & 24,25 & 84,25 & 4,32 & 0,02 & 3,33 & 11,58 \\
\hline 8 & 21,02 & 75,68 & 3,65 & 0,06 & 2,89 & 10,41 \\
\hline 9 & 22,01 & 84,01 & 4,87 & 0,02 & 3,03 & 11,55 \\
\hline 10 & 29,32 & 79,35 & 2,98 & 0,05 & 4,03 & 10,91 \\
\hline Media & 26,54 & 87,37 & 4,57 & 0,04 & 3,65 & 12,01 \\
\hline \multicolumn{7}{|c|}{ Diciembre 2004} \\
\hline 1 & 52,14 & 55,24 & 1,52 & 0,04 & 7,17 & 7,60 \\
\hline 2 & 48,65 & 45,36 & 1,47 & 0,06 & 6,69 & 6,24 \\
\hline 3 & 47,25 & 59,32 & 1,98 & 0,05 & 6,50 & 8,16 \\
\hline 4 & 49,97 & 48,25 & 2,01 & 0,01 & 6,87 & 6,63 \\
\hline 5 & 47,14 & 56,32 & 1,02 & 0,06 & 6,48 & 7,74 \\
\hline 6 & 54,25 & 65,14 & 1,56 & 0,02 & 7,46 & 8,96 \\
\hline 7 & 56,99 & 68,84 & 1,25 & 0,05 & 7,84 & 9,47 \\
\hline 8 & 49,35 & 49,15 & 1,98 & 0,02 & 6,79 & 6,76 \\
\hline 9 & 47,24 & 58,66 & 2,32 & 0,05 & 6,50 & 8,07 \\
\hline 10 & 48,25 & 69,33 & 2,57 & 0,06 & 6,63 & 9,53 \\
\hline Media & 50,12 & 57,56 & 1,77 & 0,04 & 6,89 & 7,91 \\
\hline
\end{tabular}


Tabla 20b. Pérdida de suelo bajo lluvia simulada $\left(55 \mathrm{~mm} \mathrm{~h}^{-1}\right)$. Los valores medios en negrita identifican diferencias estadísticas significativas (test de $U$ de Mann-Whitney, $P<0.05$ ) entre los manejos de herbicidas y geotextiles

\begin{tabular}{|c|c|c|c|c|c|c|}
\hline \multirow[b]{2}{*}{ Parcelas } & \multicolumn{2}{|c|}{ Conc. de sedimentos (g) } & \multicolumn{2}{|c|}{ Tasa de erosión ( $\left.\mathrm{g} \mathrm{m}^{2} \mathrm{~h}^{-1}\right)$} & \multicolumn{2}{|c|}{ Tasa de erosión $\left(\mathrm{Mg} \mathrm{ha}^{-1} \mathrm{~h}^{-1}\right)$} \\
\hline & Herbicida & Geotextil & Herbicida & Geotextil & Herbicida & Geotextil \\
\hline \multicolumn{7}{|l|}{ Julio 2004} \\
\hline 1 & 23,22 & 0,61 & 92,89 & 2,45 & 0,93 & 0,02 \\
\hline 2 & 17,90 & 0,48 & 71,61 & 1,92 & 0,72 & 0,02 \\
\hline 3 & 17,21 & 0,40 & 68,84 & 1,59 & 0,69 & 0,02 \\
\hline 4 & 24,51 & 0,26 & 98,04 & 1,04 & 0,98 & 0,01 \\
\hline 5 & 22,00 & 0,54 & 88,00 & 2,15 & 0,88 & 0,02 \\
\hline 6 & 11,06 & 0,59 & 44,25 & 2,34 & 0,44 & 0,02 \\
\hline 7 & 14,40 & 0,23 & 57,62 & 2,68 & 0,58 & 0,03 \\
\hline 8 & 10,55 & 0,62 & 42,20 & 6,50 & 0,42 & 0,06 \\
\hline 9 & 14,74 & 0,23 & 58,95 & 2,67 & 0,59 & 0,03 \\
\hline 10 & 12,01 & 0,55 & 48,06 & 5,95 & 0,48 & 0,06 \\
\hline Media & 16,76 & 0,45 & 67,05 & 2,93 & 0,67 & 0,03 \\
\hline \multicolumn{7}{|c|}{ Diciembre 2004} \\
\hline 1 & 10,90 & 0,30 & 43,59 & 1,22 & 0,44 & 0,01 \\
\hline 2 & 9,83 & 0,37 & 39,33 & 2,33 & 0,39 & 0,02 \\
\hline 3 & 12,86 & 0,41 & 51,46 & 3,33 & 0,51 & 0,03 \\
\hline 4 & 13,81 & 0,07 & 55,24 & 0,44 & 0,55 & 0,00 \\
\hline 5 & 6,61 & 0,46 & 26,45 & 3,60 & 0,26 & 0,04 \\
\hline 6 & 11,64 & 0,18 & 46,55 & 0,72 & 0,47 & 0,01 \\
\hline 7 & 9,80 & 0,47 & 39,18 & 4,48 & 0,39 & 0,04 \\
\hline 8 & 13,44 & 0,14 & 53,74 & 0,91 & 0,54 & 0,01 \\
\hline 9 & 15,07 & 0,40 & 60,28 & 3,25 & 0,60 & 0,03 \\
\hline 10 & 17,05 & 0,57 & 68,20 & 5,45 & 0,68 & 0,05 \\
\hline Media & 12,10 & 0,34 & 48,40 & 2,57 & 0,48 & 0,03 \\
\hline
\end{tabular}


Tabla 21. El tiempo de encharcamiento $(T p)$, tiempo de escorrentía $(T r)$, y retraso del tiempo de escorrentía respecto al tiempo de encharcamiento $(T r-T p)$ obtenidos a partir de experimentos con Iluvia simulada a $55 \mathrm{~mm} \mathrm{~h}^{-1}$. Y el Water Drop Penetration Time WDPT en segundos. Los valores medios en negrita identifican diferencias estadísticas significativas (test de $\mathrm{U}$ de Mann-Whitney, $\mathrm{P}<$ 0.05 ) entre los manejos de herbicidas y geotextiles

\begin{tabular}{|c|c|c|c|c|c|c|c|c|}
\hline Parcelas & $\begin{array}{c}\text { Tp } \\
\text { Herb } \\
\end{array}$ & $\begin{array}{c}\text { (s) } \\
\text { Textil } \\
\end{array}$ & $\begin{array}{c}\mathrm{Tr} \\
\text { Herb } \\
\end{array}$ & $\begin{array}{c}\text { (s) } \\
\text { Textil } \\
\end{array}$ & $\begin{array}{l}\text { Tr-Tp } \\
\text { Herb } \\
\end{array}$ & $\begin{array}{c}\text { (s) } \\
\text { Textil } \\
\end{array}$ & $\begin{array}{c}\text { WDPT } \\
\text { Herb }\end{array}$ & $\begin{array}{c}\text { (s) } \\
\text { Textil } \\
\end{array}$ \\
\hline \multicolumn{9}{|c|}{ Julio 2004} \\
\hline 1 & 345 & 20 & 521 & 31 & 176 & 11 & 2,14 & 125,36 \\
\hline 2 & 369 & 15 & 499 & 34 & 130 & 19 & 2,01 & 124,01 \\
\hline 3 & 347 & 23 & 563 & 29 & 216 & 6 & 3,65 & 96,25 \\
\hline 4 & 389 & 14 & 583 & 28 & 194 & 14 & 2,32 & 142,32 \\
\hline 5 & 298 & 16 & 578 & 26 & 280 & 10 & 1,25 & 99,25 \\
\hline 6 & 358 & 25 & 524 & 45 & 166 & 20 & 2,22 & 95,32 \\
\hline 7 & 298 & 24 & 563 & 33 & 265 & 9 & 1,68 & 135,20 \\
\hline 8 & 364 & 29 & 548 & 38 & 184 & 9 & 4,21 & 98,32 \\
\hline 9 & 375 & 35 & 578 & 49 & 203 & 14 & 1,36 & 87,29 \\
\hline 10 & 275 & 24 & 499 & 34 & 224 & 10 & 2,45 & 158,25 \\
\hline Media & 341,80 & 22,50 & 545,60 & 34,70 & 203,80 & 12,20 & 2,33 & 116,16 \\
\hline \multicolumn{9}{|c|}{ Diciembre 2004} \\
\hline 1 & 114 & 96 & 198 & 135 & 84 & 39 & 1,25 & 9,25 \\
\hline 2 & 98 & 78 & 178 & 127 & 80 & 49 & 1,59 & 4,86 \\
\hline 3 & 115 & 85 & 195 & 125 & 80 & 40 & 1,44 & 6,35 \\
\hline 4 & 96 & 47 & 243 & 124 & 147 & 77 & 1,02 & 7,49 \\
\hline 5 & 117 & 85 & 265 & 145 & 148 & 60 & 1,65 & 8,24 \\
\hline 6 & 110 & 60 & 210 & 124 & 100 & 64 & 1,68 & 9,21 \\
\hline 7 & 142 & 65 & 245 & 136 & 103 & 71 & 1,41 & 5,66 \\
\hline 8 & 150 & 86 & 263 & 125 & 113 & 39 & 1,33 & 10,74 \\
\hline 9 & 162 & 48 & 287 & 124 & 125 & 76 & 1,02 & 9,87 \\
\hline 10 & 135 & 92 & 245 & 112 & 110 & 20 & 1,49 & 7,84 \\
\hline Media & 123,90 & 74,20 & 232,90 & 127,70 & 109,00 & 53,50 & 1,39 & 7,95 \\
\hline
\end{tabular}




\subsubsection{Repelencia al agua de los suelos}

Las mediciones del WDPT demuestran que la repelencia de los geotextiles al agua es un factor clave para entender las diferencias hidrológicas con los suelos tratados con herbicidas. El rápido encharcamiento y escorrentía de los algodones se debe a ese carácter hidrofóbico del material de algodón. El geotextil de algodón reciclado incrementa las pérdidas de agua fruto de ese carácter hidrofóbico (Tabla 21).

Durante las lluvias naturales no se pudo determinar el tiempo de encharcamiento y de escorrentía (Tp y $\mathrm{Tr}$ ) pero el que tormentas de pocos minutos produjeran elevadas escorrentías confirman la elevada repelencia de los geotextiles de algodón. Se realizaron mediciones para determinar el grado de repelencia del algodón instalado en las parcelas de la estación experimental de El Teularet. Por una parte, los experimentos con lluvia simulada demostraron que el Tp se produjo antes en los Geotextiles (22 y 74 segundos respectivamente para el verano y el invierno) y en los herbicidas (341 y 123 segundos para el verano y el invierno respectivamente), los cuales mostraron un claro comportamiento repelente. Además, aunque el Tp fue reducido en invierno debido a la humedad del suelo, en verano fue más rápido por el efecto de la repelencia del agua.

En el tratamiento con herbicida, el suelo mostró valores bajos de WDPT: 1,3 y 2,3 segundos para el invierno y el verano, respectivamente. Sin embargo, los geotextiles dieron lugar a valores altos de repelencia como demuestra que el WDPT alcanzase los 116 segundos en verano y los 8 segundos en invierno.

\subsection{Discusión}

Los geotextiles de algodón son ampliamente utilizados en las sociedades modernas debido a que se producen a partir del reciclado de la ropa, y a que las industrias locales del Este de la península ibérica los producen a precio de $0.5 € \mathrm{~m}^{-2}$, lo que hace el producto más barato que otros métodos de control de las malas hierbas (Giménez Morera et al., 2007). El uso de los geotextiles de algodón, además de su aplicación en la agricultura, también puede ser una ayuda sustancial en el desarrollo de las industrias textiles locales y en el reciclaje de materiales.

Investigaciones previas han destacado el efecto positivo de los geotextiles en el control de la erosión y del suelo y la pérdida de agua (Rickson, 2000). Habitualmente, los geotextiles protegen el suelo del impacto de las gotas de lluvia y aumentan la infiltración del agua. La revisión de Rickson (2006) confirma los efectos positivos de los geotextiles en un sentido amplio, incluyendo el manejo de la vegetación (Rickson, 2003). Este efecto positivo ha sido confirmado por otros investigadores. Bhattacharyya et al., (2008; 2009) utilizó geotextiles de hoja de palma para reducir la pérdida de suelo en su degradación en suelos arenosos del Reino Unido. También se encontraron resultados similares por Jankauskas et al., (2008a; 
2008b) en Lituania para el control de la erosión en taludes de carretera. Smets et al., (2009) encontraron que los regueros y las cárcavas pueden ser controlados mediante geotextiles biológicos, tanto en laderas con elevadas pendientes como en suelos de pendientes moderadas. Davies et al., (2006) también encontraron que los geotextiles pueden ser una estrategia positiva para el control y la conservación de aguas y suelos. La mayoría de los estudios se han centrado en superficies pequeñas como los taludes de carretera, o en pequeñas estaciones experimentales, y siempre se confirman como buenos gestores de las aguas y los suelos (Smets et al., 2007).

La experimentación presentada en esta Tesis Doctoral demuestra que los geotextiles son una práctica eficiente en el control de las aguas y los suelos. Sin embargo, la eficiencia de los geotextiles es variable. Los resultados demuestran un efecto negativo de los geotextiles en la infiltración de las aguas debido a su respuesta hidrofóbica. Este comportamiento no se había encontrado con anterioridad debido a que el tipo de geotextil estudiado compuesto de algodón no es muy utilizado en agricultura, especialmente en la agricultura mediterránea basada en manejos dominados por el laboreo y los herbicidas. El clima mediterráneo está caracterizado por una fuerte sequia veraniega, lo que favorece el desarrollo de repuestas hidrofóbicas. Una de las razones de este comportamiento hidrofóbico con una alta variabilidad estacional se debe a las fuertes variaciones estacionales de la humedad del suelo (Doerr et al., 2002). Debemos destacar que la repelencia es una propiedad natural de algunos suelos (Doerr et al., 2007), pero esta es la primera vez que los geotextiles se presentan en la literatura científica como hidrofóbicos.

A pesar de la visión negativa de la repelencia, esta propiedad puede ser positiva para el cultivo de frutales y cítricos ya que pueden crear una zona seca cerca del tronco del árbol que evitará la proliferación de hongos que suelen ser un problema sanitario en las zonas de regadío mediterráneas. Pero, también es cierto que por debajo del geotextil el agua se mantiene más estable y puede favorecer el aumento de algunas plagas y la pérdida de pies jóvenes (Giménez-Morera et al., 2007). Seguramente, el problema de la hidrofobia del geotextil será insignificante en algunas zonas debido al mantenimiento de valores constantes de humedad en el suelo, pero este no es el caso del mediterráneo.

La repuesta hidrofóbica de los geotextiles no debe ser una razón para no utilizar geotextiles en agricultura en el mediterráneo ya que, la propia hidrofobia del geotextil alejará del tronco el agua. Pero sin duda, el aumento de la escorrentía en las zonas cubiertas con geotextil es una desventaja para estos geotextiles que deben de proteger el suelo y favorecer la infiltración. Este aspecto requiere más estudio ya que un flujo preferencial puede ser beneficioso en territorios secos como el mediterráneo.

Otra implicación importante de la repelencia de los geotextiles es que pueden favorecer la formación de regueros y de cárcavas. Aunque a escala de pedón el geotextil reduce hasta ser insignificante la erosión del suelo, los caudales generados en los geotextiles pueden desencadenar fuertes incisiones y altas tasas de erosión una vez alcanza las zonas no protegidas. 


\subsection{Conclusiones}

El estudio durante un año bajo lluvia natural y simulada del efecto de los geotextiles de algodón sobre los procesos de erosión y generación de escorrentía demuestran que estos materiales de origen industrial reducen la erosión del suelo pero aumentan las pérdidas de de agua. La escorrentía superficial aumentó en verano cuando los suelos estaban secos. Las altas tasas de escorrentía en los geotextiles se debieron a la respuesta hidrofóbica del algodón. Por lo tanto, bajo condiciones climáticas mediterránea, los geotextiles se deben de utilizar con precaución y deben ser evaluados antes de ser utilizados. Estas pruebas deben ser dirigidas a conocer cómo influye el uso de geotextiles agrícolas en la pérdida de agua ya que esta cuestión es clave para su posible utilización. 


\title{
Resumen
}

El alto riesgo de erosión de los suelos cultivados mediterráneos se debe a la pendiente del suelo, a las altas intensidades de la lluvia y a la baja cubierta vegetal. El manejo tradicional con laboreo o herbicidas también contribuye a altas tasas de erosión. Este artículo revisa el uso de geotextiles de algodón para controlar el control de las pérdidas de suelo y aguas en zonas agrícolas bajo condiciones ambientales mediterránea. Ocho parcelas pareadas $(1,2$, 4 and $16 \mathrm{~m}^{2}$ ) fueron estudiadas durante un año bajo lluvia natural. Cuarenta simulaciones de lluvia en suelos húmedos (invierno) y secos (verano) y mediciones con el test "water drop penetration time (WDPT)" fueron llevadas a cabo para analizar el efeto de los geotextiles en la pérdida de suelo y agua en un campo agrícola de secano típico en el Este de España. Los resultados demuestran que el geotextil de algodón reduce la pérdida de suelo a valores insignificantes (de 14 a $0,1 \mathrm{Mg} \mathrm{ha}^{-1}$ año-1) debido a la baja concentración de sedimentos fruto de la cubierta total del suelo por el geotextil. Sin embargo, las tasas de infiltración decrecen y la escorrentía aumenta debido a la respuesta hidrofóbica del material reciclado de algodón. La escorrentía aumenta de 8 a $16 \%$ para el periodo (año 2004) estudiado bajo lluvia natural y de 27 a $87 \%$ bajo lluvia simulada respectivamente para el verano y el invierno. El geotextil de algodón reduce la pérdida de suelo a escala local (pedon o parcela), pero aumenta la escorrentía.

Palabras clave: Geotextil, Pérdida de suelo y agua, Manejo del suelo, Agricultura, Mediterráneo, Repelencia.

\begin{abstract}
High soil erosion risk of Mediterranean cultivated soils is due to steep slopes, high rainfall intensities and low vegetation cover. Traditional land management as ploughing and Herbicidas give rise to high soil erosion rates. This paper reports on the use of a cotton Geotextil to control soil and water losses on agricultural land under Mediterranean climatic conditions. Eight paired plots (1, 2, 4 and $\left.16 \mathrm{~m}^{2}\right)$ were studied during one-year period under natural rainfall. Forty rainfall simulations under wet and dry climatic conditions, and water drop penetration time (WDPT) tests, were carried out in order to analyze the effect of a Geotextil on soil and water losses on a typical rainfed orchard in Eastern Spain. Results showed that an $8 \mathrm{~mm}$ thick cotton Geotextil reduced soil loss to negligible values (from 14 to $0.1 \mathrm{Mg} \mathrm{ha}^{-1} \mathrm{y}^{-1}$ ) due to the low sediment concentration as Geotextil covered $100 \%$ of the soil. However, infiltration rates decreased and runoff increased due to the hydrophobic response of the cotton material. The runoff discharge increased from 8 to $16 \%$ for the 2004 period under natural rainfall and from 27 to $87 \%$ under simulated rainfall when summer dry conditions were reached. The cotton Geotextil reduced local soil losses at plot-scale, but increased runoff.
\end{abstract}

Keywords: Geotextil, Soil and water losses, Land management, Agriculture, Mediterranean, Water repellency. 
Publicado en Cuadernos de Investigación en la Ingeniería (2009)

Giménez-Morera, A. 2009. Uso de geotextiles para el mantenimiento de un caudal ecológico. Riu dels Sants. Cuadernos de Investigación en la Ingeniería, III, 61-72.

Capítulo 6

Uso de geotextiles para el mantenimiento de un caudal ecológico y creación de una zona húmeda. El caso del Riu dels Sants en la comarca de la Costera. Valencia 


\subsection{Introducción}

El riu dels Sants tiene su nacimiento en el SW de la provincia de Valencia, en las coordenadas geográficas latitud $38^{\circ} 58 \mathrm{~N}$ y longitud $0^{\circ} 36 \mathrm{~W}$. Se sitúa a 1.500 metros al noroeste de L'Alcúdia de Crespins y presenta un recorrido sinuoso con una longitud total de 5.400 metros. El río alimenta de agua para riego a más de quince poblaciones de la Comarca de La Costera. Es uno de los pocos ríos en los cuales toda el agua es utilizada para riego. Esta agua llega a los diferentes pueblos y partidas mediante una enrevesada y complicada red de acequias, canaletas y bifurcaciones en infraestructuras creadas por los mismos agricultores. La distribución del caudal por riego se realiza mediante las cinco acequias tradicionales del Riu Sants, es decir, las acequias de Setenes, Orts, Canyamars, Ranes i Vila.

Son ancestrales las discrepancias entre los diferentes usuarios del río alrededor de la distribución de sus aguas para las diferentes acequias que toman el agua del mismo. La actual distribución de sus aguas quedó fijada por una sentencia de la Real Audiencia de Valencia de fecha 9 de diciembre de 1613. Aunque parece ser que esta distribución ya era la misma que había antes de la conquista cristiana de estas tierras. Esta distribución no se hace en base a un caudal fijo para cada acequia, sino que el agua que lleve el río sea mucha o poca se divide en 24 partes o filas, de las cuales dos filas corresponden a la acequia de Setenes, una a la de Orts, una a la de Canyamars, once la de la Vila y nueve la de Ranes.

Desde muy antiguo existen las disputas de los beneficiarios del agua del río principalmente por dos motivos: el primero de ellos por los recurrentes periodos de sequía, con la disminución del caudal del río y en segundo lugar por el intento constante de los diferentes pueblos beneficiarios de dicho caudal de ir poco a poco convirtiendo las tierras de secano en tierras de regadío.

De esta forma una constante en el río ha sido los repetidos intentos de poder aumentar el caudal del mismo. Por eso se han sucedido en el tiempo una serie de proyectos que iban encaminados a: (i) poder obtener más agua del manantial; y (ii) evitar las filtraciones en el cauce. Se han realizado estudios y propuestas sobre el río como las presentadas por los ingenieros Lucio de Valle el 22 de julio de 1846, Rafael Janini en 1897 y la de Fausto Elio en 1928 (Elio, 1928). El trabajo realizado por Rafael Janini de descripción del río ha seguido siendo utilizada posteriormente en la memoria de otros proyectos.

También ha sido una idea acariciada desde muy antiguo, sobre todo por parte de las acequias de la Vila y Ranes, la de tomar cada acequia la parte del agua que le tocaba desde un punto común y cerca del manantial. De esta forma, el propio Cavanilles expuso su idea de derivar y separar el río desde el mismo nacimiento. La memoria de Lucio del Valle también hace mención expresa a este hecho condicionando el mismo a la aceptación expresa de todos los partícipes del río. 
Una vez constituida la, en aquel momento División Hidráulica del Júcar, comienza una relación casi habitual entre ella y la Junta del Riu dels Sants. De esta forma en los aforos hechos en el río el 4 de febrero de 1928 nos da como resultados unas pérdidas de agua del río de $207,8 \mathrm{Is}^{-1}$, de los $1.073,5 \mathrm{ss}^{-1}$ aforados en el partidor de Setenes, entre este y el partidor de la acequia de Canyamars. Estos aforos y otros datos conformarán un informe que fue subscrito por el Gobernador Civil de Valencia (Cristino Bermúdez) y dará lugar a una providencia de fecha 5 de marzo de 1928. En esta y en su punto $3^{\circ}$ de la parte dispositiva dice: " $3^{\circ}$ Asimismo la Citada Junta de Gobierno del Río de los Santos presentará la aprobación de la Jefatura de la División Hidráulica del Júcar el proyecto de corrección de filtraciones existentes en todo el cauce del citado Río, debiendo figurar como base de la citada corrección la construcción de cajeros de fábrica hidráulica cimentados más bajo que la solera del cauce y a los que irán adosadas exteriormente zanjas o cunetas que permitan comprobar en cada momento la no existencia de filtraciones y su corrección en caso de presentarse." Es evidente la preocupación de la administración por las pérdidas de agua del río y como ya, se plantean soluciones a este problema.

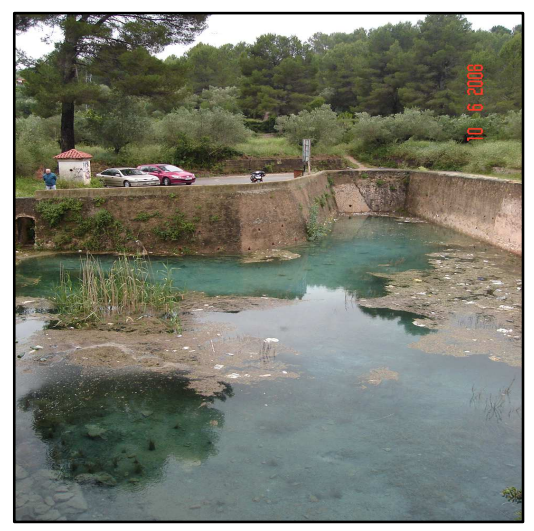

Figura 14. Manantial del Riu dels Sants. L'Alcúdia de Crespins

En el año 1969 el MOPU, ante la continúa disminución del caudal que de forma natural manaba del río de los Santos realiza un "Estudio hidrogeológico sobre los embalses subterráneos de la cuenca del río Cáñoles" (MOPU, 1969), que determina el lugar más adecuado para perforar los pozos que continuarán suministrando caudal al río de los Santos. La Comunidad de Regantes instala los pozos en el mismo nacimiento. En los registros en el año 1991 estos pozos funcionaban 3.000 horas al año y se extraían 10 millones de $\mathrm{m}^{3}$ anuales. Con la puesta en marcha de estos pozos de extracción, el manantial deja de manar, dependiendo desde ese mismo momento de la puesta en marcha de los pozos para que el caudal del río llevara agua. Los costes energéticos hacen que los 
motores para la extracción de agua solamente funcionen cuando existe la necesidad de riego. La desaparición de la flora y la fauna del río es irremediable ya que no existe un caudal continuo y solamente mana el agua del manantial de forma esporádica. Por ello se debe desarrollar una estrategia de regeneración del territorio fluvial.

Haciendo mención a las aportaciones sobre hidrología realizadas por Cerdá, A., lo normal en una cuenca mediterránea sería que el caudal de un río durante el invierno fuera superior al caudal en el verano e incluso que el mismo desapareciera totalmente como ocurre en la mayoría de los ríos de la vertiente mediterránea y que el mismo subiera en los meses de otoño por las lluvias que caracterizan nuestro clima. También nos indica en sus investigaciones que el único clima del mundo donde no llueve o llueve menos en los meses donde hace calor es en el mediterráneo.

El río de los Santos es algo extraordinario. El río, en los meses en los que existe más lluvia es decir los meses de otoño comparativamente con los meses en los que la lluvia es prácticamente inexistente y existe una evaporación muy alta, presenta un comportamiento totalmente dispar si es comparado con otros ríos ya que mantiene todo su caudal durante todas las estaciones del año de forma constante cuando el río nace por el mismo sin ayuda mecánica.

El río de los Santos tenía en su nacimiento una media de mil trescientos litros por segundo, lo cual representaba una cantidad importantísima de agua con un caudal totalmente constante tanto en invierno como en verano. Esta continuidad en sus caudales favoreció la implantación de procesos fabriles y el nacimiento de industrias que se abastecían de sus aguas así como una creciente y próspera agricultura y ganadería en todo su recorrido.

Pero no solamente son estas características peculiaridades de este río, a lo largo de su recorrido nos encontramos con un patrimonio cultural importantísimo con cientos de años de antigüedad como son las acequias, los partidores y los lavaderos que han sido y son utilizados en la actualidad. Además el paso del río por la población provoca que las temperaturas se regulen siendo las mismas en invierno y en verano más suaves debido a la sensación térmica que provoca el paso del río por la población.

En la actualidad alguna de las zonas por las que transcurre el río ha sufrido una transformación que se podría calificar de atentado ecológico, ya que se ha incidido en criterios económicos para la impermeabilización y desplazamiento de su cauce con fines urbanísticos. Un ejemplo claro se muestra en la figura 15 en la que se observa que para el mantenimiento de taludes se utilizan unas paredes y un lecho de hormigón 


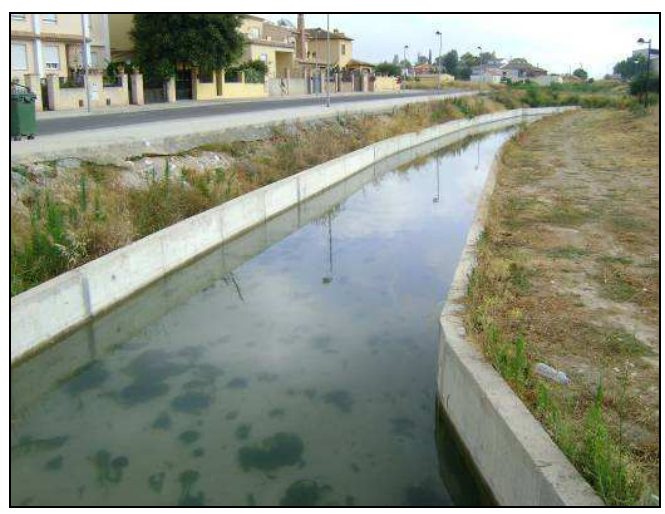

Figura 15. Desvío del cauce del Riu Sants a su paso por Canals.

La desaparición del caudal natural ha provocado una degradación del cauce del río. Las especies autóctonas de zonas húmedas están desapareciendo, los taludes al no tener sostenimiento vegetal desaparecen y al no existir un caudal continuo las basuras se acumulan y degradan el paisaje.

Al mismo tiempo, las zonas húmedas que existen a lo largo del recorrido, aunque sean impermeables y mantengan niveles de agua durante gran parte del año, acaban secándose si este caudal no es continuo provocando la degradación de la calidad de las aguas y la desaparición de flora y fauna acuática.

La restauración paisajística en cauces deberá de tener como principal objetivo la recuperación del entorno, para ello se tendrán que tratar de integrar las acciones humanas en el paisaje con el menor impacto posible. Es por lo que previamente a la aplicación de cualquier actuación, se debe valorar un estudio exhaustivo de la zona de actuación con el fin de poder elegir una alternativa técnica y paisajística viable.

En este artículo se pretende describir el aprovechamiento del conocimiento de las bondades de los geotextiles en la rehabilitación de las zonas húmedas para preservar el patrimonio medioambiental y en este caso, el del Riu dels Sants, el patrimonio cultural.

En el tramo intermedio del Riu dels Sants existe una zona denominada "El Gorg de I'Omet", esta zona fue utilizada como zona de baño y esparcimiento ya que como su propio nombre indica, en el cauce del río existe un ensanchamiento y una profundidad diferencial con respecto al lecho del río. Junto a la misma, y debido a filtraciones por las paredes laterales del río existe una zona delimitada perimetralmente por la propia flora en la que se estanca agua y crea una zona húmeda. 
El objetivo de este trabajo es evaluar la utilización de los geotextiles que ayuden a la preservación del cauce y a la impermeabilización de algunas zonas altamente permeables.

\subsection{Materiales y métodos}

Se han realizado aforos en diferentes tramos del río por parte de la Confederación Hidrográfica del Júcar, observándose en los mismos que a lo largo de su recorrido existen zonas permeables y zonas impermeables. Es en el segundo tramo del río donde más pérdidas de agua se producen, en total un 19,35\%, desde el nacimiento del río hasta casi la salida del mismo de la población de Canals.

Se ha realizado estudio sobre la descomposición de las aguas y tiempo de filtración de las mismas dependiendo de la época del año. Se ha determinado la supervivencia de la flora y fauna en condiciones extremas.

Como solución a la impermeabilización de los tramos de río que comprendería el segundo tramo, se ha experimentado con un aislante geocompuesto de "Bentonita NBL". Este material está compuesto por un geotextil tejido que forma la capa base, una capa intermedia de Bentonita y en su capa superior un geotextil no tejido.

Con respecto al aspecto medioambiental se plantea la utilización de "Biorrollos" de fibras orgánicas de coco, para el fijado de las orillas del propio cauce.

Se ha estudiado la zona objeto midiendo su perímetro de actuación. Se actúa única y exclusivamente en aquel en el que por las bondades del terreno se considera zona húmeda, ampliando la misma a efectos únicamente técnicos (Figuras 16 y 17).
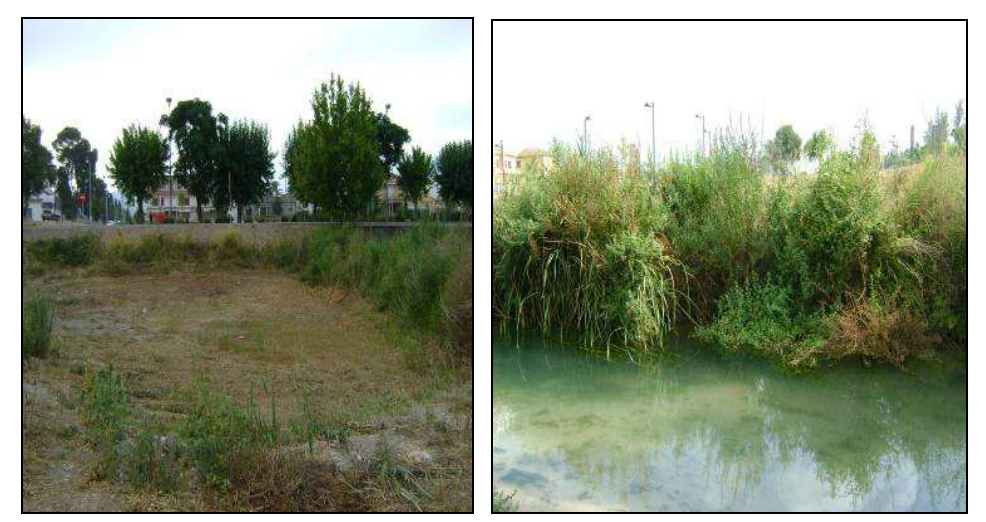

Figura 16. Zona de actuación en el Riu dels Sants 


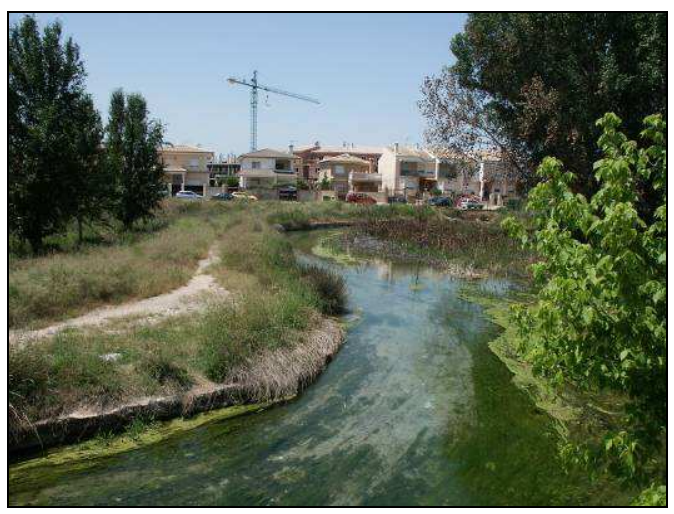

Figura 17. Vista de la zona del Gorg de l'Omet donde se realizan las obras de acondicionamiento de la "nueva" zona húmeda. El ser un espacio periurbano debe ayudar a conferir una gran calidad paisajística a la conurbación Canals-L'Alcúdia de Crespins.

En primer lugar se procede a la preparación del terreno. Se eliminan los elementos (piedras y ramas) que pueden interferir en la instalación del geotextil y en su posterior funcionamiento como impermeabilizante. La zona de actuación se encuentra totalmente nivelada con el cauce del río, con lo cual la primera de las actuaciones será el producir un pequeño desnivel con el que de forma natural y a través de una pequeña canalización desde el río a la zona de actuación, creando una entrada de agua continua cuando el río no esté seco consiguiendo que el agua que está en la zona sea restituida totalmente a través de un método natural no teniendo que hacer aportaciones extras de agua a no ser que el cauce se quede seco en periodos en los que las altas temperaturas pueden degradar las mismas. En este caso se ha previsto que pueda ser aportada agua desde pozos cercanos. También se canalizará la salida del agua al cauce, creando de esta forma una corriente continua natural, bien de forma natural o de forma artificial mediante bombas.

Aunque se ha comentado que la tierra que forma estas zonas húmedas es una tierra arcillosa y por lo tanto impermeable, la ampliación de la misma deberá de ir acompañada de una impermeabilización total, que se logrará a partir de los rollos de bentonita. La bentonita sódica, es una arcilla que tiene una gran capacidad de expansión y se recomienda por su baja permeabilidad, la misma se encuentra entre dos geotextiles que se unen mediante un sistema de agujado.

El geotextil empleado está compuesto de dos geotextiles de alta resistencia, 4,88 $\mathrm{kg}$ de bentonita de sodio por metro cuadrado y una membrana de polietileno de alta densidad 
unida al geotextil no tejido. La Bentonita tiene la característica de que sin confinamiento puede expandirse hasta 15 veces su volumen en seco pero cuando está confinada entre dos geotextiles bajo presión la misma se expande formando una membrana impermeable muy densa e impenetrable. Una vez realizada la impermeabilización de la zona mediante este sistema, se acomete la regeneración de los taludes que la delimitan.

Para la instalación de cualquier sistema de bioingeniería tendremos que haber saneado y perfilado el talud, y eliminar regueros y cárcavas que puedan generar problemas de estabilidad y posterior revegetación. A su vez se construyen cunetas en coronación de cada uno de los taludes para canalizar las aguas pluviales provenientes de la ladera. Se procede al relleno y habilitación del talud entre las cotas de rasante y el borde del cauce del río quedando los últimos $5 \mathrm{~cm}$ libres para la instalación de la geocelda, Proweb.

Para su instalación tendremos que colocar anclajes de hierro galvanizados con un diámetro de 10-12 $\mathrm{mm}$ y $60 \mathrm{~cm}$ de longitud separados entre sí a $50 \mathrm{~cm}$ en la coronación del talud. La geocelda se coloca sobre los anclajes de hierro, extendiendo la geocelda hasta que adquiere la dimensión de la placa $(5 \times 4 \mathrm{~m})$. Cada dos unidades adyacentes de paneles de geoceldas se unirán por medio de grapas con pistola neumática, en la parte superior de cada placa se colocarán anclajes cada $50 \mathrm{~cm}$. El número de anclajes será de $1 \mathrm{ud} / \mathrm{m}^{2}$.

A continuación se realiza un relleno de las geoceldas con tierra vegetal y con posterioridad se sembrará de especies autóctonas de humedal que permitirán darle un aspecto natural y paisajístico conveniente.
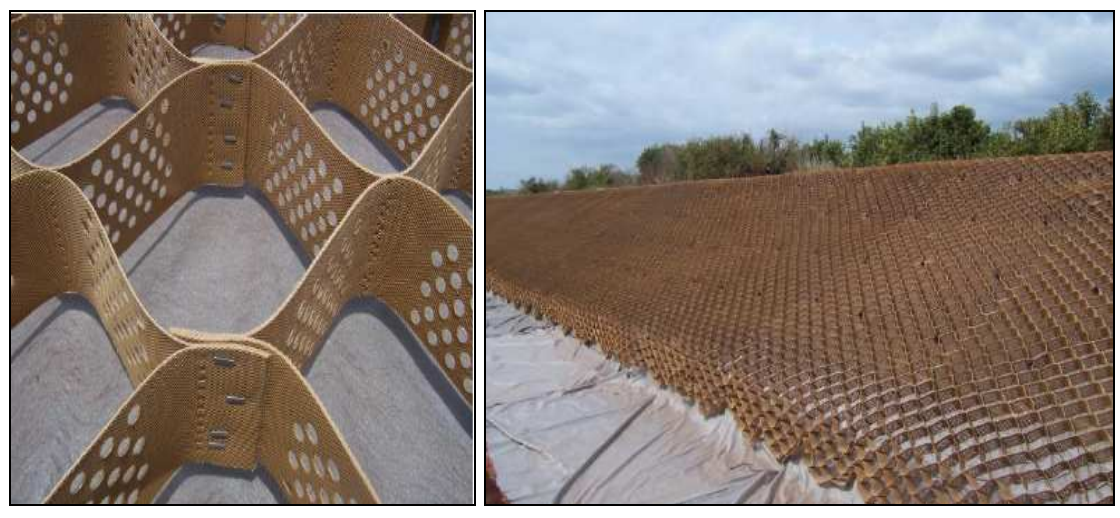

Figura 18. Detalle geocelda y colocación de la misma.

Las condiciones hidráulicas de la geocelda permite soportar un flujo intermitente de $4 \mathrm{~m} \mathrm{~s}^{-1}$ de velocidad máxima, con una duración de la avenida de 24 horas y con relleno de tierra vegetal sobre la que se aplicará una hidrosiembra. 
Tabla 22. Tabla de variable hidráulica y comportamiento de la geocelda

\begin{tabular}{lccc}
\hline Tipo de flujo & Vmax diseño & Duración de la avenida & Relleno \\
Intermitente & $4 \mathrm{~m} \mathrm{~s}^{-1}$ & 34 horas & Tierra vegetal + hidrosiembra \\
\hline
\end{tabular}

Una vez estabilizados los taludes se procede a la siembra de los mismos. Para la misma se propone la utilización de siembra mediante un tratamiento basado en una mezcla de fibra de madera refinada y un aglomerante especial utilizado solo en procesos de hidrosiembra. Una vez curada esta mezcla se forma una cobertura protectora insoluble en agua con poros que permiten aireación y que fija el suelo y las semillas. Este es un tratamiento de reducido impacto ambiental. Al proyectarse mediante hidrosiembra, el suelo permanece relativamente intacto, reduciendo así riesgos adicionales de erosión. Con el tiempo, el producto se descompone en dióxido de carbono, un producto natural de descomposición orgánica utilizado por las plantas para el proceso de fotosíntesis y agua.

La matriz formada permite soportar fuertes lluvias después de la aplicación sin que se produzca pérdidas de suelo por escorrentía. Los estabilizantes y floculantes resistentes al agua unen químicamente la matriz al suelo, absorbiendo agua y permitiendo un establecimiento de la vegetación superior. La máxima efectividad se alcanza cuando la matriz se deshidrata y está perfectamente seca.

Este tipo de hidrosiembra ha demostrado niveles de efectividad cercanos a la perfección, siendo la efectividad del $98 \%$ dos horas después de la aplicación y del $99 \%$ después del secado.

Tabla 23. Efectividad de la hidrosiembra siguiendo los protocolos y pruebas de PROJAR.

\begin{tabular}{|l|c|c|c|c|}
\hline & $\begin{array}{c}\text { Utah Water } \\
\text { Research La boratory }\end{array}$ & $\begin{array}{c}\text { San Diego State } \\
\text { Unive rsity }\end{array}$ & $\begin{array}{c}\text { Texas Transpo rtation } \\
\text { Institute }\end{array}$ & TRI/Environmental Inc \\
\hline Test & Protocolo propio & Protoco lo propio & Protocolo propio & ASTM D6459 \\
\hline Tasa de a plicación & $350 \mathrm{~g} / \mathrm{m}^{2}$ & $400 \mathrm{~g} / \mathrm{m}^{2}$ & $400 \mathrm{~g} / \mathrm{m}^{2}$ & $400 \mathrm{~g} / \mathrm{m}^{2}$ \\
\hline $\begin{array}{l}\text { Condicion es Test: } \\
\text { Pendiente }\end{array}$ & $\begin{array}{c}2,5 \mathrm{H}: 1 \mathrm{~V} \\
\text { Marga arenosa } \\
\text { Tipo de suelo }\end{array}$ & $\begin{array}{c}2 \mathrm{H}: 1 \mathrm{~V} \\
\text { Arenoso-a rcilloso } \\
\text { Duración Test }\end{array}$ & $\begin{array}{c}2 \mathrm{H}: 1 \mathrm{~V} \\
\text { Marga a renosa } \\
3 \text { suce sos de } 1,8 \mathrm{~h}\end{array}$ & $\begin{array}{c}3 \mathrm{H}: 1 \mathrm{~V} \\
\text { Marga arenosa } \\
3 \text { sucesos de } 1 / 3 \mathrm{~h}\end{array}$ \\
\hline Tasa de lluvia & $127 \mathrm{~mm} / \mathrm{h}$ & $48,26 \mathrm{~mm} / \mathrm{h}$ & $88,90 \mathrm{~mm} / \mathrm{h}$ & $101,6 \mathrm{~mm} / \mathrm{h}$ \\
\hline Factor de cobertura & 0.0004 & 0.0001 & 0.0026 & 0.01 \\
\hline \%Efectividad & $99.96 \%$ & $99.99 \%$ & $99.74 \%$ & $99 \%$ \\
\hline
\end{tabular}

La composición de la hidromanta está formada por $500 \mathrm{gr} \mathrm{m}^{-2}$ de Munch tecnológico, $30 \mathrm{gr}$ $\mathrm{m}^{-2}$ de abono de lenta liberación, $15 \mathrm{gr} \mathrm{m}^{-2}$ de ácidos húmicos y $35 \mathrm{gr} \mathrm{m}^{-2}$ de semillas. Por último se propone la instalación de biorrollos de fibra de coco con especies acuáticas. En la 
parte baja del margen se instala una estructura cilíndrica de fibra de coco de $30 \mathrm{~cm}$ de diámetro y $3 \mathrm{~m}$ de longitud que está estructurada en una red de polipropileno de $50 \mathrm{~mm}$ de apertura de malla y $3 \mathrm{~mm}$ de diámetro. El biorrollo es anclado por encima de los últimos 30 $\mathrm{cm}$ en la base protectora del talud. Para la estabilización del anclaje se utilizan estacas cilíndricas de madera tratada con autoclave IV de $\mathrm{cm}$ de diámetro y $125 \mathrm{~mm}$ de longitud con una densidad de 2 udes $/ \mathrm{ml}$ situados por delante y por detrás del biorrollo en disposición al tresbolillo. Se refuerzan los puntos de unión con cuerda de polipropileno de $3,5 \mathrm{~mm}$ de diámetro. Las especies que se incluirán en el biorrollo son la Carex vulvita, la Iris pseudacorus, la Scirpus hcloschoenus y la Cladium mariscos. Será imprescindible que el biorrollo vegetado se encuentre en contacto permanente con la lámina de agua para la supervivencia de las especies acuáticas (Figura 19).

Tabla 24. Relación de los gastos de actuación

\begin{tabular}{cccc}
\hline Descripción & Metros $^{2}$ & Precio $€$ & Totales $€$ \\
\hline Trabajos previos & 141,31 & 7 & 989,17 \\
Agrotextil con Bentonita & 64,80 & 10,15 & 657,72 \\
Geocelda Proweb & 76,51 & 11,35 & 868,38 \\
Hidrosiembra & 76,51 & 2,95 & 225,70 \\
Biorrollos & 94,00 & 94,65 & $8.897,10$ \\
\hline Total & & & $11.638,07$ \\
\hline
\end{tabular}
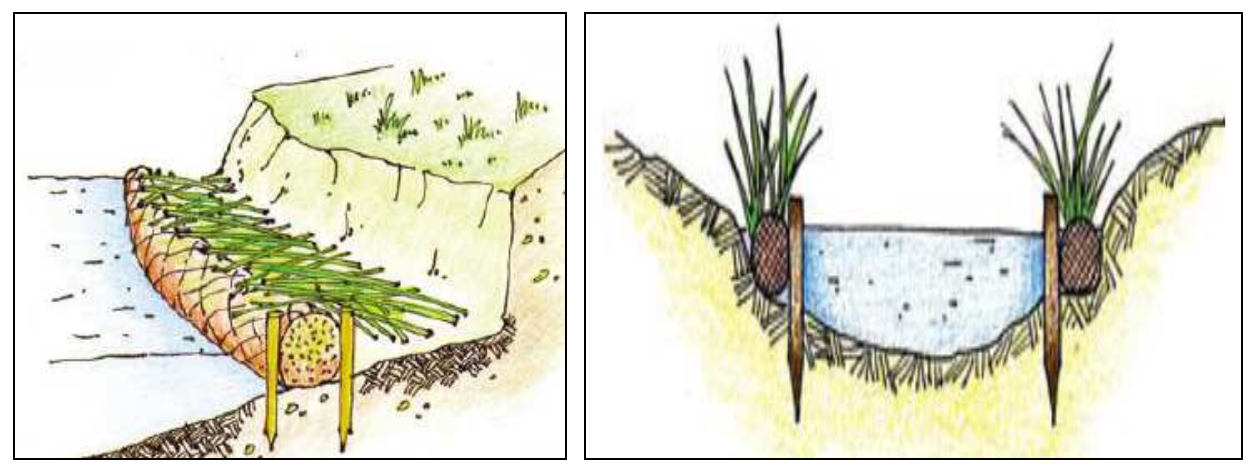

Figura 19.Perfiles de colocación de los biorrollos. A partir de PROJAR 
El contacto del biorrollo de coco con el agua permitirá un crecimiento rápido de las semillas, con lo cual en poco tiempo se producirá una revegetación abundante con plantas acuáticas autóctonas de ríos mediterráneos. El perímetro de talud es de $111 \mathrm{~m}$, con una zona inundada que presentará un perímetro de $94 \mathrm{~m}$. El área de actuación supondrá 64,8 $\mathrm{m}^{2}$ y el área del talud $76,51 \mathrm{~m}^{2}$. La repercusión económica de la actuación se distribuye según la tabla 24.

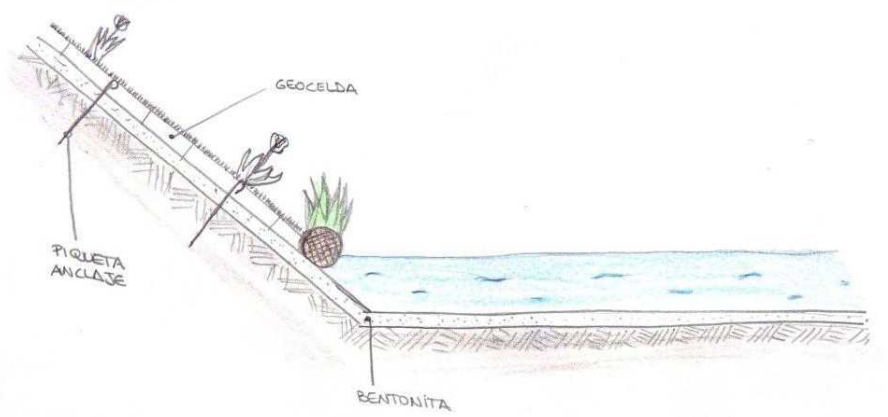

Figura 20. Esquema con todos los componentes de la restauración. A partir de PROJAR

\subsection{Resultados}

En los resultados se ve la necesidad de encauzar el río para mejorar el rendimiento hidráulico y eliminar las pérdidas de agua por filtración. Será necesario el mantener los derechos existentes de explotación, minimizando los costes derivados de ellos, facilitar la limpia y monda del cauce común, conjugar el uso recreativo con el de riego y finalmente corregir el impacto medioambiental negativo acompañado todo ello con el mantenimiento del hábitat y el ecosistema existente. Pero estas filtraciones altamente discutidas, en realidad ¿son pérdidas hidrológicas o sirven para la recarga del acuífero?.

Con respecto a la impermeabilización de la zona dos del río observamos que a un coste relativamente pequeño podría acometerse sin ningún tipo de impacto medioambiental utilizando el tipo de material propuesto. Dicha impermeabilización no sería total y se aplicaría únicamente en la zona expuesta, dejando las filtraciones menores que entendemos deben de continuar existiendo.

En cuanto a la protección de las riberas del río los materiales propuestos han dado un resultado óptimo. Cabe destacar la posibilidad del reverdecimiento de las orillas hechas con hormigón ya dentro del casco urbano mediante los "Biorrollos" de fibra de coco. Además su utilización ha supuesto no solamente el desarrollo de vegetación en la parte alta, no 
expuesta a la erosión por fricción del agua, sino que en la parte baja, si expuesta, su utilización ha permitido el crecimiento de vegetación y el arraigado de la misma.

La zona húmeda presenta un resultado óptimo después de la aplicación del agrotextil. El desarrollo de la vegetación en los lugares donde se implante el agrotextil es realmente espectacular ya que se ha logrado la creación de un hábitat vegetal en menos de dos semanas. Mediante este proyecto se ha observado que existe la posibilidad de utilización de los geotextiles para la rehabilitación de zonas con un alto contenido paisajístico. El desarrollo posterior a su aplicación ha sido positivo. Se ha logrado una impermeabilización total de la zona y se ha conseguido en un tiempo corto una estabilización de los taludes perimetrales a la misma seguida de una revegetación estabilizada por los biorrollos de coco.

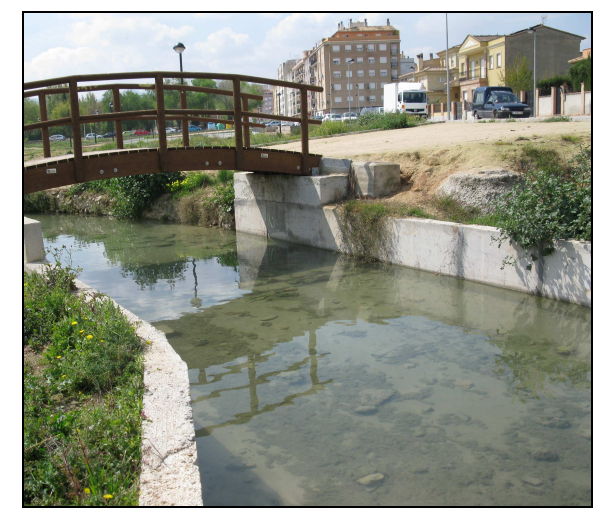

Figura 21. El Riu dels Sants a su paso por Canals

\subsection{Discusión}

En la actualidad, continúan las divergencias y las distintas opiniones sobre las aguas del Riu dels Sants. Dichas divergencias, provienen principalmente de los costes que origina la elevación del agua y de los derechos sobre las aguas que continúan teniendo los agricultores. Dichos costes hacen que el río permanezca como se ha comentado con anterioridad con el cauce seco durante la mayor parte del año.

La solución que se plantea, por nuestra parte, es la de la utilización del cauce del río no solamente como conducto de distribución de las aguas sino como un conjunto urbano más integrado de la población de Canals. Para ello es necesario que dicho cauce lleve un caudal mínimo ecológico para que en su transcurso puedan desarrollarse la flora y fauna 
autóctona que recuperen ecológicamente el río y recuperen el paisaje urbano tradicional de las poblaciones de L'Alcúdia de Crespins y Canals. La dificultad que entraña el mantenimiento de este caudal mínimo o ecológico viene dada por los costes en energía eléctrica necesarios para su mantenimiento durante todo el año.

La "solución" que plantea el autor es la de un abancalamiento del río en tramos mediante pequeñas presas, con un triple objetivo. En primer lugar dichas presas retendrían el agua estancada, durante el periodo que se considerara oportuno, permitiendo de esta forma mantener el hábitat de ribera y acuático. En segundo lugar el cauce del río al paso de las poblaciones de Canals y L'Alcudia de Crespins siempre estaría húmedo y mejoraría las condiciones climáticas de las dos poblaciones. Y en tercer lugar, abaratar los costes energéticos de la elevación del agua, ya que la misma, según el periodo climático en el que nos encontráramos, no sería necesario ser bombeada diariamente.

\subsection{Conclusiones}

Es necesario acometer un planteamiento ambiental y paisajístico correcto lo que significa que desaparezcan del espectro visual todas aquellas obras que han conformado un paisaje de hormigón principalmente en la parte urbana del río mediante el uso de agrogeotextiles cuya eficacia queda demostrada y su impacto visual es reducido.

El planteamiento propuesto es viable económicamente, compatible ambientalmente por su escaso impacto y cultural y patrimonialmente necesario. El esfuerzo desde las administraciones públicas en el sostenimiento medioambiental debe de reafirmarse con actuaciones que vayan encaminadas hacía la preservación de nuestro patrimonio cultural, ambiental y ecológico.

Mediante este proyecto se ha observado que existe la posibilidad de utilización de los geotextiles para la rehabilitación de zonas con un alto contenido paisajístico. El desarrollo posterior a su aplicación ha sido positivo. Se ha logrado una impermeabilización total de la zona y se ha conseguido en un tiempo corto una estabilización de los taludes perimetrales a la misma seguida de una revegetación estabilizada por los biorrollos de coco.

Al proyecto se le pueden unir críticas de haber convertido una zona húmeda en una zona en la cual existe agua permanentemente o un lago, a estas críticas podíamos añadir que es casi seguro que cuando el río nacía de forma natural y su caudal era constante, esta zona se encontraría por descontado llena de agua y han sido las acciones del hombre las que la han convertido en una zona húmeda degradada.

Con la utilización de los geotextiles se consigue en poco tiempo unos resultados espectaculares, que minimizan las críticas a que el proceso no ha sido del todo natural ya que también se han utilizado fibras de polipropileno que únicamente han servido para unión de los elementos del geotextil. 
La restauración, mantenimiento o conservación de una zona o espacio húmedo puede realizarse a través de métodos naturales. El geotextil es uno de los elementos principales que se han utilizado para acometer la restauración de una zona húmeda en un entorno urbanita. Los geotextiles ayudan a la preservación de los espacios húmedos y al mantenimiento de los taludes de ribera, sin que los mismos se vean afectados por escorrentías en épocas de intensas lluvias evitando su desmoronamiento y la formación de cárcavas en los mismos. 


\section{Capítulo 6.Uso de agrogeotextiles versus mantenimiento de un caudal ecológico. El caso del Riu dels Sants en la comarca de la Costera. Valencia-}

Resumen. La reducción del caudal circulante del riu dels Sants, ha sido una constante desde 1970. Esta reducción de caudal ha sido debida en gran parte al aumento incontrolado de la demanda extractiva. El no control de perforaciones, cambios de cultivos y sistemas de riego ha hecho que durante la mayor parte del año, el cauce se encuentre seco en su totalidad. En estos momentos, se busca única y exclusivamente una rentabilidad económica a la extracción de agua, y sirve el cauce del ría como mero espectador del paso del agua por él. Esta situación ha hecho que empeoren las condiciones de contaminación a las que está expuesto el cauce del río y se degrade año tras año. Esto hace necesaria la búsqueda de proyectos que ayuden a la regeneración del cauce y al mantenimiento de un caudal mínimo ecológico. Este trabajo apunta algunas soluciones en la encrucijada de un río sin caudal.

Palabras clave: Río, Cauce fluvial, Ecosistema, Caudal ecológico, Hábitat de ribera, Hábitat vegetal.

Abstract. The reduction of the circulating volume of Riu dels Sants, has been a constant from 1970. This reduction of volume has had to a great extent to the uncontrolled increase of the extractive demand. The not control of perforations, changes of cultures and systems of irrigation has done that during most of the year, the channel is dry in its totality. At the moment, an economic yield looks for only and exclusively the water extraction, and serves the channel as laughs like mere spectator of the passage of the water by him. This situation has caused that makes worse the conditions of contamination to which the channel of the river is exposed and year is degraded after year. This makes the search necessary of projects that help to the regeneration of the channel and the maintenance of an ecological minimum volume. This work points some solutions in the crossroads of a river without volume.

Keywords: River, Fluvial channel, Ecosystem, Ecological discharge, River habitat. 
Publicado en Cuadernos de Investigación en la Ingeniería (2008)

Giménez-Morera, A, Cerdà, A. Bodí, M.B. 2008. Viabilidad económica del agrogeotextil en citricultura. Estación experimental de Montesa. Cuadernos de Investigación en la Ingeniería, II, 105-118.

\section{Capítulo 7}

Viabilidad económica del geotextil en citricultura. Estación experimental de Montesa 


\subsection{Introducción}

Los geotextiles son bien conocidos por su capacidad de reducir la pérdida de suelo y aguas en ambientes en los que la erosión del suelo es elevada (Coelho, 2001). Taludes de carretera, derrubios de minas y desmontes son espacios en los que las aplicaciones de geotextiles han tenido más éxito (Rickson, 2006). Su uso en agricultura ha sido menos extendido a pesar de que las pérdidas de suelo son mucho mayores en espacios agrícolas que en espacios forestales (Cerdà, 2001-2002). Los beneficios ambientales del uso de los geotextiles en la agricultura son varios. Por una parte reducen la erosión y favorecen la conservación del agua del suelo, lo que es fundamental en zonas semiáridas (Kirby, 1980; López Bermúdez, 2002). Además permite reducir el uso de herbicidas y de laboreo, manejos íntimamente relacionados con la degradación del suelo. Por otra parte los geotextiles aplicados a la agricultura pueden degradar el paisaje al incorporar materiales industriales en zonas agrícolas. Es por ello que se recomienda el uso de los geotextiles en espacios en las que sus beneficios sean máximos y sus costes mínimos. Así en el caso del regadío localizado se aconseja acolchar las zonas de riego ya que allí es donde crecen las malas hierbas y reducen el crecimiento del cultivo. Es especialmente recomendado para las plantaciones jóvenes ya que ello evita el contacto con el herbicida de los plantones, y reduce la emergencia de malas hierbas.

Este trabajo tiene como objetivo determinar cual de los dos manejos -geotextil o escarda tradicional manual- es el más adecuado para la pervivencia de las plantas de cítricos y cual es el coste de cada uno de ellos. Esta es una aproximación economicista, agronómica y ambientalista a la gestión de los espacios agrícolas del secano del sudeste peninsular.

\subsection{Material y Métodos}

En la Estación Experimental para el Estudio de la Erosión Hídrica del Suelo Agrícola de Montesa, dedicada a la citricultura, se ha estudiado el efecto del uso de geotextiles en plantones de la variedad Clementina de Nules. El experimento se realizó sobre una superficie de $4000 \mathrm{~m}^{2}$, en la que se plantaron 200 árboles en la primavera (15 de marzo) de 2006. A cien de ellos se les aplicó un geotextil de algodón de $1 \mathrm{~m}^{2}$ también evaluado en suelos de secano (Bodí et al., 2009). A los restantes se ha aplicado escarda tradicional manual de las malas hierbas. Se pretende en los dos casos seguir las normas de la agricultura ecológica por lo que no se han aplicado herbicidas, pesticidas 0 abonos químicos de síntesis. Durante los 17 meses siguientes se han realizado las labores de mantenimiento y seguimiento de la evolución de las plantas. Se ha cuantificación la circunferencia del tronco a $5 \mathrm{~cm}$ de la superficie del suelo, la altura de la planta y el diámetro máximo de la copa cada cuatro meses, además de realizar una evaluación de la plantación mensual con un recuento de bajas. Se ha cuantificado el coste de mantenimiento de los dos manejos con el fin de conocer los costes de cada uno de ellos. 

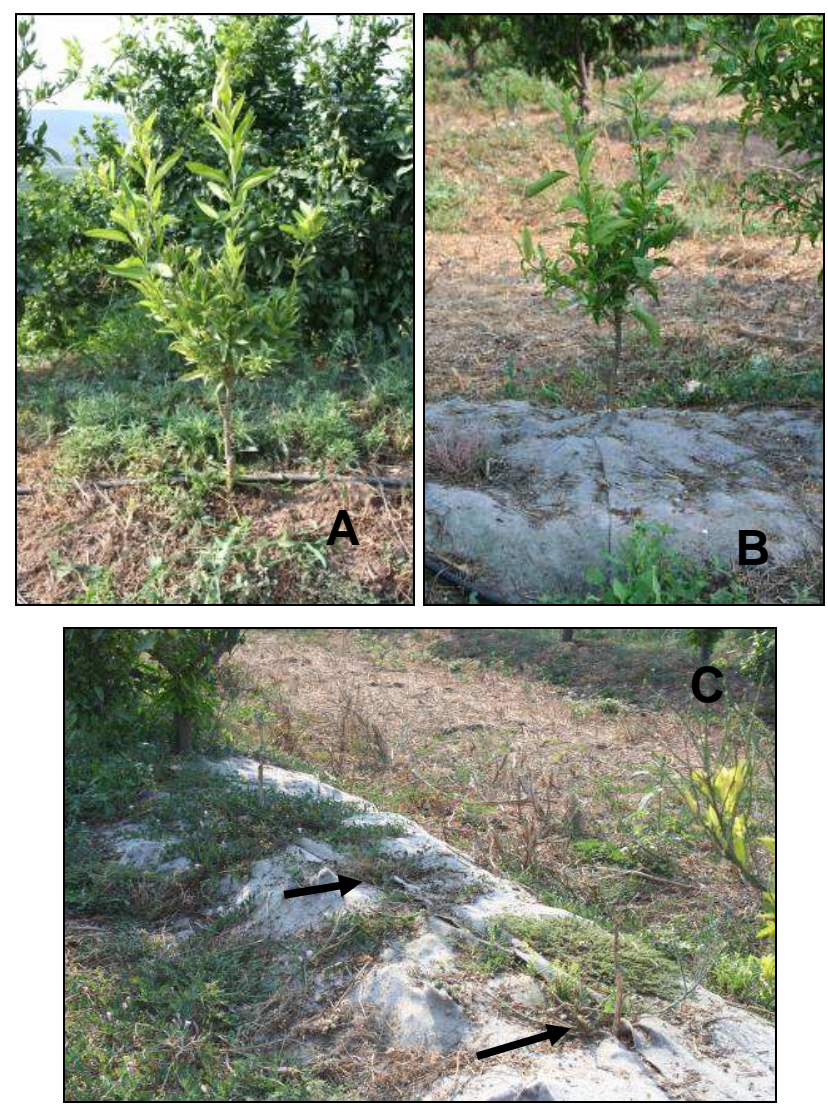

Figura 22. Vista de los dos tratamientos. Escarda tradicional manual (A), geotextil (B) y estado del geotextil 17 meses después de la plantación (C) donde se pueden apreciar las dos marras.

Entre la primavera de 2006 y agosto de 2007 se realizó el seguimiento de la plantación de árboles con el fin de determinar su viabilidad económica. Se cuantificaron los costos de la adquisición de las plantas, de su plantación, de la instalación y mantenimiento del geotextil, de las escardas manuales, los tratamientos fitosanitarios, del riego y abonado, de la instalación del riego y de los costes de amortización de la propiedad de la tierra y el agua. También se cuantifico mensualmente el número de árboles que sobrevivían. Los datos obtenidos se analizaron con el paquete estadístico SPSS 14.0. Se realizó un análisis exploratorio de cada una de las variables, con la finalidad de evaluar la calidad de la información y describir dichas magnitudes. Se calcularon para las variables continuas medidas de tendencia central y de dispersión. En el análisis bivariante se calcularon las 
correlaciones entre las variables recogidas encontrándose todas correlacionadas (i.e. circunferencia de la copa con circunferencia del tronco). Posteriormente se comparó cada variable respecto a los manejos del terreno utilizando contrastes de ANOVA y comparando geotextiles y escarda tradicional para cada variable mediante una prueba $T$ no asumiendo varianzas iguales.

Tabla 25. Costes del mantenimiento durante 17 meses distinguiendo entre geotextiles y escarda tradicional en la estación experimental de Montesa, Valencia.

\begin{tabular}{cccc}
\hline Costes (x 100 plantas) & Geotextil & Escarda tradicional & Diferencia \\
\hline Planta & 665 & 665 & 0 \\
Plantación & 125 & 125 & 0 \\
Material geotextil & 156 & 0 & 156 \\
Instalación geotextil & 210 & 0 & 210 \\
Reparación geotexti & 165 & 0 & 0 \\
Escarda tradicional & 0 & 585 & -585 \\
Instalación riego & 240 & 240 & 0 \\
Riego y abonado & 540 & 540 & 0 \\
Tratamientos fitosanitarios & 285 & 285 & 0 \\
\hline Amortizaciones (tierra + agua) & 600 & 600 & 0 \\
\hline Total & 2986 & 3040 & -54 \\
\hline
\end{tabular}

\subsection{Resultados}

\subsubsection{Coste económico diferenciado entre escarda tradicional y geotextil.}

Los costes de amortización de la propiedad de la explotación y de los derechos de riego, junto a la adquisición de la planta, la plantación, la instalación del riego por goteo, el riego y abonado y los tratamiento fitosanitarios alcanzaron el $82,22 \%$ de todos los gastos en el caso del geotextil y del $80,76 \%$ en el caso de la escarda manual tradicional. Los costes de material, instalación y reparación del geotextil sumaron $531 €$ durante los 17 meses de seguimiento de la explotación, mientras que los de la escarda tradicional fueron ligeramente superiores: $585 €$. Aunque los geotextiles deben perdurar durante al menos un trienio, en la práctica real a partir del primer año son agujereados por algunas plantas, sufren desperfectos por la fauna (jabalíes y roedores) y deben ser reparados al menos una vez año. Como se puede apreciar en la figura 22 (fotografía $\mathrm{C}$ ) se produce una rápida 
colonización de los geotextiles por distintos tipos de plantas que aprovechan los más pequeños agujeros o bien reptan desde las zonas colindantes.

\subsubsection{Supervivencia de las plantas}

Se realizó un seguimiento de la plantación de los 200 árboles. El recuento permitió comprobar que desde el principio la mortalidad de árboles fue mayor con cubierta de geotextiles que con escarda, llegándose a alcanzar la diferencia máxima 15 meses después de la plantación. En concreto, mientras en el geotextil sólo sobrevivieron 75 plantas (de 100) en la escarda lo hacían 89. En agosto de 2007 el $85 \%$ de los árboles sobrevivían con la escarda tradicional mientras que sólo lo hacían el $73 \%$ en el caso del geotextil.

Figura 23. Evolución de la supervivencia de los árboles bajo geotextiles y escarda tradicional en la estación experimental de Montesa.

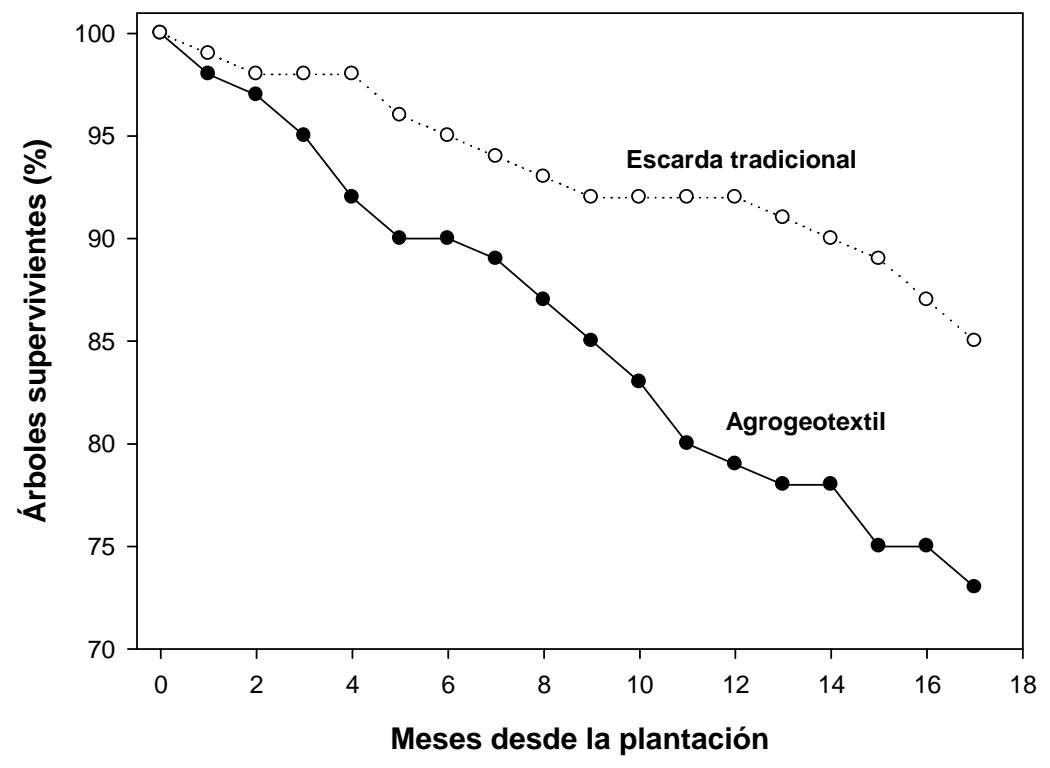

Tabla 26. Evolución de la circunferencia media a $5 \mathrm{~cm}$ de la superficie y desviación estándar del tronco de los árboles desde el día de la plantación hasta el verano del 2007 para los árboles supervivientes. 


\begin{tabular}{lllll}
\hline \multirow{2}{*}{$\begin{array}{l}\text { Días desde } \\
\text { la plantación }\end{array}$} & Geotextiles & \multicolumn{3}{c}{ Escarda tradicional } \\
\hline $\mathbf{0}$ & Media & Std & Media & Std \\
$\mathbf{1 2 5}$ & 5,47 & 0,93 & 5,68 & 1,08 \\
$\mathbf{2 4 8}$ & 5,71 & 0,83 & 5,93 & 1,03 \\
$\mathbf{3 8 4}$ & 7,14 & 0,88 & 7,20 & 0,98 \\
$\mathbf{5 1 0}$ & 7,54 & 0,83 & 7,50 & 0,98 \\
\hline
\end{tabular}

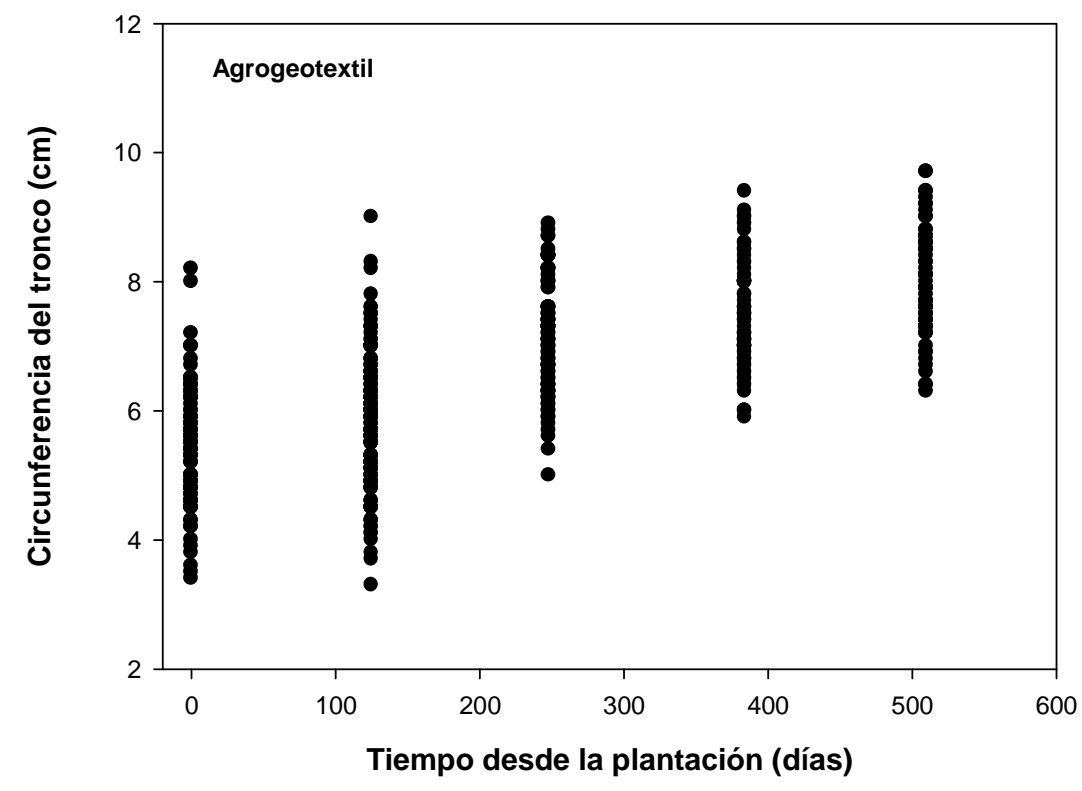

Figura 24. Evolución de la circunferencia del tronco de los plantones a $5 \mathrm{~cm}$ de la superficie desde su plantación hasta 16 meses después, bajo geotextiles. 


\subsubsection{Evolución de la plantación}

La circunferencia del tronco medida a $5 \mathrm{~cm}$ de la superficie del suelo indica un crecimiento más rápido en los periodos de temperaturas más elevadas (verano de 2006 y 2007) y una ralentización en invierno. No se encontraron deferencias significativas entre los dos tratamiento en cuanto a crecimiento de tronco $(p<0,05)$, y las desviaciones estándar fueron similares aunque ligeramente mayores en la escarda tradicional a lo largo de todo el periodo experimental.

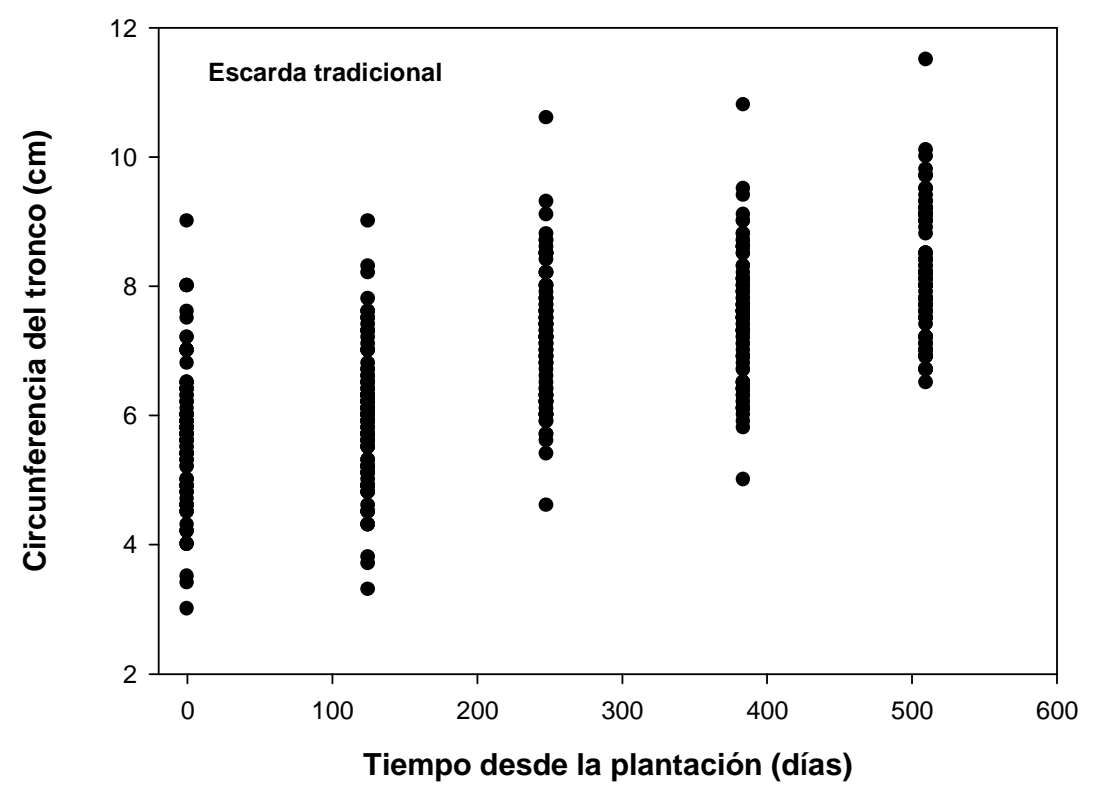

Figura 25. Evolución de la circunferencia del tronco de los plantones a $5 \mathrm{~cm}$ de la superficie desde su plantación hasta 16 meses después, bajo escarda tradicional. 
Tabla 27. Evolución del diámetro máximo medio y desviación estándar de la copa de los árboles desde el día de la plantación hasta el verano del 2007 para los árboles supervivientes.

\begin{tabular}{lcccc}
\hline Días desde & \multicolumn{2}{c}{ Geotextiles } & \multicolumn{2}{c}{ Escarda tradicional } \\
la plantación & Media & Std & Media & Std \\
\hline $\mathbf{0}$ & 0,00 & 0,00 & 0,00 & 0,00 \\
$\mathbf{1 2 5}$ & 14,58 & 2,53 & 14,78 & 2,69 \\
$\mathbf{2 4 8}$ & 20,87 & 3,01 & 21,06 & 2,73 \\
$\mathbf{3 8 4}$ & 23,33 & 2,83 & 23,91 & 2,42 \\
$\mathbf{5 1 0}$ & 32,69 & 5,83 & 32,91 & 5,61 \\
\hline
\end{tabular}

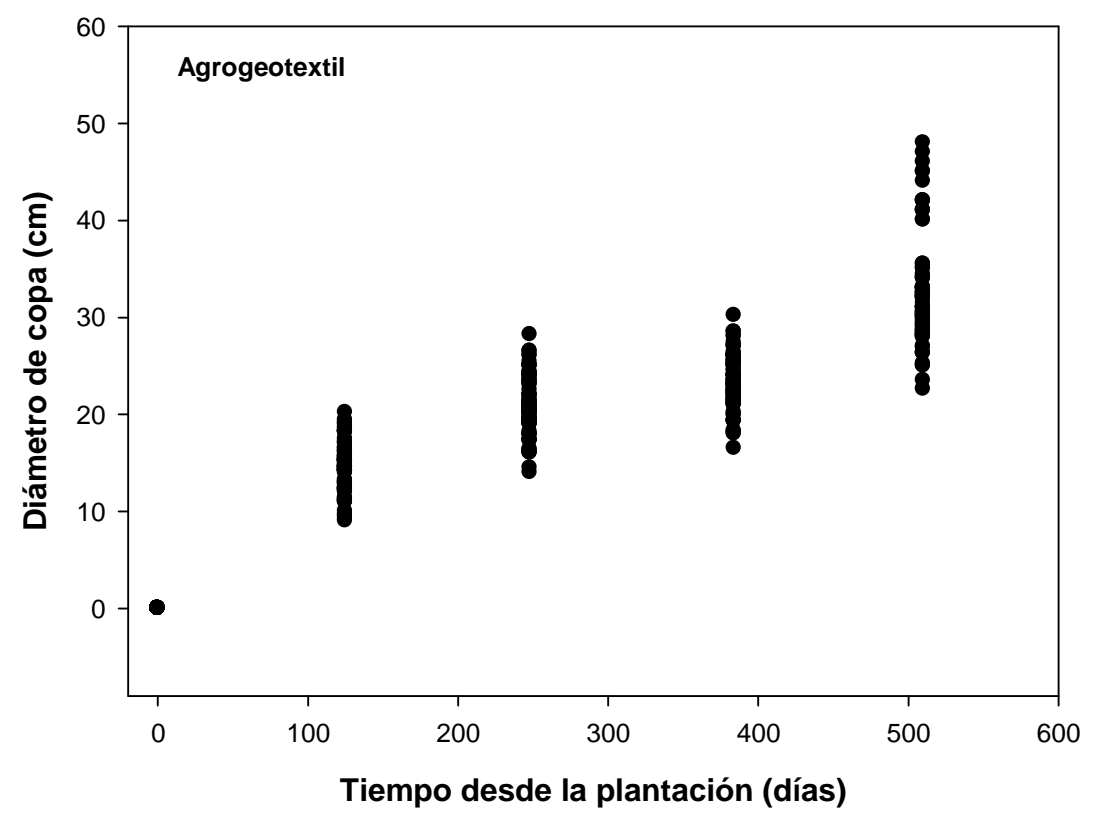

Figura 26. Evolución de diámetro máximo de la copa de los plantones desde su plantación hasta 16 meses después, bajo geotextil. 


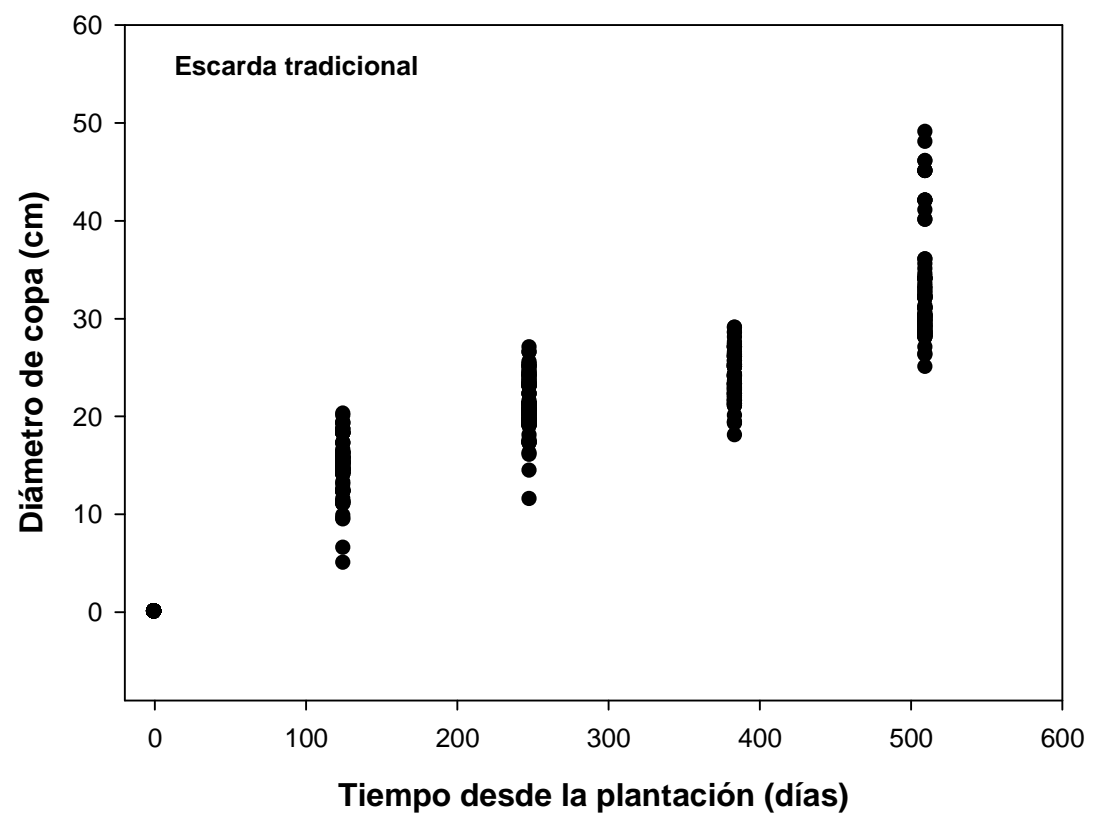

Figura 27. Evolución de diámetro máximo de la copa de los plantones desde su plantación hasta 16 meses después, bajo escarda tradicional.

El diámetro máximo de la copa confirma un crecimiento más rápido en los periodos de temperaturas más elevadas. No se encontraron diferencias significativas $(p<0.05)$ entre los dos tratamientos. Tras su plantación los árboles no presentaban una copa formada ya que al ser cortados sólo quedaron algunas hojas. Se tomó como cero el inicio del experimento para comprobar como durante el primer verano crecieron las copas hasta 15 $\mathrm{cm}$ de diámetro, mantenerse en el otoño e invierno de 2006-2007 en $21 \mathrm{~cm}$ y alcanzar los $33 \mathrm{~cm}$ en el posterior verano de 2007. No se han encontrado tampoco diferencias significativas en la desviación estándar $(p>0.05)$ aunque si se ha visto una mayor dispersión a partir del segundo año cuando los árboles más saludables han mostrado un crecimiento más rápido. 
Tabla 28. Evolución de la altura máxima media y desviación estándar de la copa de los árboles desde el día de la plantación hasta el verano del 2007 para los árboles supervivientes.

\begin{tabular}{lllll}
\hline \multirow{2}{*}{$\begin{array}{l}\text { Días desde } \\
\text { la plantación }\end{array}$} & Media & Std & Media & Std \\
\hline $\mathbf{0}$ & 35,01 & 4,23 & 35,37 & 3,82 \\
$\mathbf{1 2 5}$ & 46,30 & 3,82 & 46,83 & 3,29 \\
$\mathbf{2 4 8}$ & 49,66 & 4,42 & 50,03 & 3,56 \\
$\mathbf{3 8 4}$ & 51,18 & 4,58 & 51,65 & 3,69 \\
$\mathbf{5 1 0}$ & 65,56 & 5,33 & 65,78 & 4,53 \\
\hline
\end{tabular}

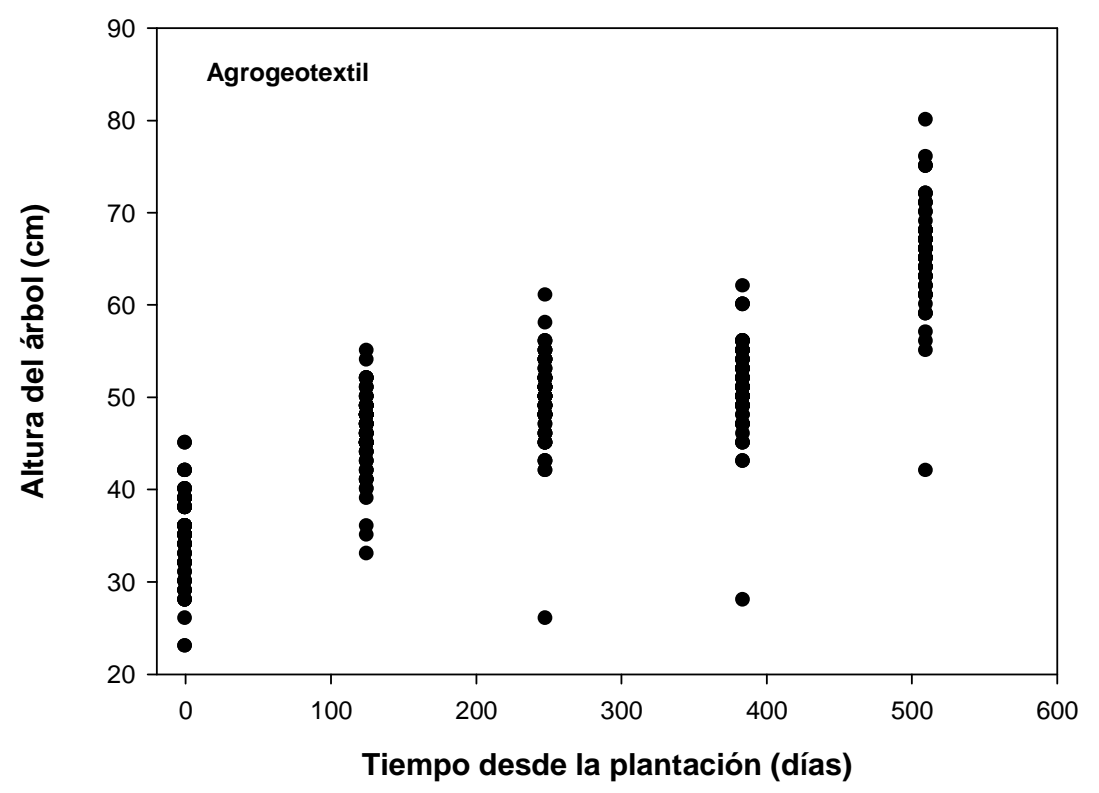

Figura 28. Evolución de la altura máxima media de los plantones desde su plantación hasta 16 meses después, bajo geotextiles. 
La altura máxima media las plantas muestra una evolución marcada por el continuo crecimiento a excepción de algunas que por problemas sanitarios han muerto u otras que han quedado rezagadas en el crecimiento. En ocasiones esto ha sido por la acción de la fauna, jabalíes y especialmente conejos. Se repite el mayor crecimiento del periodo veraniego, que es más acusado en el segundo verano, una vez arraigada la planta. En concreto, se duplica la altura de la planta durante el periodo de estudio, con valores que van desde los $35 \mathrm{~cm}$ de altura tras la plantación a 65 después de 16 meses. No se han encontrado diferencias significativas entre los dos manejos $(p<0,05)$.

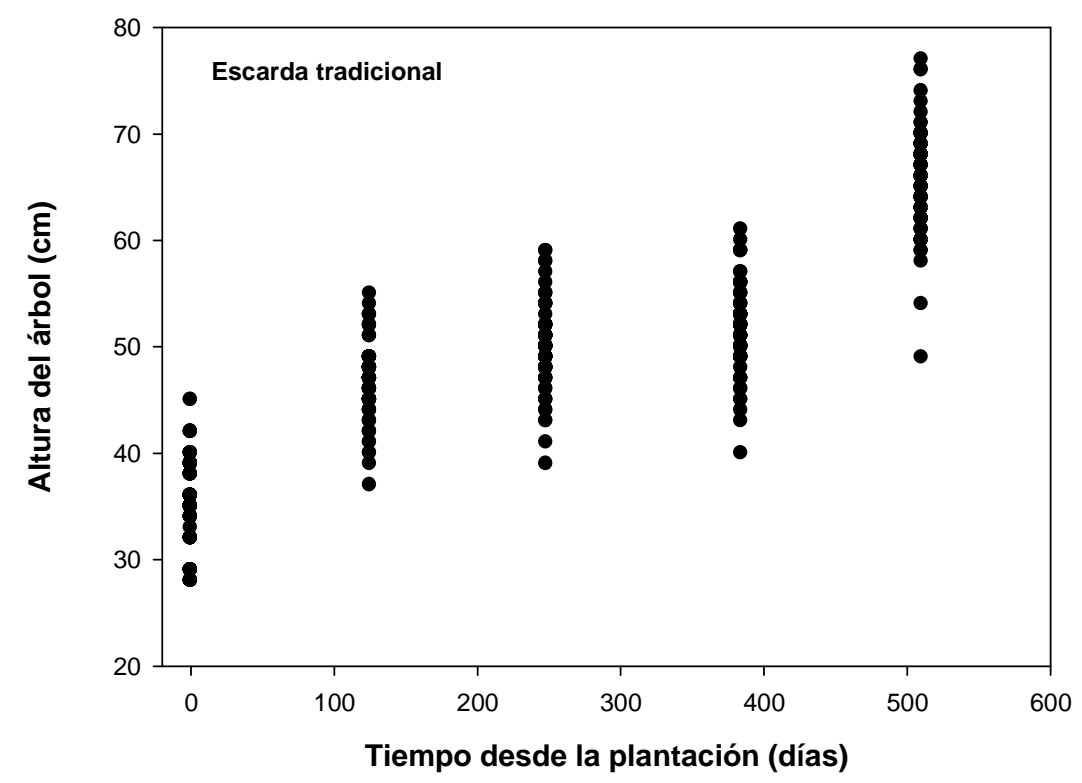

Figura 29. Evolución de la altura media máxima de los plantones desde su plantación hasta 16 meses después, bajo escarda tradicional.

\subsection{Discusión}

El uso de herbicidas que esquilman la cubierta vegetal durante todo el año da lugar a la degradación de los suelos en espacios agrícolas. En los naranjales valencianos este es un problema reciente pero creciente ya que el herbicida es el tratamiento más viable económicamente para el agricultor. Una alternativa a la agricultura convencional basada en los pesticidas, abonos químicos de síntesis y en los herbicidas es la agricultura ecológica. En está se respetan los ciclos naturales por lo que se basa en la aplicación de abonos 
orgánicos, la siega de las adventicias y el aumento de la biodiversidad. Sin embargo, y a pesar de los mejores precios de la agricultura orgánica, el manejo de las malas hierbas es muy complicado. Uno de los problemas más acuciantes para el agricultor ecológico es la eliminación de las malas hierbas que compiten con las plantas jóvenes, ya que estas son muy sensibles a la competencia con otras plantas. Por ello, el uso de geotextiles puede favorecer el control de las malas hierbas junto a las plantas y reducir los gastos. El experimento llevado a cabo en la Estación Experimental de Montesa demuestra que los geotextiles pueden suponer una reducción de los costos, pero que es insignificante si lo comparamos con la inversión realizada en la plantación. Es cierto que los geotextiles perduraran durante varios años más en la plantación, pero el estudio demuestra que el deterioro de los geotextiles ha llevado a la aparición de malas hierbas y a la colonización vegetal en algunos puntos donde es difícil instalar el geotextil. Uno de esos puntos, el más conflictivo tal vez, es el de la zona del tronco del árbol, donde después del primer año es necesario realizar escardas para evitar la competencia con las malas hierbas. Otro punto relevante de los resultados del estudio de la estación de Montesa es el mayor número de marras del geotextil frente a la escarda tradicional manual. Esta última tiene algunos problemas derivados de las heridas que en ocasiones se produce al árbol con las herramientas como la azada, y que finalmente puede dañar algunos árboles. En teoría, pero no en la práctica, el geotextil debe reducir las marras, sin embargo en este estudio se ha comprobado que es significativo el número de marras (27 frente a 15) siempre mayor en el geotextil. Las razones pueden ser varias. Exceso de humedad al haberse producido el riego sin diferencias entre uno y otro manejo. Bajo el geotextil se conserva mejor la humedad. Sin embargo, al haberse producido el mayor número de marras en verano creemos que el problema es el contrario, que el riego localizado falló (bien por taponamiento de gotero o por desplazamiento de este) y al no poder comprobarse su funcionamiento al estar por debajo del geotextil se ha producido la muerte del árbol. De momento es una incógnita la razón, pero si es claro un número de marras más elevado en el geotextil de algodón que de momento hacen inviable esta alternativa hasta que nuevos estudios determinen las causas y se encuentren las soluciones. Por otra parte los árboles que sobrevivieron muestran un crecimiento similar entre los dos tratamientos sin diferencias significativas entre ambos.

La adopción de métodos de producción ecológicos debe de ir acompañada necesariamente de incentivos que potencien dicha apuesta. Las medidas agroambientales aunque son de inclusión obligatoria en los planes de desarrollo rural desde el año 2000, son ofertadas como optativas para los agricultores. Este hecho favorece su no utilización por la relación coste/rentabilidad de los cultivos.

Aunque en el programa de desarrollo rural de la CV 2007-2013 se presentan resultados correspondientes al anterior programa 2000-2006 en los cuales podemos observar la implantación de medidas que han supuesto acciones contra la erosión y el aumento de un mayor número de hectáreas en agricultura integrada, las ayudas para la adopción de nuevos métodos continúan siendo insuficientes tal y como lo demuestran dichos resultados. 


\subsection{Conclusiones}

Se ha comprobado que el uso de geotextiles necesita de estudios previos para conocer su viabilidad agronómica, ambiental y económica. Frente a la escarda tradicional manual el geotextil no mejora el crecimiento de las plantas, es sólo ligeramente más económico y provoca un mayor número de marras. La investigación debe continuar con el fin de determinar las causas de estas marras, ya que el aumento de los costos de la mano de obra hace de los geotextiles herramientas imprescindibles para los agricultores en el futuro. La mejora de estas estrategias permitirá reducir el uso de herbicidas y ampliar la producción de textiles en la industria. 


\title{
Capítulo 7.Viabilidad económica del geotextil en citricultura. Estación experimental de Montesa
}

Resumen. El manejo ecológico de los plantones de naranjos y mandarinos presenta problemas para la gestión de las malas hierbas. Se compara el manejo con geotextiles y con escarda tradicional manual desde un punto de vista económico, ambiental y agronómico. Durante 17 meses se ha realizado un seguimiento de los 200 plantones (10 de marzo de 2006 al 10 agosto de 2007) con el fin de conocer el número de marras, circunferencia del tronco, diámetro de copa y altura del árbol para determinar la viabilidad de ambos manejos. Si bien el manejo con geotextil es ligeramente más económico, también provoca un mayor número de marras. Se discuten las razones de estas diferencias y el complejo manejo del geotextil cuando se instala en parcelas con riego localizado.

Palabras clave: Escarda tradicional, Geotextil, Supervivencia de las plantas, Evolución de la plantación, Programas de desarrollo rural.

\begin{abstract}
The ecological handling of the long waits of naranjos and mandarinos presents/displays problems for the management of the bad grass. The handling with geotextiles and manual traditional weeding is compared from an economic, environmental and agronomic point of view. During 17 months a pursuit of the 200 long waits (10 of March of 2006 to 10 August of 2007) with the purpose of knowing the number of marras has been made, circumference of the trunk, diameter of glass and height of the tree to determine the viability of both handlings. Although the handling with geotextil is slightly economic, also causes a greater number of marras. To the reasons of these differences and the complex handling of the geotextil are discussed when it settles in parcels with located irrigation.
\end{abstract}

Keywords: Traditional weeding, Geotextil, Survival of the plants, Evolution of the plantation, Programs of rural development. 
En prensa Cuadernos de Investigación en la Ingenieríal (2010)

Giménez-Morera, A. 2010. Modelización de la eficiencia de agrotextiles en plantaciones de cítricos.Cuadernos de Investigación en la Ingeniería.

\section{Capítulo 8}

Modelización de la eficiencia de geotextiles en plantaciones de cítricos 


\subsection{Introducción}

Para el análisis de productividad/eficiencia en geotextiles se ha considerado un determinado número de unidades de decisión denominadas DMU's que vendrán definidas por un conjunto de outputs (cuanto más mejor) y un número de inputs (cuanto menos mejor).

En Data Envelopment Analysis (DEA), la información recogida empíricamente se introduce en un modelo fraccional que responde al objetivo de maximizar el ratio de eficiencia siguiendo la condición de que todos y cada uno de los ratios análogos para las distintas actividades sean iguales o menores que la unidad. Las incógnitas son pesos de alegación (Barker,1984). El modelo DEA es un método no paramétrico para la estimación de fronteras de producción y evaluación de la eficiencia de una muestra de unidades de producción. Este tipo de análisis calcula la eficiencia relativa para cada DMU comparando sus inputs y outputs respecto a todas las demás DMUs. Sin embargo el método DEA no proporciona un ranking completo sino que clasifica las actividades en no eficientes y eficientes, concediendo a las últimas un índice igual a 1 para todas ellas. Por tanto, el método DEA no resulta adecuado cuando se quiere conseguir un índice diferencial para cada actividad. En otras palabras se detectan ineficiencias pero no se asegura una medida objetiva de la eficiencia. Algunos autores (Bonilla et al, 1996) enumeran algunas de las desventajas de la aplicación de este método incidiendo en que este tipo de análisis funciona relativamente mal cuando el número de DMU es bajo.

Como consecuencia de ello, hemos propuesto un modelo multicriterio que mide los niveles relativos de eficiencia para un conjunto de alternativas. En primer lugar se clasificarán las alternativas como ineficiente y no-ineficiente y se identificará un sistema de precio único para las alternativas no ineficientes. Un ranking completo de alternativas se puede obtener con el método Single Price Model (SPM) propuesto inicialmente en (Barker,1984). Este método se sigue por diversos investigadores como por ejemplo Muller,Talluri y Ballestrero (Muller,2003-2004), (Talluri,2002),(Ballestero,1999).

La maximización condicionada la aplicaremos a cada una de las actividades para obtener su índice de eficiencia (store). Aplicaremos el método (SPM) a los geotextiles, intentando jerarquizar las actividades (geotextiles) según criterios objetivos concretados en un sistema único de pesos. El sistema único garantiza la consistencia de los datos que obtenemos . La jerarquización de los geotextiles nos permitirá seleccionar aquellos que sean más eficientes y los distinguirán de aquellos que lo siguen (Ballestero,1999). 


\subsection{Experimental}

Vamos a valorar la eficiencia de cuatro geotextiles y la escarda tradicional, con el objetivo de comparar los mismos y tener una referencia con respecto a métodos tradicionales. Se ha intentado con este modelo buscar geotextiles cuyas características fueran dispares para poder abarcar todas las situaciones posibles, fibras sintéticas, manta natural 100\% paja, manta natural $100 \%$ coco y manta de textiles reciclados. La muestra se ha realizado sobre un campo de cultivo situado en la localidad de Montesa, con riego localizado, y sobre una parcela de investigación de $4.000 \mathrm{~m}^{2}$ con una plantación de 200 cítricos subdivididos en cinco Parcelas. Se han acondicionado esas cinco parcelas con la aplicación de geotextiles sobre una superficie que abarca una plantación de 100 cítricos.

Para dicho análisis hemos considerado como variables las siguientes:

Variables cuanto más mejor:

Crecimiento del cultivo: El estudio se ha realizado con un cultivo de cítricos. El crecimiento de la planta es una de las variables a tener en cuenta ya que el mismo determinará la consecución de beneficios en un mayor o menor tiempo. Dependiendo del uso de dichos geotextiles se ha comprobado que su desarrollo varía y por lo tanto deberemos de tenerlo en cuenta en el análisis ya que para la mayoría de los encuestados es una de las variables más apreciada.

Menor reposición del geotextil: Dependiendo del geotextil utilizado, su reposición varía ya que las inclemencias del tiempo, crecimiento vegetativo de los alrededores y consistencia son motivo para que los mismos se tengan que reponer o reparar con bastante asiduidad. Desde este punto de vista y debido a las diferencias que existen entre los mismos, se decide tomar esta variable como referencial.

Menor cantidad de riego: Se aprecia durante el estudio que según el geotextil utilizado, la humedad se mantiene en menor o mayor grado, esta variable se tiene en cuenta ya que la misma nos permitirá la optimización y regulación de un bien escaso como el agua.

Variables cuanto más peor:

Precio de los geotextiles : Del proceso de investigación realizado a través de encuestas tanto a los distribuidores como a los agricultores, hemos determinado unos precios de referencia para cada geotextil, precios que nos servirán como referencia y una de las variables a tener en cuenta.

Horas empleadas en su colocación: Hacemos referencia a esta cuestión aplicándola como variable ya que los resultados obtenidos en cuanto a horas de colocación del geotextil si que son significativas a la hora de comparar y decidirse por unos u otros. 
Marras: Se ha observado durante el trabajo de campo y la experimentación que en número de marras varía según el geotextil utilizado. Al igual que la anterior variable, es de importancia el considerar las mismas ya que se aprecian diferencias considerables entre los cultivos que utilizan geotextiles y aquellos que utilizan el método tradicional de escarda.

Utilización de herbicidas: Aunque una de las aplicaciones de los geotextiles sea la de evitar la utilización de herbicidas, en algunos de ellos es necesaria aunque en pequeñas cantidades la utilización de los mismos. Dicha utilización varía en cuantías muy pequeñas pero se consideran ya que como hemos indicado anteriormente uno de los objetivos primordiales es la no utilización de los mismos.

La tabla de resultados derivadas del estudio es la siguiente:

Tabla 29. Resultados según método utilizado

\begin{tabular}{lccccccc}
\hline Método & Crecimiento & <Rep. & <Rieg. & Precio & Horas Col. & Marras & Herb y Lab. \\
\hline (A1) Manta de fibras sintéticas & 8,75 & 8 & 8 & 50,4 & 60 & 0,75 & 50 \\
(A2) Manta natural 100\% paja & 8,75 & 3 & 3 & 180 & 60 & 0,75 & 100 \\
(A3) Manta natural 100\% coco & 8,75 & 7 & 5 & 480 & 60 & 0,75 & 65 \\
(A4) Manta Textiles reciclados & 8,75 & 6 & 8 & 43,2 & 60 & 0,75 & 60 \\
(A5) Escarda Tradicional & 9 & 0 & 1 & 0 & 0 & 0,25 & 790 \\
\hline
\end{tabular}

Después de conocidos los valores numéricos de las variables objeto de estudio, tendremos que conocer si los métodos están dominados o no. Para ello se deben de plantear unos modelos de minimización que serán resueltos mediante el programa denominado LINGO (Lineal Generalize Optimizer) que formula problemas lineales y no lineales, analiza su solución y propone resultados optimizados que nos ayudan a encontrar los mejores.

Este modelo de minimización se aplicará a cada una de los métodos objeto del estudio.

Para saber si el método están dominados por cualquier otro de los modelos señalados se plantearán problemas de minimización (Anexo I).

La resolución de los problemas de minimización dará lugar a concluir que modelos se encuentran o no dominados (Tabla 30) 
Tabla 30. Resultados de las dominancias

\begin{tabular}{lcc}
\hline \multicolumn{1}{c}{ Método } & Rdo.min. & D-ND \\
\hline (A1) Manta de fibras sintéticas & 1.000 .000 & $\mathrm{ND}$ \\
(A2) Manta natural 100\% paja & 0.000000 & $\mathrm{D}$ \\
(A3) Manta natural $100 \%$ cocc & 0.000000 & $\mathrm{D}$ \\
(A4) Manta Textiles reciclados & 1.000 .000 & $\mathrm{ND}$ \\
(A5) Escarda Tradicional & 1.000 .000 & $\mathrm{ND}$ \\
\hline
\end{tabular}

De los resultados de las minimizaciones extraemos como conclusión que el modelo A1 no está dominado por ninguno de los modelos al igual que los modelos A4 y A5, sin embargo el modelo A2 se encuentra dominado por el modelo A4 mientras que el modelo A3 se encuentra dominado por una combinación lineal de los modelos A1 y A4.

Continuando con el proceso, ponderaremos, convirtiendo las variables cuanto más peor (Inputs) en variables "cuanto más mejor". Para esta operación, calcularemos el máximo de las actividades no dominadas y restaremos de este valor cada uno de los valores de los modelos.

Tabla 31.Ponderaciones.Métodos ND con los valores máximos sombreados.

\begin{tabular}{lcccc}
\hline Método & Precio & Horas Col. & Marras & Herb y Lab. \\
\hline (W1) Manta de fibras sintéticas & 50,4 & 60 & 0,75 & 50 \\
(W2) Manta natural 100\% paja & & & & \\
(W3) Manta natural 100\% coco & & & & \\
(W4) Manta Textiles reciclados & 43,2 & 60 & 0,75 & 60 \\
(W5) Escarda Tradicional & 0 & 0 & 0,25 & 790 \\
\hline
\end{tabular}


Tabla 32.Ponderaciones .Tabla convertida.

\begin{tabular}{lcccc}
\hline Método & Precio & Horas Col. & Marras & Herb y Lab. \\
\hline (W1) Manta de fibras sintéticas & 0 & 0 & 0 & 740 \\
(W2) Manta natural 100\% paja & & & & \\
(W3) Manta natural 100\% coco & & & & \\
(W4) Manta Textiles reciclados & 7,2 & 0 & 0 & 730 \\
(W5) Escarda Tradicional & 50,4 & 60 & 0,5 & 0 \\
\hline
\end{tabular}

De los resultados obtenidos por las ponderaciones, se establece un nuevo modelo de minimización que nos permitirá la obtención de los pesos de cada modelo, previos al cálculo de los índices de eficiencia (Anexo II).

A partir de la resolución del problema planteado mediante el Lingo, los resultados se pueden observar en la tabla 33.

Tabla 33. Resultados de la minimización

\begin{tabular}{ccccccc}
\hline W1 & W2 & W3 & W4 & W5 & W6 & W7 \\
\hline & & & & & & \\
0,110672 & 0,0034585 & 0,003953 & 0,000549 & 0,00046113 & 0,05533597 & 0,00003738917 \\
\hline
\end{tabular}

El último paso de nuestro procedimiento será el cálculo de los índices de eficiencia. Para ello multiplicaremos los pesos obtenidos por los valores que corresponda de cada variable calculando el cociente entre el "beneficio agregado"/ "costo agregado". (Anexo III). 
Los índices de eficiencia obtenidos (Tabla 34) para cada modelo nos permiten dar a conocer un ranking (Tabla 35) de eficiencias preciso y sin los errores en los que se hubiera podido incurrir si solamente se hubieran obtenido resultados mediante la utilización del método DEA.

Tabla 34. Índices de eficiencias.

\section{Método A1 Método A2 Método A3 Método A4 Método A5}

\begin{tabular}{lllll}
10,41 & 5,77 & 3,02 & 10,73 & 23,05 \\
\hline
\end{tabular}

Tabla 35.Ranking de eficiencias.

\begin{tabular}{clc}
\hline Ranking & Método & Índice de Eficiencia \\
\hline & & \\
1 & Método A5 & 23,05 \\
2 & Método A4 & 10,73 \\
3 & Método A1 & 10,41 \\
4 & Método A2 & 5,77 \\
5 & Método A3 & 3,02 \\
\hline
\end{tabular}

\subsection{Resultados y discusión}

Los índices de eficiencia obtenidos nos indican que el modelo 5 es el que mayor índice de eficiencia tiene con respecto a los demás modelos, es decir que el laboreo presenta dentro de las características de las variables estudiadas la mejor opción, estos resultados confirman investigaciones anteriores (Giménez-Morera, 2008) en los que la escarda tradicional o laboreo continúa siendo el medio más rentable y con este estudio más eficiente. En este caso, no se han tenido en cuenta ningún tipo de variables de tipo medioambientales o sostenibles ya que la introducción de las mismas hubieran desvirtuado en esencia el modelo. Sin embargo observamos que el modelo 4 compuesto geotextil de materiales textiles reciclados le sigue en eficiencia. casi con el mismo nivel que obtienen los geotextiles de fibras. Los geotextiles de compuestos de paja y fibras de coco son los menos eficientes debido a que las variables durabilidad y precio actúan de forma negativa con respecto a los demás. 
Llegados a este punto, la discusión se dirigiría en saber si el usuario desea añadirle variables al modelo basadas en la sostenibilidad ambiental y reciclaje industrial que conducirían de forma precisa a la utilización de un geotextil. Sin la introducción de estas variables, se demuestra que el consumidor está en la decisión acertada en cuanto a la toma de decisiones de mantener sus campos de cultivo mediante el laboreo.

\subsection{Conclusiones}

Tras el trabajo realizado se puede extraer como principal conclusión que el método de laboreo tradicional sería el mejor método a utilizar en términos de eficiencia en los cultivos de cítricos. Sin embargo, los índices de eficiencia de los geotextiles estudiados demuestran que los mismos pueden y deben de ser utilizados en agricultura sostenible, y que además los geotextiles de textiles reciclados son los que en el ranking de eficiencias continúan al laboreo por orden de importancia, teniendo su utilización un doble impacto, por un lado el impacto medioambiental incluyendo dentro de este su acción protectora contra la erosión y por otro el de establecer la posibilidad del reciclaje de materiales textiles con utilidad en la agricultura. Como conclusión final de este estudio podemos afirmar que el método del análisis de la eficiencia, ha podido ser aplicado al estudio de geotextiles, de forma que cumpliendo la hipótesis de que el beneficio agregado de una actividad no-ineficiente debe cubrir el respectivo costo agregado, llegamos a la conclusión de que la ineficiencia se podrá asimilar como una situación de beneficios insuficientes para la cobertura de los costos, por lo tanto, el modelo que se extrae de las conclusiones del trabajo de investigación y del Ranking de actividades nos condicionará o nos ayudará en el cálculo de parámetros que deberemos de tener en cuenta a la hora de acometer proyectos destinados a cambios en el sistema de tratamiento de nuestros campos.

El modelo jerarquizado extraído del estudio de las propuestas, nos sirve por lo tanto para la creación del modelo eficiente, que de otra forma no hubiésemos podido construir 0 al menos no tendría las garantías necesarias para lograr la optimización de rentabilidades que de forma directa vienen relacionadas con las prioridades de los consumidores. 


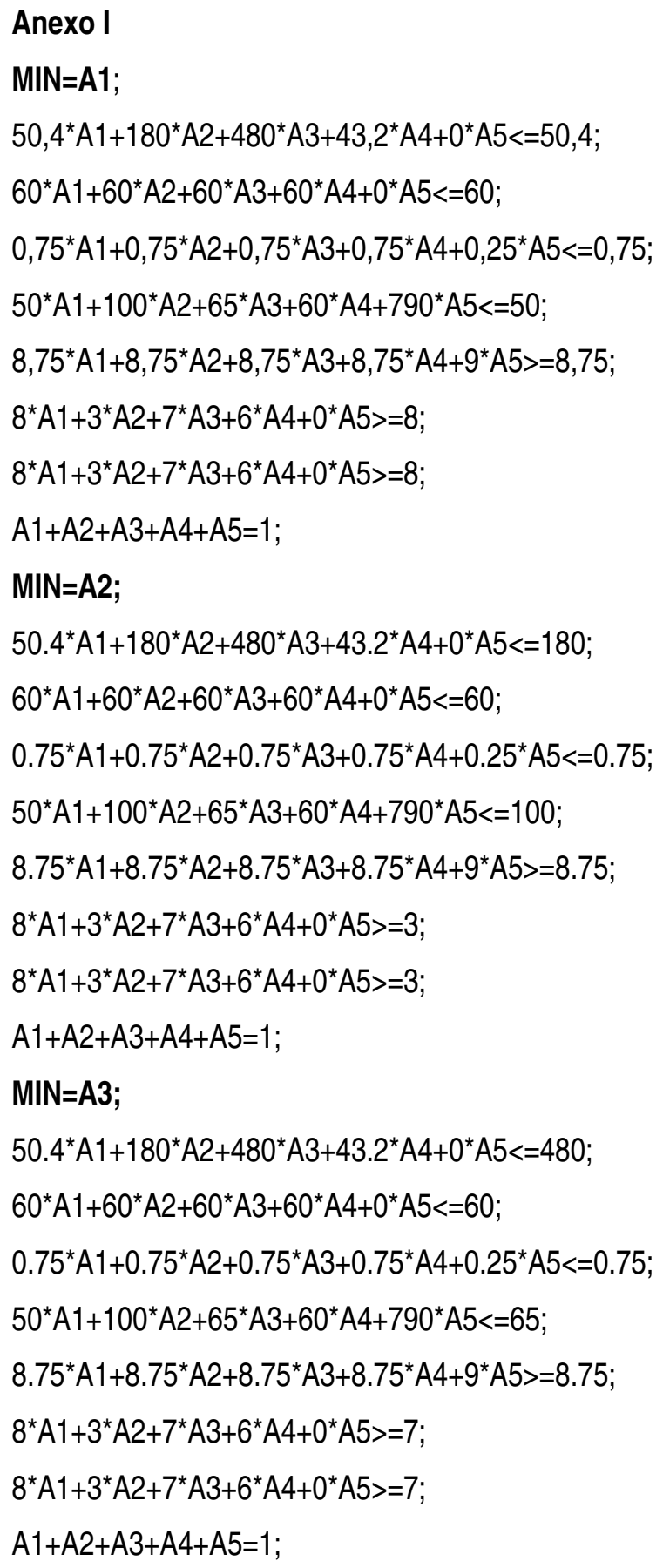


MIN=A4;

$50.4^{*} \mathrm{~A} 1+180^{*} \mathrm{~A} 2+480^{*} \mathrm{~A} 3+43.2^{*} \mathrm{~A} 4+0^{*} \mathrm{~A} 5<=43.2$;

$60 * A 1+60^{\star} \mathrm{A} 2+60^{\star} \mathrm{A} 3+60^{*} \mathrm{~A} 4+0 * \mathrm{~A} 5<=60$;

$0.75^{\star} \mathrm{A} 1+0.75^{\star} \mathrm{A} 2+0.75^{\star} \mathrm{A} 3+0.75^{\star} \mathrm{A} 4+0.25^{\star} \mathrm{A} 5<=0.75$;

$50^{\star} \mathrm{A} 1+100^{\star} \mathrm{A} 2+65^{\star} \mathrm{A} 3+60^{\star} \mathrm{A} 4+790^{\star} \mathrm{A} 5<=60$;

$8.75^{\star} \mathrm{A} 1+8.75^{\star} \mathrm{A} 2+8.75^{\star} \mathrm{A} 3+8.75^{\star} \mathrm{A} 4+9^{\star} \mathrm{A} 5>=8.75$;

$8^{\star} \mathrm{A} 1+3^{*} \mathrm{~A} 2+7^{*} \mathrm{~A} 3+6^{*} \mathrm{~A} 4+0^{*} \mathrm{~A} 5>=6$;

$8^{\star} A 1+3^{\star} A 2+7^{\star} A 3+6^{\star} A 4+0^{\star} A 5>=6$;

$A 1+A 2+A 3+A 4+A 5=1$;

$\mathrm{MIN}=\mathrm{A5}$;

$50.4^{*} \mathrm{~A} 1+180^{*} \mathrm{~A} 2+480^{*} \mathrm{~A} 3+43.2^{*} \mathrm{~A} 4+0^{*} \mathrm{~A} 5<=0$;

$60^{*} \mathrm{~A} 1+60^{*} \mathrm{~A} 2+60^{*} \mathrm{~A} 3+60^{*} \mathrm{~A} 4+0^{*} \mathrm{~A} 5<=0$;

$0.75^{\star} \mathrm{A} 1+0.75^{\star} \mathrm{A} 2+0.75^{\star} \mathrm{A} 3+0.75^{\star} \mathrm{A} 4+0.25^{\star} \mathrm{A} 5<=0.25$;

$50^{*} \mathrm{~A} 1+100^{*} \mathrm{~A} 2+65^{*} \mathrm{~A} 3+60^{\star} \mathrm{A} 4+790^{*} \mathrm{~A} 5<=790$;

$8.75^{\star} \mathrm{A} 1+8.75^{\star} \mathrm{A} 2+8.75^{\star} \mathrm{A} 3+8.75^{\star} \mathrm{A} 4+9^{\star} \mathrm{A} 5>=9$;

$8^{\star} \mathrm{A} 1+3^{\star} \mathrm{A} 2+7^{\star} \mathrm{A} 3+6^{*} \mathrm{~A} 4+0^{*} \mathrm{~A} 5>=0$;

$8^{\star} \mathrm{A} 1+3^{\star} \mathrm{A} 2+7^{\star} \mathrm{A} 3+6^{*} \mathrm{~A} 4+0^{*} \mathrm{~A} 5>=0$;

$A 1+A 2+A 3+A 4+A 5=1$ 


\begin{abstract}
Anexo II
Min $=8,75^{*} \mathrm{~W} 1+8^{*} \mathrm{~W} 2+8^{*} \mathrm{~W} 3+0^{*} \mathrm{~W} 4+0^{*} \mathrm{~W} 5+0^{*} \mathrm{~W} 6+740 \mathrm{~W} 7$;

$8,75^{*} \mathrm{~W} 1+8^{*} \mathrm{~W} 2+8^{*} \mathrm{~W} 3+0^{*} \mathrm{~W} 4+0^{*} \mathrm{~W} 5+0^{*} \mathrm{~W} 6+740^{*} \mathrm{~W} 7>=1$

$8,75^{*} \mathrm{~W} 1+6^{*} \mathrm{~W} 2+8^{*} \mathrm{~W} 3+7,2^{*} \mathrm{~W} 4+0^{*} \mathrm{~W} 5+0^{*} \mathrm{~W} 6+0^{*} \mathrm{~W} 7>=1$

$9^{*} \mathrm{~W} 1+0^{*} \mathrm{~W} 2+1^{*} \mathrm{~W} 3+50,4^{*} \mathrm{~W} 4+60^{*} \mathrm{~W} 5+0,5^{*} \mathrm{~W} 6+0^{*} \mathrm{~W} 7>=1$

$9^{*} \mathrm{~W} 1+0^{*} \mathrm{~W} 2+1^{*} \mathrm{~W} 3+0 * \mathrm{~W} 4+0^{*} \mathrm{~W} 5+0^{*} \mathrm{~W} 6+0^{*} \mathrm{~W} 7=1$

$8,75^{*} \mathrm{~W} 1+8^{*} \mathrm{~W} 2+1^{*} \mathrm{~W} 3+0 * \mathrm{~W} 4+0^{*} \mathrm{~W} 5+0$ * $\mathrm{W} 6+0$ * $\mathrm{W} 7=1$

$8,75^{*} \mathrm{~W} 1+0^{*} \mathrm{~W} 2+8^{*} \mathrm{~W} 3+0^{*} \mathrm{~W} 4+0^{*} \mathrm{~W} 5+0^{*} \mathrm{~W} 6+0^{*} \mathrm{~W} 7=1$

$8,75^{*} \mathrm{~W} 1+0^{*} \mathrm{~W} 2+1^{*} \mathrm{~W} 3+50,4^{*} \mathrm{~W} 4+0^{*} \mathrm{~W} 5+0^{*} \mathrm{~W} 6+0^{*} \mathrm{~W} 7=1$

$8,75^{*} \mathrm{~W} 1+0 * \mathrm{~W} 2+1 * \mathrm{~W} 3+0 * \mathrm{~W} 4+60 * \mathrm{~W} 5+0 * \mathrm{~W} 6+0 * \mathrm{~W} 7=1$

$8,75^{*} \mathrm{~W} 1+0^{*} \mathrm{~W} 2+1^{*} \mathrm{~W} 3+0^{*} \mathrm{~W} 4+0^{*} \mathrm{~W} 5+0,5^{*} \mathrm{~W} 6+0^{*} \mathrm{~W} 7=1$

$8,75^{*} \mathrm{~W} 1+0^{*} \mathrm{~W} 2+1^{*} \mathrm{~W} 3+0^{*} \mathrm{~W} 4+0^{*} \mathrm{~W} 5+0^{*} \mathrm{~W} 6+740^{*} \mathrm{~W} 7=1$
\end{abstract}




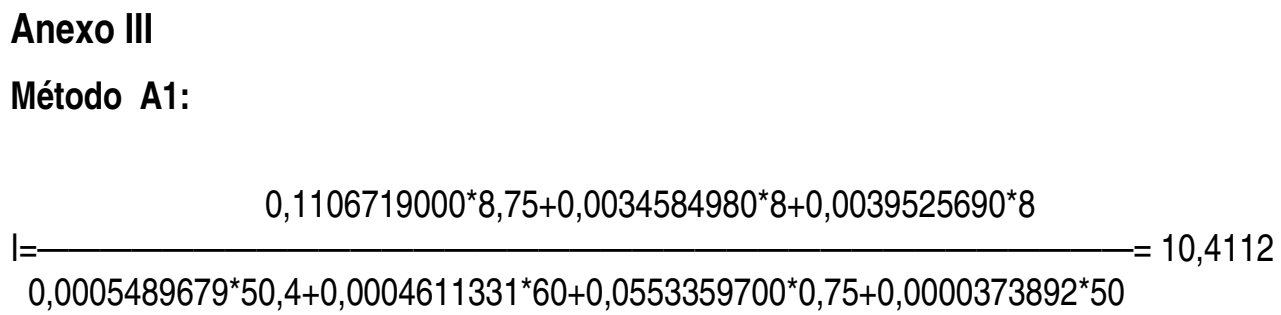




\section{Capítulo 8.Modelización de la eficiencia de geotextiles en plantaciones de cítricos}

Resumen. Aunque la viabilidad económica en el uso de geotextiles en citricultura ha sido ya estudiada (A.Giménez-Morera 2008) contemplando las repercusiones de su uso, es necesaria la utilización de otras metodologías que nos permitan la jerarquización de los distintos geotextiles más utilizados comparativamente con el laboreo para ayudar en la toma de decisiones por parte del usuario.

Utilizamos en este trabajo un análisis de productividad/eficiencia que nos conducirá a modelos matemáticos que buscarán rankings completos o incompletos. Se han tomado unidades de decisión previamente seleccionadas que provienen de un estudio de las características principales que hacen que el usuario adopte la decisión de usar o no usar un geotextil. Obtendremos un ranking completo de alternativas mediante el método Single Price Model.

La jerarquización de los geotextiles y el laboreo nos permitirá seleccionar aquellos que sean más eficientes y los distinguirá de aquellos que lo siguen.

Palabras clave: Data Envelopment Analysis (DEA), Single Price Model (SPM), Eficiencia.

Abstract Although the economic viability in the use of geotextiles in citricultura already has been studied (A.Giménez-Morera 2008) contemplating the repercussions of its use, is necessary the use of other methodologies that allow the hierarchical structuring us of the different geotextiles more used comparatively with the working to help in the decision making on the part of the user. We used in this work a productivity analysis/efficiency that will lead to us to complete or incompletes mathematical models that will look for rankings. Units of decision have been taken previously selected that come from a study of the basic characteristics that cause that the user makes the decision to use or not to use a geotextil. We will obtain a complete ranking of alternatives by means of the Single method Price Model. The hierarchical structuring of the geotextiles and the working will allow to select those us that are more efficient and it will distinguish them of that they follow it.

Keywords: Data Envelopment Analysis (DEA), Single Price Model (SPM), Efficiency. 
Capítulo 9.

Conclusiones 


\section{Conclusiones}

\section{Capítulo 2. Pérdida de suelo y agua en las nuevas plantaciones de cítricos en laderas de la cuenca Mediterránea Occidental.}

2.1. La erosión del suelo en nuevos cultivos de cítricos en laderas muestran altas tasas de erosión bajo precipitación simulada.

2.2. Las huertas mecanizadas y con uso de herbicidas muestran una erosión todavía mayor que en huertas con otros tipos de tratamientos.

2.3. Comparativamente con otros tipos de agricultura existe una gran necesidad de utilización de nuevas estrategias que tiendan a evitar las pérdidas de suelo y agua, desarrollando una agricultura sostenible.

\section{Capítulo 3. Uso de geotextiles en agricultura.}

3.1. El uso de geotextiles mejora las condiciones térmicas e hídricas de los suelos reduciendo la pérdida de nutrientes, semillas y agua en superficies planas.

3.2. El uso de geotextiles anula o disminuye las escorrentías.

3.3. En un clima mediterráneo evitan una rápida evapotranspiración del agua.

3.4. El geotextil es un material no contaminante y carece de las limitaciones que tienen otros materiales que contienen polímeros.

3.5. El uso de geotextiles es una alternativa real al uso de herbicidas y laboreo tradicional.

3.6. El uso de geotextiles favorece la recuperación de suelos degradados y posibilita una agricultura más respetuosa con el medio ambiente.

3.7. La diversidad en la oferta de productos geotextiles es suficientemente amplia para cubrir las necesidades del sector agrícola.

Capítulo 4. Geotextil versus herbicida en el control de la pérdida de agua y suelo en el secano Valenciano en condiciones de lluvia real

4.1. Es necesario la investigación de nuevos materiales geotextiles que no muestren la mínima repelencia al agua.

4.2. El uso de herbicidas proporciona elevadas tasas de escorrentía y elevadas tasas de erosión. 
4.3. Los herbicidas deber de ser aplicados sólo en momentos de escasez de recursos hídricos para el cultivo y no de forma indiscriminada a lo largo del año como se está haciendo en el secano y en el regadío Valenciano.

Capítulo 5. El impacto de los geotextiles de algodón en el control de la pérdida de suelo y agua en cultivos agrícolas del secano mediterráneo

5.1. Los estudios de campo concluyen que el uso de los geotextiles de algodón reducen las pérdidas de suelo en huertos inclinados.

5.2. La utilización de geotextiles de algodón también supone la pérdida de agua por la repelencia que presenta el mezclado de fibras que conforman el geotextil.

5.3. El uso de geotextiles para huertos en superficies inclinadas debe de ser estudiado con mayor detenimiento.

Capítulo 6. Uso de geotextiles para el mantenimiento de un caudal ecológico y creación de una zona húmeda. El caso del Riu dels Sants en la comarca de la Costera. Valencia

6.1. En el acondicionamiento de cauces de ríos periurbanos es desaconsejable la utilización de materiales no naturales para favorecer la impermeabilización de los mismos.

6.2. El uso de geotextiles como método de impermeabilización natural es viable y sostenible medioambientalmente.

6.3. El geotextil representa una alternativa para la ayuda y preservación de caudales ecológicos en ríos periurbanos.

6.4. La utilización de los geotextiles es una alternativa para la rehabilitación de una zona húmeda.

6.5. El uso de geotextiles reduce el impacto medioambiental que causan otros materiales no naturales.

6.6. El uso de geotextiles ayuda a la estabilización de los taludes perimetrales de las zonas de actuación.

6.7. El uso del geotextil de fibra de coco es una buena alternativa para la revegetación y la estabilización de la zona.

6.8. Los resultados de la rehabilitación se observan en un corto periodo de tiempo.

6.9. Los geotextiles son una opción válida para la rehabilitación de zonas fluviales 
6.10. Con los geotextiles se puede conseguir la impermeabilización total de la zona fluvial, los que en el caso de estudio del Riu dels Sants es definitivo para su implantación en todo el cauce.

6.11. La estabilización de las orillas se ha conseguido con hidrosiembra y biorrollos de coco, junto a plantas acuática. Esta es una buena opción para mantener un paisaje de ribera típico del medterráneo.

\section{Capítulo 7. Viabilidad económica del geotextil en citricultura .Estación Experimental de Montesa}

7.1. La utilización de geotextiles puede suponer una reducción de costes pero resultan insignificantes si lo comparamos con las inversiones realizadas en la plantación.

7.2. Los geotextiles muestran un deterioro en el campo a partir del primer año que conlleva la aparición de malas hierbas y a la colonización vegetal especialmente en la zona del tronco del árbol.

7.3. El uso de geotextiles en cítricos supone la necesidad de agricultores especializados en su manejo.

7.4. Se producen mayores marras en la utilización de los geotextiles comparado con la escarda tradicional. Dichas marras son bastante significativas.

7.5. El uso de los geotextiles como alternativa medioambiental en los cultivos debe de ir acompañada necesariamente de ayudas a la agricultura sostenible o ecológica, de otra forma su utilización no es viable económicamente.

7.6. Las ayudas actuales no son incentivo suficiente para compensar los costes de introducción de los geotextiles en la agricultura valenciana.

7.7. Para la economía Valenciana la aparición de nuevas ayudas para la utilización de geotextiles supondría actuar en diferentes frentes, por un lado potenciaría la l+D+l en nuevos materiales textiles, permitiría la reconversión de la agricultura tradicional en agricultura sostenible y ayudaría a la industria textil valenciana a una reconversión hacia este sector.

\section{Capítulo 8. Modelización de la eficiencia de geotextiles en plantaciones de cítricos.}

8.1. En términos de eficiencia el método del laboreo tradicional es con diferencia el modelo más eficiente.

8.2. Las mantas de textiles reciclados son después de la escarda tradicional y con una pequeña diferencia sobre la manta sintética las que le siguen en eficiencia. 
8.3. Las mantas de coco y paja son las menos eficientes. La de coco debido a sus altos costes mientras que la de paja por su baja durabilidad.

8.4. El estudio de eficiencias confirma la no viabilidad del uso de geotextiles sin apoyo económico por parte de las administraciones que deberían de potenciar su uso por la bondad de los mismos, demostrada en los diferentes capítulos de esta tesis.

\section{Capítulo 9. Conclusiones generales}

9.1. Los geotextiles son una opción válida para la rehabilitación ambiental de paisajes mediterráneos.

9.2. En las zonas agrícolas, los geotextiles controlan los procesos de erosión acelerados. No obstante, debemos apuntar que debido a la hidrofobia de los geotextiles de algodón pueden provocar un aumento de las escorrentías durante lluvias cortas y súbitas.

9.3. En el regadío valenciano de cítricos, los geotextiles son una opción viable frente al manejo con escarda manual y herbicidas. Pero provocan un aumento de la marras probablemente por la falta de aireación del suelo y el consiguiente desarrollo de hongos o taponamiento de los goteros.

9.4. En los espacios húmedos de zonas fluviales los geotextiles se han mostrado como una opción a la rehabilitación y restauración de espacios fluviales degradados. Son recomendables por su reducido impacto paisajístico. En este estudio además se ha demostrado que son viables en ríos que han perdido la descarga hídrica y que tienen caudales muy irregulares.

9.5. La viabilidad económica de los geotextiles en las riberas de los ríos esta demostrada por el escaso impacto paisajístico -incluso mejora paisajística en algunos casos- y por su viabilidad económica frente a las intervenciones tradicionales.

9.6. La implantación de los geotextiles en agricultura de secano y de regadío no es viable económicamente por sus elevados costos económicos. No obstante, su reducido impacto ambiental, el favorecer una industria textil local, y el uso de material reciclado deben favorecer un aumento de las ayudas que permitan a este producto ser viable en una agricultura sostenible. 
Capítulo 10.

Referencias bibliográficas 


\section{Capítulo 10. Referencias bibliográficas}

Albadalejo, J., Castillo, V. y Díaz, E. 2000. Soil loss and runoff semiarid land as amended with urban solid refuse. Land degradation and development, 11, 363-373.

Arnáez, J., Ruiz-Flaño, P. y Lasanta, T. 1996. Comportamiento hidrofomórfico de los microambientes de campos abandonados con lluvias intensas: experiencias en el valle de Aisa (Pirineo Aragonés). IV Reunión de Geomorfología, La Coruña; 659-669.

Ballestero, E. 1999. Measuring efficiency by a single price system. European Journal of Operational Research, 115, pp 616-623

Barker, D.H. 1988. Geotextiles in slope protection and erosion control. Civil Engineering, March: 52-55.

Barker, R.D., Charnes, A. y Cooper, W.W. 1984. Some models for estimating technical and scale inefficiencies in Data Envelopment Analysis. Management Science, 30, pp 1078-1091

Barrow, C.J. 1991. Land Degradation: development and breakdown of terrestrial environments. Cambridge University Press, Cambridge, 333 pp.

Belmonte-Serrato, F., Romero-Díaz, A. y López-Bermúdez, F. 1999. Efectos sobre la cubierta vegetal, la escorrentía y la erosión del suelo de la alternancia cultivo-abandono en parcelas experimentales .Investigaciones Geográficas 22: 95-107.

Bhattacharyya, R., Davies, K. y Fullen, M.A. Booth CA. 2008. Effects of palm-mat geotextiles on the conservation of loamy sand soils in East Shropshire, UK. Advances in GeoEcology 39: 527-538.

Bhattacharyya, R., Fullen, M.A., Davies K. y Booth C.A. 2009. Utilizing palm-leaf geotextile mats to conserve loamy sand soil in the United Kingdom. Agriculture, Ecosystems \& Environment 130: 50-58.

Bienes, R., Guerrero-Campo J., Aroca, J.A., Gómez B., Nicolau, J.M. y Espigare, T. 2000. Runoff coefficient and soil erosion rates incroplands in a Mediterranean continental region in Central Spain. In Third International ESSC Congres "Man and Soil at the Trird Millennium".Valencia, 302.

Bisdom, E.B.A., Dekker, L.W. y Schoute, J.F.T. 1993. Water repellency of sieve fractions from sandy soils and relationships with organic material and soil structure. Geoderma, 56, 105-118.

Boardman, J., Foster, I.D.L. y Dearing, J.A. 1990. Soil Erosion on Agricultural Land. John Wiley and Sons Ltd: Chichester. 
Boardman, J. y Poesen, J. 2006. Soil erosion in Europe. Wiley, Chichester, 532 pp.

Bonilla. M., Casasús, T, Medal, A y Sala, R. 1996 Un análisis de la eficiencia de los puertos Españoles. Convenio de colaboración Universidad de Valencia-Autoridad Portuaria de Valencia.

Bodí, M.B. y Cerdà, A. 2008. La Estación Experimental para el Estudio de la Erosión y Degradación de los Suelos de El Teularet-Sierra de Enguera. En Erosión y degradación del suelo agrícola en España, Cerdà, A. (ed.) Universitat de València Estudi General: Valencia; 209-238.

Cantón, Y., Domingo, F., Solé-Benet, A. y Puigdefábregas, J. 2001. Hydrological and erosion response of a badlands system in semiarid SE Spain. Journal of Hydrology, 252: 65-84.

Casalí, J., López, J.J. y Giráldez, J.V. 1999. Ephemeral gully erosion in southern Navarra (Spain).Catena, 36: 65-84.

Ceballos, A., Schnabel, S., Gómez-Amelia, D. y Cerdà, A. 1998. Relation entre la escala espacial y escorrentía superficial en una pequeña cuenca hidrográfica semiárida ante condiciones contrastadas de humedad del suelo (Extremadura, Suroeste de España). Cuaternario y Geomorfología 12: 63-75.

Ceballos, A. 1997.Balance de agua en una cuenca hidrográfica bajo explotación de dehesa en Extremadura. Tesis Doctoral, Universidad de Extremadura.

Cerdà, A. y Bodí , M. 2008. Erosión y degradación de los suelos de los olivares del Macizo del Caroig. In La sustentabilidad del olivar en el Macizo del Caroig, Martínez, J. (ed.), Asociación Macizo del Caroig; 117-145.

Cerdà, A. y Doerr, S.H. 2007. Soil wettability, runoff and erodibility of major dryMediterranean land use types on calcareous soils. Hydrological Processes 21: 23252336.

Cerdà, A. y Doerr, S.H. 2008. The effect of ash and needle cover on surface runoff and erosion in the immediate post-fire period. Catena 74: 256-263. DOI:10.1016/j.catena.2008.03.010

Cerdà, A., Giménez-Morera, A. y Bodí, M.B. 2009. Soil and water losses from new citrus orchards growing on sloped soil in the western Mediterranean basin. Earth Surface Processes and Landforms 34: 1822-1830.

Cerdà, A., Ibáñez, S. y Calvo, A. 1997. Design and operation of a small and portable rainfall simulator for rugged terrain. Soil Tech. 11: 161-168.

Cerdà, A., Imeson, A.C. y Poesen, J. 2007. Soil water erosion in rural areas. Catena 71: 191-192. 
Cerdà, A. y Jurgensen, M. 2008. The influence of ants on soil and water losses from an orange orchard ind eastern Spain Journal of Apploed Entomology-Zeitschrift für Angewandte Entomologie 132(4): 303-314. 10.1111/j 1439-0418.2008.01267.x

Cerdà, A. y Navarro, R. 1997. Tasas de erosión en una solana de la Serra Grossa. La Costera. Cuadernos de Geografía 59: 27-46

Cerdà, A. 1996. Seasonal variability of infiltration rates under contrasting slope conditions in Southeast Spain. Geoderma 69: 217- 232.

Cerdà, A. 1997a. The effect of patchy distribution of Stipa tenacissima 1.on runoff and erosion.Journal of Arid Environments 36: 37-51

Cerdà, A. 1997b. Soil erosion after land abandonment in semiarid environment of Southeastern Spain. Arid Soil Research and Rehabilitation 11: 163-176

Cerdà, A. 1997c. Influencia de la litolofía en los procesos de erosión en badlands. Los casos de Anna (Valencia) y Petrer (Alicante). Pirineos 149-150: 3-20.

Cerdà, A. 1998a. Postfire dynamics of erosional processes under Mediterranean climatic conditions. Seitschrift für Geomorphologie 42: 373-398.

Cerdà, A. 1998b. The influence of geomorphological position on the erosional and hydrological processes on a Mediterranean Slope. Hydrological Processes 12: 661-671.

Cerdà, A. 1999. Parent material and vegetation affect soil erosion in eastern Spain. Soil Science Society of America Journal 63: 362-368

Cerdà, A. 2001. Erosión hídrica del suelo en el Territorio Valenciano. El estado de la cuestión a través de la revisión bibliográfica. Geoforma Ediciones, Logroño, 79 pp.

Cerdà, A. 2002. Agricultura y Erosión en España. Mitos y realidades. Saitabi 51-52: 473501.

Cerdà, A. 2007. Soil water erosion on road embankments in eastern Spain. Science of the Total Environment 378: 151-155.

Cerdà, A., Bodí, M.B. y Hevilla-Cucarella, E. 2007. Erosión del suelo en plantaciones de cítricos en ladera. Valle del riu Canyloes, Valencia. Afoecolofía 2: 85-91

Cerdà, A. y Doerr, S. 2005. Influence of vegetation recovery on soil hydrology and erodibility following fire: an 11-year investigation.International Journal of Wildland Fire 14; 423-437.

Cerdà, A. 2006 . La estación experimental para el estudio de la erosión hídrica del suelo de El Teularet - Sierra de Enguera. Informe anual, $205 \mathrm{ff}$

Coelho, A.T., Galvao, T.C. de B. y Pereira, A. R. 2001. The effects of vegetative cover in the erosion prevention of a road slope. Environmental Management and Health, 12, 78-87. 
Davies, K., Fullen, M.A. y Booth, C.A. 2006. A pilot project on the potential contribution of palm-mat geotextiles to soil conservation. Earth Surface Processes and Landforms 31: 561-569.

De Alba, S. 1998. Procesos de degradación del suelo por erosión en ecosistemas agrícolas de condiciones ambientales mediterráneas en la región central de España. Unpublished $\mathrm{PhD}$ thesis, Universidad Autónoma de Madrid.

Doerr, S.H., Dekker, L.W., Ritsema, C.J., Shakesby, R.A. y Bryant, R. 2002. Water repellency of soils: the influence of ambient relative humidity. Soil Science Society of America Journal 66: 401-405.

Doerr, S.H., Scott, D.F., Dekker, L.W., Ritsema, C.J. y Carter, D. 2007. Water repellence of soils: new insights and emerging research needs. Hydrological Processes 21: 2223-2228.

Fausto, E. 1928. Proyecto "Cauce común del Río de los Santos..

García-Orenes, F., Cerdà, A., Mataix-Solera, J., Guerrero, C., Bodí, M.B., Arcenegui, V. y Zornoza, R. (in press). Effects of agriculture management on soil properties and soil and water losses in eastern Spain. Soil and Tillaje Research, DOI: 10.1016/j.still. 2009.06.002.

García-Ruiz, J.M., Lasanta, T., Ortigosa, L., Ruiz Flaño, P., Martí, C. y González, C. 1995. Sediment yield under different land-uses in the Spanish Pyrenees. Mountain Research and Development 15: 229-240.

Giménez-Morera, A., Bodí, M.B. y Cerdà, A. 2007. Agrotextiles en citricultura. Viabilidad económica, ambiental y agronómica en agricultura ecológica. In La investigación ante la sociedad del conocimiento. Sostenibilidad y Medio Ambiente. Servei Publicacions Universitat Politècnica de València: València; 111-116.

Giménez-Morera, A., Bodí, M.B. y Cerdà, A. 2008. Viabilidad económica del agrotextil en citricultura. Estación experimental de Montesa. Cuadernos de Investigación de la Ingeniería. Avances en desarrollo sostenible y medioambiente, II. Marfil: Alcoi; 105-118

Giménez-Morera, A. 2008 .El uso de agrotextiles en agricultura. Editorial Marfil, 93-118.

Giráldez, J.V., Laguna, A. y González, P. 1989. Soil conservation under minimum tillage techniques in mediterranean dry farming. In Soil Erosion Protection Measures in Europe, Schwertmann U, Rickson RJ, Auerswald K (eds). Soil Technology Series. Elsevier: The Netherlands; 139-148.

Gómez- Amelia, D., Ceballos, A., Schnabel, S. y Cerdà, A. 1998. Experimentos con lluvia simulada en la cuenca experimental de Guadalperalón. Norte de Extremadura. Primeros resultados. NORBA Revista de Geografía X: 67-80.

Gómez, J.A., Giráldez, J.V., Pastor, M. y Fereres, E. 1999. Effects of tillage method on soil physical properties, infiltration and yield in an olive orchard. Soil \& Tillage Research 52: 167-175. 
Gómez, J.A., Romero, P., Giráldez, J.V. y Federes, E. 2004. Experimental assessment of runoff and soil erosion in an olive grove on a Vertic soil in southern Spain as affected by soil management. Soil Use and Management 20: 426-431.

González-Hidalgo, J.C. 1994. Efectos de la superficie protegida en la variación de la producción de sedimentos. Cuaternario y Geomorfología 8: 65-76.

Imeson, A.C., Lavee, H., Calvo, A. y Cerdà, A. 1998 The erosional response of calcareous soils along a climatolofical gradient in Southeast Spain. Geomorphology 24: 3-16.

Jankauskas, B., Jankauskiene, G., Fullen, M.A. y Booth, C.A. 2008a. Utilizing palm-leaf geotextiles to control soil erosion on roadside slopes in Lithuania. Lithuanian Journal of Science (Agricultural Sciences) 3: 22-28

Jankauskas, B., Jankauskiene, G., Fullen, M.A. y Booth, C.A. 2008b. The effects of biogeotextiles on the stabilization of roadside slopes in Lithuania. The Baltic Journal of Road and Bridge Engineering 3: 175-180.

Kirkby, M.J. y Morgan, R.P.C. 1980 .Soil Erosion. John Wiley \& Sons, Chichester, 312 pp

Kosmas, C., Danalatos, N., Cammeraat, L.H., Chabart, M., Diamantopoulous, J.y Farand, L. 1997. The effect of land use on runoff and soil erosion rates under Mediterranean conditions. Catena 29: 45-59.

Lal, R. 1999. Soil quality and soil erosion. Soil and Water Conservation Society: Boca Raton, FL.

Lasanta, T., García Ruiz, J.M., Pérez-Rontomé, C. y Sancho-Marcçen, C. 2000. Rundoff and sediment yield in a semi-arid environment: the effect of land manafement after farmland abandonment. Catena 38:265-278.

López Bermúdez, F., Romero Díaz, A. y Martínez-Fernández, J. 1998. Vegetation and soil erosion under a semi-arid Mediterranean climate: a case study from Murcia (Spain). Geomorphology 24: 51-58.

López Bermúdez, F. y Romero Díaz, A. 1992-1993. Génesis y consecuencias erosivas de las lluvias de alta intensidad en la región mediterránea. Cuadernos de Investigación Geográfica 18-19: 7-28.

López Bermúdez, F. 2002 . Erosión y Desertificación. Heridas de la Tierra. Editorial Nivola, Tres Cantos, $189 \mathrm{pp}$

López-Bermúdez, F. y Albadalejo, J. 1990. Factores ambientales de la degradación del suelo en el área mediterránea. In Degradación y regeneración del suelo en condiciones ambientales mediterráneas, Albaladejo J, Stocking MA, Díaz E. (eds.). Consejo Superior de Investigaciones Científicas: Murcia; 15-45.

MAPA. 2003. Libro blanco de la Agricultura y el Desarrollo Rural. Análisis Territoriales. MAPA, Madrid, $846 \mathrm{pp}$ 
Maroto, Joseph V. 1987. Aproximación a la evolución histórica de las técnicas agrícolas y su fundamentación científica. Consellería de agricultura y pesca. Generalitat Valenciana. Serie Estudis.

Martinek, K.1986. Geotextiles used by the German Federal Railway- experiences and specifications. Geotextiles and Geomembranes 3: 175-200.

Martínez-Raya, A., Francia, J.R., Ruiz-Guitiérrez, S., Martínez-Vilela, A. y Aguilar, J.2001. Evaluation of soil protection with different types of plant cover. In Conservation Agriculture. A Worldwide Challenge. I World Congress on Conservation Agriculture, García-Torres L, Benites J, Martínez-Vilela A (eds); 431-434.

Montgomery, D.R. 2007. Soil erosion and agricultural sustainability. PNAS 104: 1326813272.

MOPU. 1969. "Estudio hidrogeológico sobre los embalses subterráneos de la cuenca del río Cáñoles".

Muller, B. 2003. Multi criteria decision making using Data Envelopment Analysis at the example of life cycle analysis for dairy production. Kieler Milchwirtschaftliche Forschungsberichte.55 (3), pp 233-253

Muller, B. 2003. Ranking of technically efficient processes in the frame of the Data Envelopment Analysis (DEA) at exemplary cases of the dairy sector. Kieler Milchwirtschaftliche Forschungsberichte.55 (2), pp 89-105

Naredo, J.M. 2004. La evolución de la agricultura en España (1994-2000). Universidad de Granada, Granada, 549 pp .

Nicolau, J.M. 1996. Effects of topsoiling on erosion rates and processes in coal-mine spoil banks in Utrillas (Spain). International Journal of Surface Mining Reclamation \& Environment 10: 73-78.

Nicolau, J.M. 2002. Runoff generation and routing on artificial slopes in a Mediterraneancontinental environment: the Teruel coalfield, Spain. Hidrological Processes 16: 631-647.

Pérez Cueva, A.J. Atlas climático de la Comunidad Valenciana. Generalitat Valenciana, València, 243 pp (1994).

Pérez-Cabello, F. 2001. La capacidad de reconstrucción ambiental posterior al incendio forestal: modelización en el prepirineo oscense. Tesis Doctoral Inédita, Universidad de Zaragoza.

Pimentel, D. 1993. World Soil Erosion and Conservation. Cambridge University Press: Cambridge.

Piqueras, J. 1999. El espacio valenciano. Una síntesiss geográfica. Ed. Gules: Valencia.

Poesen, J. y Hooke, J. 1997. Erosion, flooding and channel management in Mediterranean environments of southern Europe. Progress in Physical Geography 21: 157-199. 
Puigdefábregas, J., Solé, A., Gutierrez, L., del Barrio, G. y Boer, M.A. 1999. Scales and proceses of water and sediment redistribution in dry-lands: results from the Rambla Honda field site in Southeast Spain.

Puigdefábregas, J., Solé, A., Lázaro, R. y Nicolau, J.M. 1992. Factores que controlan la escorrentía en una zona semiárida sobre micaesquistos. II Reunión Nacional de Geomorfología; 117-127.

Regües, D. y Gallart, F. 2004. Seasonal patterns of runoff and erosion responses to simulated rainfall in a badland area in Mediterranean mountain conditions (Vallcebre, Southeastern Pyrenees). Earth Surface Processes and Landforms 29: 755-767

Rickson, R.J. 2000. The use of geotextiles for vegetation management. Aspects of Applied Biology 58: 107-114.

Rickson, R.J. 2003. Geotextiles in land reclamation: applications for erosion control and vegetation establishment. In Land Reclamation: Extending the Boundaries, Moore HM, Fox HR, Elliot S. (eds.), Proceedings, 7th International Conference of the International Affiliation of Land Reclamationists. Runcorn, U.K. Balkema; 305-314.

Rickson, R.J. 2006. Controlling sediment at source: an evaluation of erosion control geotextiles. Earth Surface Processes and Landforms 31: 550-560.

Ries, J.B., Langer, M. y Rehberg, Ch. 2000. Experimental investigation on water and wind erosion on abandoned fieds and arable land in the central Ebro Basin, Aragón/Sapin. Zeitschift für Geomorphologie 121: 91-108.

Romero-Díaz, A., Cammeraat, L.H., Vacca, A, y Posmas, C. 1999. Soil erosion at three experimental sites in the Mediterranean vegetation types to runoff and erosion. In Vegetation and erosion. Processes and Environments, Thormes JB (ed). John Wiley \& Sons: Chichester; 347-362.

Romero-Díaz, M.A., López-Bermudez, F., Thormes, J.B., Fancis, C.F. y Fisher, G.C. 1998. Variability of overland flow erosion rates in a semi-arid Mediterranean environment under matorral cover, Murcia, Spain. Catena 13: 1-11.

Sala, M. y Calvo, A. 1990. Response of four different Mediterranean vegetation types to runoff and erosion. In Vegetation and Erosion. Processes and Environments, Thorme JB(ed). John Wiley \& Sons: Chichester; 347-362.

Smets, T., Poesenm J., Fullen, M.A. y Booth, C.A. 2007. Effectiveness of palm and simulated geotextiles in reducing run-off and inter-rill erosion on medium and steep slopes. Soil Use and Management 23: 306-316.

Smets, T., Poesen, J., Langhans, C., Knapen, A. y Fullen, M.A. 2009. Concentrated flow erosion rates reduced through biological geotextiles. Earth Surface Processes and Landforms 34: 483-502. 
Solé, A., Calvo, A., Cerdà, A., Lázaro, R., Pini, R. y Barbero, J. 1997. Influences of microrelief patterns and plant cover on runoff relates processes in badlands from Tabernes (SE Spain). Catena 31: 23-38.

Solé Benet, A. 2006. Spain. In Soil Erosion in Europe, Boardman J, Poesen J (eds). Wiley: Chichester; 311-346.

Talluri, S. 2002. Single price system model for optimal decisions in capital equipment purchasing. International Journal of production research, 40 (4), pp 1003-1016

Theisen, M.S. 1992. The role of geosynthetics in erosion and sediment control: An overview. Geotextiles and Geomembranes 11: 535-550.

Thornes, J.B. 1985. The ecology of erosion. Geography 70: 222-236.

Walkley, A., Black, I.A. 1934. An Examination of Degtjareff method for determining soil organic matter and a proposed modification of the cromic titration method. Soil Science 34: 29-38.

Wessel, A.T. 1988. On using the effective contact angle and the water drop penetration time for classification of water repellency in dune soils. Earth Surface Processes and Landforms 13: 555-562.

White, S.M., Garcia Ruiz, J.M., Martí, C., Valero, B., Errea, M.P. y Gómez Villar, A. 1997. The 1996 Biescas Campsite disaster in the Central Spanish Pyrenees and its temporal and spatial contex. Hydrolofical Processes 11: 1797-1812 